\title{
INTRODUCTION
}

\author{
By Asaph Hall and H. E. Burton
}

Part I of this volume contains the visual observations made with the equatorials of this observatory from January 1, 1908, to January 1, 1927, except a few observations made in 1908 and published in Publications of the United States Naval Observatory, Second Series, Volume VI. A few observations made in 1907 are also included in this part, since they did not appear in Volume VI.

The instruments in use have been the 26-inch and the 12-inch equatorials; also, occasionally, a number of 5-inch equatorials, the 5-inch finder of the 26-inch equatorial, and the 4-inch finder of the 12-inch equatorial.

Miscellaneous data concerning the principal instruments of the equatorial and astrographic divisions are as follows, the altitude being measured from mean sea level to floor under equatorial and to top of pier under photoheliograph.

\begin{tabular}{|c|c|c|c|c|c|c|c|c|c|c|}
\hline Instrument & \multicolumn{2}{|c|}{ Longitude. } & \multicolumn{3}{|c|}{ Latitude } & $\begin{array}{l}\text { Alti- } \\
\text { tude }\end{array}$ & $\begin{array}{l}\text { Focal } \\
\text { Length }\end{array}$ & Object Glass by- & Mounting by- & Erected \\
\hline The 26-inch equatorial. & $\begin{array}{r}\mathrm{h} \\
5 \quad 8\end{array}$ & $\begin{array}{c}\mathrm{s} \\
15.78\end{array}$ & $\begin{array}{r}\circ \\
+38\end{array}$ & 55 & $\begin{array}{c}\prime \prime \\
12.3\end{array}$ & $\begin{array}{r}\text { Feet } \\
1280\end{array}$ & $\begin{array}{c}\text { Feet } \\
32.475\end{array}$ & Clark (1873) $\ldots$ & Warner and Swasey. & 1893 \\
\hline The 12-inch equatorial & 58 & 15. 55 & +38 & 55 & 12. 3 & 2313 & 15.050 & Clark (1895) .......... & Saegmüller........... & 1895 \\
\hline The 10-inch photographic equatorial. & 58 & 15.59 & +38 & 55 & 6. 7 & 2250 & 9.42 & G. H. Peters (1ว11) & Clark (old 26-inch).. & 1911 \\
\hline The 5-inch photoheliograph & 58 & 15.69 & +38 & 55 & 10.5 & ${ }^{2} 265$ & 40 & Clark (1874) & Clark & 1894 \\
\hline
\end{tabular}

1 U. S. Coast and Geodetic Survey, 1927.

2 Derived from contour map prepared by the Bureau of Yards and Docks of the Navy Department, 1915.

The new Naval Observatory was occupied in 1893. The center of the clockhouse floor being taken as the position of the observatory, the coordinates and altitude above sea level are as follows:

\begin{tabular}{lcccccc}
\multicolumn{3}{c}{ Longitude } & \multicolumn{3}{c}{ Latitude } & Alttude \\
$\mathrm{h}$ & $\mathrm{m}$ & $\mathrm{s}$ & $\circ$ & $\circ$ & $\prime \prime$ & \\
5 & 8 & 15.78 & +38 & 55 & 14.0 & 1284 feet
\end{tabular}

Personnel.-The equatorial division, including the 26-inch and 12-inch equatorials, was established December $1,1903 .^{1 a}$.

The work of the photographic equatorial and photoheliograph was incorporated with the equatorial division in September, $1909,{ }^{2}$ and was continued with it through December, 1927.

The following astronomers have had supervision of these instruments:

W. S. Eichelberger, professor of mathematics, United States Navy, in charge of all observational work through July 28, 1908.

Asaph HaLL, professor of mathematics, United States Navy, in charge of the equatorial division from July 29, 1908.

1 U. S. Coast and Geodetic Survey, 1927.

1a Superintendent's Report for 1904, p. 27.

${ }^{2}$ Superintendent's Report for 1910, p. 8. 
George H. Peters, assistant, assistant astronomer, associate astronomer, astronomer, in charge of photographic equatorial and photoheliograph.

The following members of the Naval Observatory staff have taken part in both the observations and reductions:

Asaph HaLl, professor of mathematics, United States Navy, from March 20, 1908.

H. L. RICE, assistant astronomer, professor of mathematics, United States Navy, to September 21, 1907.

J. C. Hammond, assistant astronomer, to October 3, 1908.

George H. Peters, from January 1, 1908.

Matt Frederickson, assistant, to October 28, 1909.

JAMES B. Eppes, assistant, from October, 1908, to January 2, 1912.

HARRY E. BurTon, miscellaneous computer, assistant, assistant astronomer, associate astronomer, from November 4, 1909, to November 5, 1919, and from April 1, 1925.

Chester B. Watts, assistant; from January 2, 1912, to September 30, 1914.

A. G. Webster, Jr., miscellaneous computer, from October 6, 1914, to June 30, 1915.

Ernest Clare Bower, assistant, associate astronomer, from July 7, 1915, to April 1, 1925.

During his connection with the equatorial division Mr. Bower took an active part in the observing and computing. He introduced a number of good schemes of computation and arranged for publication many of the observations given in this volume.

Occasional observations were made by persons when not officially connected with the equatorial division, as follows:

With the 26-inch equatorial by R. Burnside PotTer; with the 12-inch equatorial by George A. Hill, William A. Conrad, and John Edwin Willis; with the 5-inch equatorials by J. A. HoogewerfF, H. E. Smith, F. B. Littell, J. C. Hammond, George A. Hill, H. E. Burton, Paul Sollenberger, and Gerald C. WHITTAKer; with the 5-inch finder of the 26 -inch equatorial by C. W. Frederick.

Also, reductions of observations taken by the equatorial division and computations in connection with them have been made by the computing section under the direction of Miss E. A. Lamson, assistant, associate astronomer.

\section{THE 26-INCH EQUATORIAL}

For a description of the 26 -inch and 12 -inch equatorials reference is made to Publications of the United States Naval Observatory, Second Series, Volume VI.

The following data concerning the 26-inch equatorial were furnished by Warner and Swasey, Cleveland, Ohio, who designed and constructed the telescope, elevating floor, and dome.

Column, 25 feet high; weight, 18 tons.

Telescope

Polar axis of steel, 9 inches in diameter; weight, 1,800 pounds.

Declination axis of steel, 8 inches in diameter; weight, 1,200 pounds.

Main driving wheel, 51 inches in diameter. 
Revolving the polar axis moves $61 / 2$ tons.

Revolving the declination axis moves 2 tons.

Weight of driving clock, 1,300 pounds.

Driving clock moves telescope in solar, sidereal, and lunar time.

Object glass, by Alvan Clark \& Sons; diameter, 26 inches clear aperture; weight with cell, 220 pounds.

Tube $321 / 2$ feet long, 32 inches in diameter; weight, 11/2 tons.

Dials on pier indicate declination, right ascension, and hour angle.

Total weight of telescope and mouriting, 28 tons.

Diameter of elevating floor, 41 feet.

Elevating Floor

Four hydraulic rams, 8 inches in diameter, give a rise of 12 feet.

Total weight of floor, 15 tons, nearly balanced by counterweights.

Outside diameter of dome, 45 feet.

Dome

Direct pressure required to revolve the dome, $21 / 2$ pounds per ton.

Shutter opening, 39 feet long by 6 feet wide.

Weight of double shutters, $2 \frac{1}{2}$ tons.

Weight of dome, 24 tons.

In the following pages may be found data pertaining to this instrument not given in Volume VI.

The objective.-The lenses were removed from the cell and cleaned by Mr. Lundin, Sr., of Alvan Clark \& Sons Co., on May 20, 1908. The separators between the lenses appear to have been changed slightly, causing a small, unknown change in the focal length of the object glass. The lenses were removed from the cell and cleaned by Mr. Lundin, Sr., on November 13, 14, 1912. The separators were not changed.

On April 5, 1913, the lenses were removed from the cell by Mr. Lundin, Jr., and separated far enough to wipe off finger marks and chalk dust left from the cleaning of November 13, 14, 1912. The separators were not changed.

In March, 1915, at the suggestion of Prof. C. S. Hastings, of Yale University, an examination was made of the position of the Newton's rings produced by means of a sodium flame held 6 or 7 feet in front of the objective.

The center of the ring system was found to be about 3 inches from the center of the objective, and a small portion of the objective near the cell was discolored.

The lenses were removed from the cell and cleaned by Mr. Lundin, Jr., on June 14, 15, 16, 1915. Two of the separators were built up a trifle, in order to bring the center of the Newton's rings to the center of the objective. The focal length of the objective was changed slightly and made shorter by 0.027 inch. (See p. 30.)

Eventually the 26-inch lenses ought to be refigured in such a way as to remove all stains and scratches, and the lenses should be separated some distance, in order that the glass might follow more rapidly the temperature changes of the air and that the reflections from the interior surfaces of the objective might be minimized.

However, on account of the difficulty of obtaining large pieces of optical glass, and having in view possible accidents, it is considered advisable that the refiguring should not be undertaken until the Naval Observatory has in its possession new lenses of 26 inches diameter or larger.

On July 9, 1909, a loose rivet was taken out from inside the tube of the 26-inch. 
EQUATORIAL OBSERVATIONS, 1908-1926

The list of the positive eyepieces with which the 26 -inch equatorial is provided is given in the following table:

Positive Eyepieces, 26-inch Equatorial

\begin{tabular}{|c|c|c|c|c|c|c|}
\hline Eyepiece & Power & $\begin{array}{r}\text { Focal } \\
\text { Length }\end{array}$ & Field & Maker & Type & Remarks \\
\hline & & $\mathrm{mm}$ & ' & & & \\
\hline I & 390 & 25. 4 & 4. 9 & Edward Kahler & Single lens & \\
\hline II & 585 & 16. 9 & 3. 2 & Edward Kahler & Single lens & \\
\hline III & 780 & 12. 7 & 2. 6 & Edward Kahler & Single lens & \\
\hline IV & 1560 & 6. 3 & 1. 8 & Edward Kahler & Single lens & \\
\hline $1 \mathrm{~A}$ & 178 & 55.6 & 12.0 & & Ramsden & \\
\hline $2 \mathrm{~A}$ & 284 & 34. 8 & 8. 1 & Edward Kahler & Ramsden & \\
\hline $3 \mathrm{C}$ & 360 & 27.5 & 7. 8 & Edward Kahler & Ramsden & Double convex eye-lens. \\
\hline 3 & 392 & 25. 2 & 9. 9 & Clark \& Sons & Ramsden & \\
\hline $7 \mathrm{C}$ & 761 & 13. 0 & 3. 2 & Edward Kahler & Ramsden & Crown. \\
\hline $8 \mathrm{~F}$ & 875 & 11. 3 & 3. 2 & Edward Kahler & Ramsden & Flint. \\
\hline 9 & 1103 & 9.0 & 2. 6 & Edward Kahler & Ramsden & \\
\hline 10 & 1282 & 7. 7 & 2. 1 & Edward Kahler & Ramsden & \\
\hline 11 & 1802 & 5.5 & 1. 6 & Edward Kahler & Ramsden & \\
\hline AF54 & 183 & 54.0 & 12. 0 & Steinheil & Achromatic & \\
\hline AF27 & 367 & 27. 0 & 6. 3 & Steinheil & Achromatic & \\
\hline $3 \mathrm{~A}$ & 375 & 26. 4 & 6. 6 & Edward Kahler & Achromatic & \\
\hline $3 \mathrm{~B}$ & 388 & 25.5 & 6.5 & M. E. Kahler & Achromatic & \\
\hline AF20 & 495 & 20.0 & 3. 9 & Steinheil & Achromatic & \\
\hline AF20 & 495 & 20.0 & 3.8 & Steinheil & Achromatic & \\
\hline $5 \mathrm{~A}$ & 525 & 18. 9 & 4. 2 & Edward Kahler & Achromatic & \\
\hline $5 \mathrm{~B}$ & 525 & 18. 9 & 4. 2 & M. E. Kahler & Achromatic. & \\
\hline $\mathrm{F}_{15}$ & 650 & 15. 2 & 4. 1 & M. E. Kahler & Achromatic & \\
\hline $8 \mathrm{C}$ & 771 & 12. 8 & 3. 0 & Edward Kahler & Achromatic & \\
\hline $6 \mathrm{~A}$ & 888 & 11. 1 & 2. 3 & Steinheil & Achromatic & \\
\hline 1 & 173 & 57. 2 & 13. 2 & Clark \& Sons & Kellner & \\
\hline 2 & 252 & 39. 3 & 9.3 & & Kellner & \\
\hline $\mathrm{H}_{1}$ & 390 & 25.4 & 6. 7 & Hensoldt & Kellner & Totally reversing prism. \\
\hline $\mathrm{H}_{3 / 4}$ & 520 & 19. 1 & 4. 0 & Hensoldt & Kellner & Totally reversing prism. \\
\hline $\mathrm{H}_{12}$ & 779 & 12.7 & 2. 0 & Hensoldt & Kellner & Totally reversing prism. \\
\hline AL27 & 367 & 27.0 & 6.4 & Steinheil & Orthoscopic & May be used with or \\
\hline AL20 & 495 & 20.0 & 4. 0 & Steinheil & Orthoscopic & without totally revers- \\
\hline AL9 & 1100 & 9.0 & 0.9 & Steinheil & Orthoscopic & ing prism. \\
\hline
\end{tabular}

The mounting.- The mounting of the 26-inch equatorial is on the whole well constructed and very creditable to the distinguished designers. The instrumental constants change but little. (See Appendix III, Vol. IV, Second Series, Publications of the Naval Observatory; also report of Superintendent of the United States Naval Observatory for 1910, pp. 10, 11, and Astronomical Journal, No. 645. For exhibit of instrumental constants see p. 45 et seq.)

But, with reference to future improvements at this and other observatories, attention is invited to the following. (See also Introduction to Vol. VI, Second Series, Publications of the Naval Observatory.)

Through long usage, probably, there is a slight endwise play in the declination spindle. (See Report of Superintendent for 1911, p. 13.) Apparently it was not intended by the makers that the instrument should be used below the pier, but for many purposes it is necessary to use it occasionally in this position. It is suggested that the construction should permit use below the pier as well as above, with an adjustment for endwise motion. 


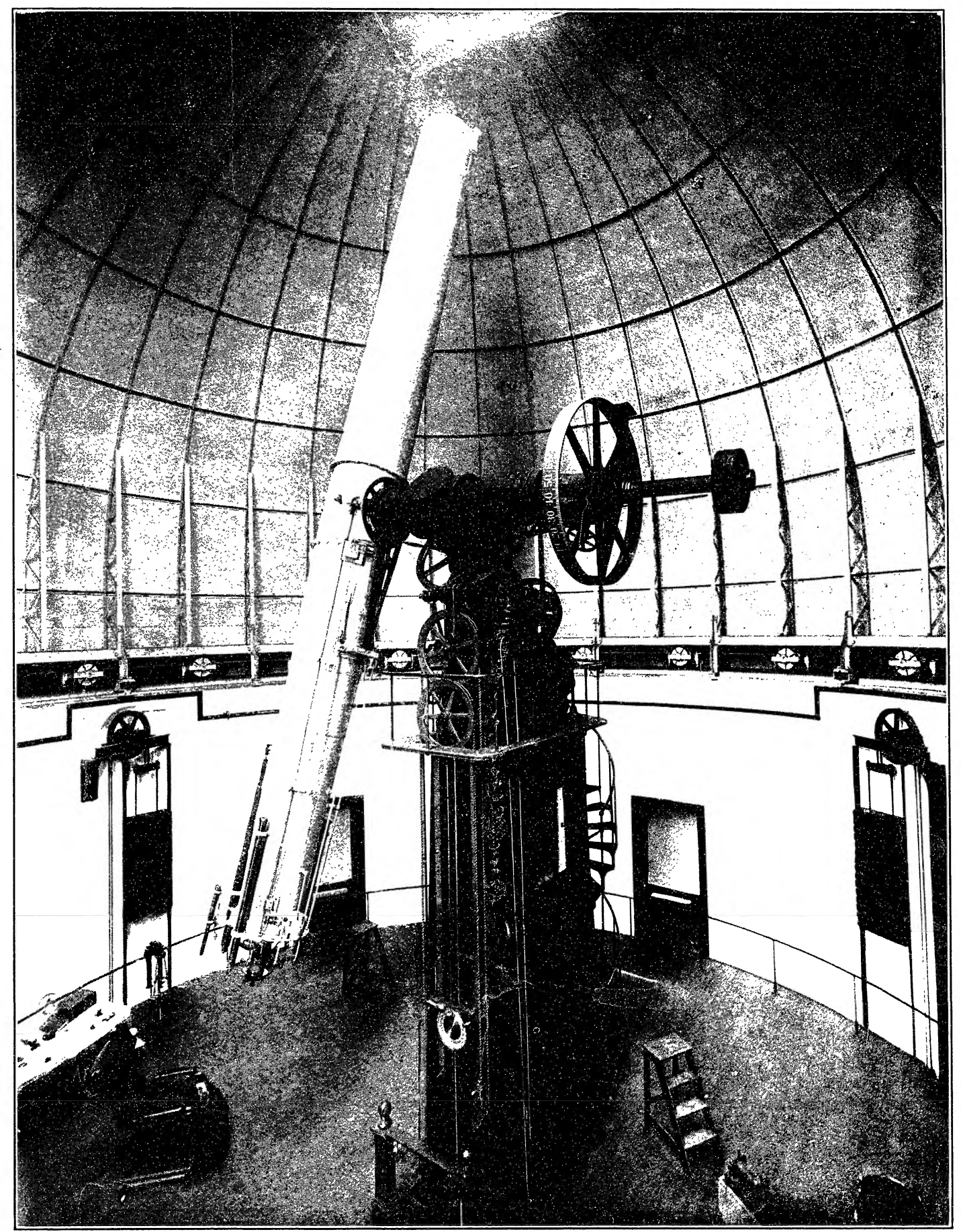

THE 26-INCH EQUATORIAL 
The circles.-The large hour and declination circles are read by knife-edge verniers to $1^{\text {s }}$ and $10^{\prime \prime}$, respectively. The knife-edges collect dirt and easily become marred. It would be better to arrange for microscopes reading to $0^{s} .1$ and $1^{\prime \prime}$.

Originally the declination circle was not properly illuminated, and only portions of the two verniers could be read. Mr. FEcker, superintendent of the Warner \& Swasey Instrument Shop, in the summer of 1909 constructed new mountings for the two small electric lamps which light the circle and verniers and placed them at a greater distance from the circle than were the old mountings, so as to give a fairly good illumination over the whole extent of each vernier. It was possible, then, to determine with the declination circle the instrumental constants $\xi$ and $e$ of Chauvenet's notation.

The driving clock.-As stated in Volume VI, Second Series, of the Naval Observatory Publications, the driving clock of the 26 -inch equatorial has periodic errors which are troublesome.

In July, 1909, the worm screw which drives the large toothed wheel centered on the polar axis was sent to the makers of the mounting to be reground. (See Report of Superintendent for 1910, p. 10.)

During the year 1910-11 a careful study of the causes of the periodic error of the driving clock and of the means of remedying it was made by a board consisting of Prof. G. K. Calmoun, United States Navy, Assistant Astronomer J. C. Hammond, and Assistant E. D. Tillyer. (See Report of Superintendent for 1911, pp. 11-14.)

In order to diminish the error, the driving side of the bevel gears was scraped, under the direction of the board, by a skilled mechanic from the Washington Navy Yard. The gears from the clock to the driving worm were marked, so that in case of removal they could be replaced in their proper positions.

Although the periodic error of the 26-inch driving clock was reduced by this process, it is still difficult to make measures in position angle and distance when it is necessary to slide the eyepiece far.

As suggested by Mr. Swasey, the periodic error of the driving clock may eventually be smoothed out further by wear. It might be worth while, also, to obtain four new bevel gears, cut as accurately as possible, and try them in place of the four bevel gears which were scraped and marked.

In the construction of equatorials which are to be used especially for micrometric measures it is a question whether it would not be better to go back to the sector and sector strap arrangement, somewhat as provided on the old Clark mountings, for in them the periodic error of the driving worm is considerably diminished. (See Naval Observatory volume for 1874, first series.) However, it is necessary to pull back the sector strap about every two hours.

The driving clock of the 26-inch equatorial was last taken down and cleaned in the summer of 1926 by Mr. A. G. Ilse, instrument maker at the Naval Observatory, assisted by Mr. Gustave Harrison, mechanic.

It was found that the lower side of the large driving wheel centered on the polar axis was rubbing against the worm-screw box. To relieve this condition and $1757-29-2$ 
have the worm screw mesh properly with the teeth of the large wheel, one sixtyfourth inch was planed from the cast-iron block on which the worm-screw box rests.

The 26-inch equatorial building.- The walls are of brick faced with rough white marble. Care is taken as to ventilation of the dome room, so that the instrument can be made to follow the changes of temperature as rapidly as possible. The outdoor temperature would be more easily maintained in the observing room if the instrument were mounted in a building entirely separate from office rooms.

It would be better not to have masonry wails but to support the track of the dome on steel uprights set in concrete, the walls to be double, of sheet iron and louvre work, and arranged so as to be easily ventilated.

It is to be noted that moisture works through the walls of the dome, probably where the stone floor of the outside gallery is set into the walls. Inside the dome the walls are plastered, and it is necessary to repair this plaster about every three years.

The elevating floor.- Since December 7, 1896, the elevating floor has been moved by the direct pressure of the city water, reenforced by air pressure from a tank in the main building. On a few occasions the floor, when it was started up, could not be stopped but went up against the iron brackets fixed to the walls and supporting the cables to which the cast-iron counterpoises are attached. Apparently the leather valve cups were too hard, so that occasionally the valves would stick. (See also Report of the Superintendent for 1901, p. 10.)

In June, 1921, the control cylinders for moving the floor and the pilot valve were relined at the Washington Navy Yard, and the piston of the pilot valve was refitted.

In October, 1922, the movement of the floor was further improved by the Otis Elevator Co. A check valve was inserted in the discharge pipe, so as to prevent a partial vacuum in this pipe between the large dome and the main building where the discharge of water takes place. Also the ports in the cylinder carrying the pilot valve were made to match better with the ports in the cylinder of the control valve.

The water has frozen once or twice in the floor rams. Probably on two or three of the coldest nights of each winter it is better to cut off the water from the rams and not use the instrument. Occasionally the floor moves up when the water in the supply pipe is supposed to be cut off, and the instrument should not be left within reach of the floor.

The dome.-In August, 1909, the inner surface of the dome was repainted with cork paint to prevent moisture condensing and dripping on the instrument.

On April 12, 1916, one of the horizontal guide wheels was broken that runs between the two fixed tracks under the dome. Apparently in the trucks of three wheels each the ball bearings were worn, so that the guide wheels were lowered, and the shaft of one guide wheel hit against a web between the two fixed tracks.

In July and August, 1921, the trucks and guide wheels of the dome were repaired and adjusted by workmen from the Washington Navy Yard under the direction of the Acting Superintendent of the Observatory, Capt. G. E. GELM, assisted by Mr. Bower. 
Since 1921 the dome has been raised on screwjacks several times by Mr. W. L. WEAST, the Observatory engineer, assisted by the firemen, for testing and adjusting the running gear.

The illumination of the instrument.-The resistance coils under the floor described in Volume VI have been gradually done away with. These coils reduced the voltage of the 110-volt commercial lighting circuit, so that the current could be used for the small lamps on the instrument. For some time all the lamps on the 26 -inch have been 4 -volt, the commercial current being passed through small transformers and sliding rheostats.

As stated in Volume VI, p. Ax, the bright-field illumination is produced by reflecting light from a small 2-candlepower lamp to the inner surface of the objective by means of a prism within the telescope tube near the eye end and just outside the cone of rays.

The adjustments for this illumination were improved by Mr. H. C. Cleve, formerly instrument maker at the Naval Observatory, and by Mr. J. RHeinbold, foreman of the nauvical instrument repair shop. The bright field can be used with magnifying powers up to 750 .

THE CLARK MICROMETER II OF THE 26-INCH EQUATORIAL

For previous investigations of Clark Micrometer II reference may be made to the following:

(a) Washington Observations for 1877-Appendix I.

(b) Publications of the Naval Observatory, Second Series, Volume III, page AIv.

(c) Publications of the Naval Observatory, Second Series, Volume VI, pages AxIII-Axvir.

The movable slide of this micrometer consists of three brass bars which are rectangular parallelopipedons. A short bar, about $2 \frac{1}{2}$ inches long, serves as a nut for the micrometer screw. At each end of the short bar, and at right angles to it, is attached a bar about 5 inches long, and the two long bars carry the movable threads. Each long bar has a hook on its free end to which a spring is attached, so that in observing the micrometer screw is moved against the pull of the two springs.

The fixed threads are on the brass plate to which the eyepiece is screwed. This plate seems to be of sheet brass, for it has a tendency to buckle. It is necessary to use care in screwing this plate down; otherwise the movable slide will break some of the threads.

The pitch of the micrometer screw is approximately 0.02 of an inch, so that for the 26-inch equatorial one revolution is about $10^{\prime \prime}$. The pitch of the original box screw was about 0.04 of an inch.

In August, 1909, a new box screw was made by Warner and Swasey of nearly the same pitch as the micrometer screw. This new screw was made to work in a check nut, so as to take up lost motion.

November, 1910, the Clark Micrometer II was sent to Warner and Swasey that the movable slide might be refitted. At the same time, with the idea of keeping 
the long sides of the slide parallel, a light brass bar was brazed to them, at right angles to them and near the hooks to which the springs are attached. Apparently this bar produced no change in the value of a micrometer revolution.

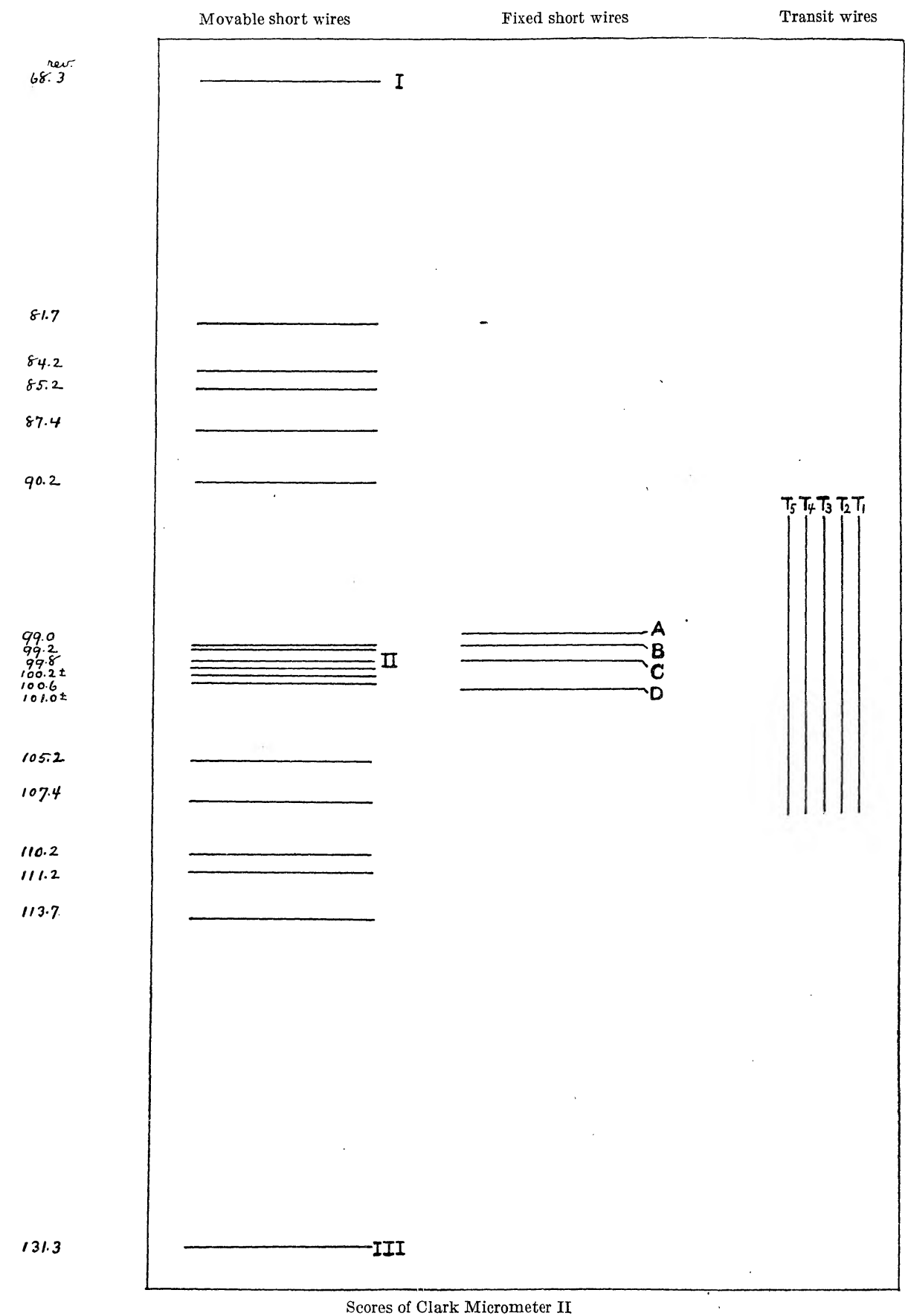

(1) Scores of Clark Micrometer II.-Wire I is the movable wire nearest the micrometer head and the readings increase as the wires are moved toward the head. When $I$ is in coincidence with the fixed wire $C$, the head should read 68.3 revolutions in order to enter the table of progressive errors without corrections to the readings. Assuming this reading for the coincidence of $\mathrm{I}$ and $\mathrm{C}$, the coincidences 
of the movable wires with $\mathrm{C}$ are as given at the left of the line, which indicates the position of the score. I, II, III are the original scores for movable wires, 31.5 revolutions apart, and $\mathrm{B}$ is the original fixed wire score. Other scores were cut later.

$A$ is the fixed wire score nearest the micrometer head. The intervals between the fixed wire scores are:

$$
\mathrm{A}-\mathrm{B}=\mathbf{r e v .} \quad \begin{array}{r}
\text { rev. } \\
\mathrm{B}-\mathrm{C}=0.8 \quad \mathrm{rev} . \\
\mathrm{C}-\mathrm{D}=\mathbf{1 . 6}
\end{array}
$$

The intervals between the scores for the movable and the fixed short wires are shown on the same scale.

The interval between two consecutive transit wire scores is 0.18 inch, approximately, represented on about one-ninth the scale used for short-wire scores.

The length of the short wires is about $13 / 4$ inches and the length of the transit wires about 3 inches, which dimensions are indicated on about one-ninth the scale used for short-wire scores.

(2) Investigation of the errors of the screw under the Transit of Venus measuring engine.-For the examination of screw errors the micrometer was placed under the Transit of Venus measuring engine, and the screw was examined by Messrs. HaLl, Burton, and Watts in April, May, September, and October, 1914.

The periodic error was determined by measuring the value of half revolutions of the Clark screw in terms of the same part of the micrometer screw of the engine micrometer. Approximately $18^{\mathrm{r}} .1$ of the engine micrometer $=1^{\mathrm{R}}$ of Clark II in the determination of periodic error.

All measures of periodic and progressive errors were taken with the micrometer head both north and south.

Measuring half revolutions in the middle of the Clark screw the periodic error was found to be

$$
-0 \mathrm{r} .0044 \cos u-0: .0009 \sin u
$$

in revolutions of the engine micrometer, or,

$$
-0^{\mathrm{R}} .0002 \cos u-0^{\mathrm{R}} .0000 \sin u \text {, }
$$

in revolutions of Clark II, a negligible correction.

Applying the same process to the outside divisions of the Clark screw, there was obtained

$$
-0^{\mathrm{R}} .0003 \cos u+0^{\mathrm{R}} .0000 \sin u,
$$

in revolutions of Clark II, also negligible.

For other determinations of periodic errors, including the coefficients of cos $2 u$ and $\sin 2 u$, see p. 17 .

The progressive errors. - At the time of this examination of the screw of Clark II the movable micrometer slide carried only three wires, spaced at intervals of $31^{\mathrm{R}} .5$, approximately.

It was decided to take the middle part of the screw as the fundamental space and express the other spaces in terms of it. The space $89^{\mathrm{R}}-111^{\mathrm{R}} .5$ was taken, therefore, as fundamental - that is, the progressive errors of these revolutions were assumed to be zero-and then the interval $84^{\mathrm{R}} .5-116^{\mathrm{R}}$ was subdivided by the use of the same part of the screw of the engine into spaces of $4^{\mathrm{R}} .5$. This process was followed in order that the determinations of the middle part of the screw, which is used a great deal, might not be too weak by reason of repeated subdivisions. 
Corrections to the readings were applied for periodic error, and the progressive errors were treated like division errors of a scale, the results appearing as corrections to be added with the signs as written to the actual readings of Clark II.

As the result of 14 sets of measures of the interval $84^{\mathrm{R}} \cdot 5-116^{\mathrm{R}}$, across and back, the equations for progressive errors were found to be, in terms of the engine micrometer:

$$
\begin{aligned}
& \Delta+(89)-(84.5)=21.968 \\
& \Delta+(93.5)-(89)=21.969 \\
& \Delta+(98)-(93.5)=21.967 \\
& \Delta+(102.5)-(98)=21.971 \\
& \Delta+(107)-(102.5)=21.969 \\
& \Delta+(111.5)-(107)=21.977 \\
& \Delta+(116)-(111.5)=21.973
\end{aligned}
$$

Assuming (89) and (111.5) each to be zero, these equations give the following results in terms of the engine micrometer screw and that of Clark II, respectively, denoted by $r$ and $R$ :

$$
\begin{array}{rr}
\mathrm{r} & \mathrm{r} \\
(84.5)=+0.003=+0.0006 \\
(89)=0.000=0.0000 \\
(93.5)=-0.002=-0.0004 \\
(98)=-0.006=-0.0012 \\
(102.5)=-0.006=-0.0012 \\
(107)=-0.007=-0.0014 \\
(111.5)=0.000=0.0000 \\
(116)=+0.002=+0.0004
\end{array}
$$

Then the two intervals $66^{\mathrm{R}} .5-98^{\mathrm{R}}$ and $107^{\mathrm{R}}-138^{\mathrm{R}} .5$ of Clark II were subdivided into spaces of $4^{\mathrm{R}} .5$ thirteen and fifteen times, respectively, by the use of the threads 31.5 revolutions apart, the distance of which was compared with the middle part of the screw. The space $\Delta$ in each case was determined by the use of values which had been found provisionally for (62), (66.5), (93.5), (98), (107), (129.5), (138.5). From the two subdivisions there result finally:

$$
\begin{array}{cc}
\Delta+(71)-(66.5)=21.973 & \Delta+(111.5)-(107)=21.961 \\
\Delta+(75.5)-(71)=21.972 & \Delta+(116)-(111.5)=21.962 \\
\Delta+(80)-(75.5)=21.962 & \Delta+(120.5)-(116)=21.962 \\
\Delta+(84.5)-(80)=21.976 & \Delta+(125)-(120.5)=21.953 \\
\Delta+(89)-(84.5)=21.959 & \Delta+(129.5)-(125)=21.961 \\
\Delta+(93.5)-(89)=21.965 & \Delta+(134)-(129.5)=21.955 \\
\Delta+(98)-(93.5)=21.959 & \Delta+(138.5)-(134)=21.962 \\
\Delta \text { taken as } 21^{r} .972 & \Delta \text { taken as } 21^{r} .951
\end{array}
$$

Solving the above equations, each set by itself, the corrections to the respective revolutions for Clark II are:

$$
\begin{array}{rlrl}
\mathrm{R} & & \mathrm{R} \\
(71) & =+0.0041 & (107) & =-0.0020 \\
(75.5) & =+0.0041 & (111.5) & =0.0000 \\
(80) & =+0.0020 & (116) & =+0.0023 \\
(84.5) & =+0.0029 & (120.5) & =+0.0047 \\
(89) & =0.0000 & (125) & =+0.0054 \\
(93.5) & =-0.0012 & (129.5) & =+0.0077 \\
(98) & =-0.0039 & (134) & =+0.0086 \\
& & (138.5) & =+0.0112
\end{array}
$$

The corrections belonging to the middle interval, $84^{\mathrm{R}} .5-116^{\mathrm{R}}$, as found from these two subdivisions, were given half weight and combined with the values found by directly subdividing the middle interval, giving for the middle interval the following results: 


$\begin{array}{rlrl}\mathbf{R} & \mathrm{R} \\ (84.5) & =+0.0014 & (102.5) & =-0.0012 \\ (89) & =0.0000 & (107) & =-0.0016 \\ (93.5) & =-0.0007 & (111.5) & =0.0000 \\ (98) & =-0.0021 & (116) & =+0.0010\end{array}$

By direct comparison with the central space, $84^{\mathrm{R}} .5-116^{\mathrm{R}}$, and employing the final results for this space, corrections to the micrometer readings were obtained as follows. Each individual result represents a measurement forward and back. $N$ is micrometer head north; $S$, head south. The unit is the fourth decimal place of a revolution of Clark II-that is, $0^{\mathrm{R}} .0001$.

\begin{tabular}{|c|c|c|c|c|c|c|c|c|}
\hline Rev. & $\mathrm{N}$ & $\mathrm{S}$ & Rev. & $\mathrm{N}$ & $\mathrm{S}$ & Rev. & $\mathrm{N}$ & $\mathrm{S}$ \\
\hline \multirow[t]{2}{*}{$(55)$} & \multirow{2}{*}{$\begin{array}{r}-26 \\
-19 \\
\text { Mean } \\
-20\end{array}$} & \multirow[t]{2}{*}{-19} & \multirow[t]{2}{*}{$(65.5)$} & \multirow{2}{*}{$\begin{array}{r}+25 \\
+46 \\
\text { Mean } \\
+41\end{array}$} & \multirow[t]{2}{*}{+46} & (131.5) & & +71 \\
\hline & & & & & & \multirow[t]{2}{*}{ (134) } & $\begin{array}{r}+84 \\
+71 \\
\text { Mean } \\
+74\end{array}$ & +71 \\
\hline \multirow[t]{2}{*}{$(57.5)$} & \multirow{2}{*}{$\begin{array}{r}+24 \\
+45 \\
+20 \\
\text { Mean } \\
+23\end{array}$} & \multirow{2}{*}{$\begin{array}{l}+17 \\
+14\end{array}$} & \multirow[t]{2}{*}{$(66.5)$} & $\begin{array}{l}+25 \\
+39\end{array}$ & \multirow{2}{*}{$\begin{array}{l}+30 \\
+31 \\
+33\end{array}$} & & \multicolumn{2}{|l|}{+74} \\
\hline & & & & $\begin{array}{r}\text { Mean } \\
+32\end{array}$ & & $(135.5)$ & \multirow{2}{*}{$\begin{array}{r}+103 \\
+93 \\
\text { Mean } \\
+96\end{array}$} & +93 \\
\hline$(60)$ & & +4 & $(70)$ & & +38 & \multirow{2}{*}{$(136.5)$} & & \multirow{2}{*}{+97} \\
\hline \multirow{4}{*}{ (62) } & \multirow{4}{*}{$\begin{array}{r}+35 \\
+56 \\
+39 \\
\text { Mean } \\
+41\end{array}$} & \multirow{4}{*}{$\begin{array}{l}+50 \\
+31 \\
+37\end{array}$} & $(75)$ & & +34 & & & \\
\hline & & & & & & (138.5) & +107 & +104 \\
\hline & & & $(80)$ & & +28 & & $\begin{array}{l}+101 \\
+114\end{array}$ & $\begin{array}{l}+103 \\
+102\end{array}$ \\
\hline & & & (121.5) & & +13 & & +108 & \\
\hline (65) & +34 & $\begin{array}{r}+9 \\
+50\end{array}$ & (126.5) & & +19 & & +106 & \\
\hline & Mean & & (129.5) & +70 & +43 & (140) & & +81 \\
\hline & & & & $T$. & $\begin{array}{r}50 \\
+58\end{array}$ & (141.5) & & +96 \\
\hline & & & & +56 & & $(143.5)$ & $\begin{array}{l}+134 \\
+123 \\
\text { Mean } \\
+126\end{array}$ & +123 \\
\hline
\end{tabular}


By the use of corrections already determined the following additional corrections to the screw readings were found:

\begin{tabular}{|c|c|c|c|c|c|c|c|c|}
\hline Rev. & $\mathrm{N}$ & $\mathrm{S}$ & Rev. & $\mathrm{N}$ & $\mathrm{S}$ & Rev. & $\mathrm{N}$ & $\mathrm{S}$ \\
\hline \multirow[t]{2}{*}{ (58) } & \multirow{2}{*}{$\begin{array}{r}-10 \\
\text { Mean } \\
-12\end{array}$} & \multirow[t]{2}{*}{-14} & $(71)$ & & +24 & $(129.5)$ & & +84 \\
\hline & & & (78) & +29 & & \multirow[t]{2}{*}{$(130)$} & \multirow{2}{*}{$\begin{array}{r}+73 \\
\text { Mean } \\
+72\end{array}$} & \multirow[t]{2}{*}{+70} \\
\hline \multirow[t]{2}{*}{$(58.5)$} & \multirow{2}{*}{\multicolumn{2}{|c|}{$\begin{array}{r}+4 \\
+12 \\
\text { Mean } \\
0\end{array}$}} & (118.5) & +26 & & & & \\
\hline & & & \multirow[t]{2}{*}{ (119) } & $\begin{array}{r}+21 \\
\text { Mean } \\
+26\end{array}$ & +30 & (131.5) & $\begin{array}{r}+72 \\
\text { Mean } \\
+74\end{array}$ & +75 \\
\hline \multirow[t]{2}{*}{$(65.5)$} & \multirow{2}{*}{$\begin{array}{r}+38 \\
\text { Mean } \\
+36\end{array}$} & \multirow{2}{*}{+35} & & & & \multirow{3}{*}{ (132) } & & \multirow{3}{*}{+87} \\
\hline & & & (119.5) & +50 & & & \multirow{2}{*}{$\begin{array}{r}+82 \\
\text { Mean } \\
+84\end{array}$} & \\
\hline \multirow{2}{*}{ (68) } & \multirow{2}{*}{$\begin{array}{r}+30 \\
\text { Mean } \\
+38\end{array}$} & \multirow{2}{*}{+46} & \multirow[t]{2}{*}{ (122.5) } & \multirow{2}{*}{\multicolumn{2}{|c|}{$\begin{array}{r}+29 \\
\text { Mean } \\
+22\end{array}$}} & & & \\
\hline & & & & & & \multirow[t]{2}{*}{$(136)$} & \multirow{2}{*}{$\begin{array}{r}+95 \\
\text { Mean } \\
+100\end{array}$} & \multirow[t]{2}{*}{+106} \\
\hline \multirow{4}{*}{$(68.5)$} & \multirow{4}{*}{$\begin{array}{r}+43 \\
\text { Mean } \\
+36\end{array}$} & \multirow{4}{*}{+30} & \multicolumn{2}{|l|}{ (123.5) } & +49 & & & \\
\hline & & & (125.5) & & +50 & $(141.5)$ & & +148 \\
\hline & & & $(127.5)$ & +45 & +54 & (142) & +122 & +151 \\
\hline & & & & $\begin{array}{r}\text { Mean } \\
+50\end{array}$ & & & $\begin{array}{l}+135 \\
\text { Mean } \\
+140\end{array}$ & \\
\hline
\end{tabular}


These results can be tabulated as follows, the more accurate determination being written first, and the adopted value last, in cases where there are more than one determination. As before stated, the unit is $0^{\mathrm{R}} .0001$.

\begin{tabular}{|c|c|c|c|c|c|c|c|c|c|}
\hline Rev. & Corr. & Rev. & Corr. & Rev. & Corr. & Rev. & Corr. & Rev. & Corr. \\
\hline$(55)$ & -20 & $(68.5)$ & +36 & (93. 5) & -7 & $(122.5)$ & +22 & (132) & +84 \\
\hline$(57.5)$ & +23 & $(70)$ & +38 & (98) & -21 & (123. 5) & +49 & \multirow[t]{2}{*}{ (134) } & $\begin{array}{l}+74 \\
+\quad 86\end{array}$ \\
\hline$(58)$ & -12 & \multirow[t]{2}{*}{ (71) } & $\begin{array}{l}+41 \\
+24\end{array}$ & $(102.5)$ & -12 & (125) & +54 & & +80 \\
\hline (58. 5) & 0 & & +38 & (107) & -16 & (125. 5) & +50 & (135. 5) & +96 \\
\hline$(60)$ & +4 & $(75)$ & +34 & (111. 5) & 0 & (126. 5) & +19 & (136) & +100 \\
\hline$(62)$ & +41 & $(75.5)$ & +41 & $(116)$ & +10 & $(127.5)$ & +50 & \multirow[t]{2}{*}{ (138. 5) } & $\begin{array}{l}+106 \\
+112\end{array}$ \\
\hline (65) & +36 & (78) & +29 & $(118.5)$ & +26 & (129. 5) & $\begin{array}{l}+56 \\
+77\end{array}$ & & +108 \\
\hline \multirow[t]{4}{*}{$(65.5)$} & +41 & \multirow[t]{4}{*}{$(80)$} & +20 & \multirow[t]{2}{*}{ (119) } & \multirow[t]{2}{*}{+26} & & +84 & \multirow[t]{2}{*}{$(140)$} & \multirow[t]{2}{*}{+81} \\
\hline & +36 & & +28 & & & & +66 & & \\
\hline & \multirow[t]{2}{*}{+38} & & +22 & (119. 5) & +50 & & & \multirow[t]{4}{*}{ (141. 5) } & +96 \\
\hline & & & & & & $(130)$ & +72 & & +148 \\
\hline \multirow[t]{2}{*}{$(66.5)$} & \multirow[t]{2}{*}{+32} & \multirow[t]{2}{*}{$(84.5)$} & \multirow[t]{2}{*}{+14} & \multirow[t]{2}{*}{$(120.5)$} & \multirow[t]{2}{*}{+47} & & & & \multirow[t]{2}{*}{+113} \\
\hline & & & & & & \multirow[t]{3}{*}{$(131.5)$} & +71 & & \\
\hline \multirow[t]{2}{*}{$(68)$} & \multirow[t]{2}{*}{+38} & \multirow[t]{2}{*}{$(89)$} & \multirow[t]{2}{*}{0} & \multirow[t]{2}{*}{ (121. 5) } & +13 & & +74 & $(142)$ & +140 \\
\hline & & & & & & & & (143. 5) & +126 \\
\hline
\end{tabular}

From an inspection of the preceding table it is evident that measures should not be made at less than about $65^{\mathrm{R}}$, since probably there is not sufficient tension on the springs. At $135^{\mathrm{R}}$ there is considerable tension, and probably the screw should not be used beyond this reading. The increased tension may account partially for the larger values of the progressive corrections as the readings increase. Some of the determinations have small weights, but were included in the table. There is no doubt that the screw varies slightly in its different parts, substantially as shown by the table. For usual measures of double distances taken symmetrically on each side of $100^{\mathrm{R}}$ the corrections for progressive errors are negligible.

It should be stated that in this examination under the comparator the light on the threads, daylight, seemed to change a trifle after the micrometer was reversed. Also, the slide of the micrometer of the comparator appeared to be a little loose, probably worn by long usage. Therefore, another determination of the screw errors was made. (See p. 16.) 
The values finally adopted are given on page 22 .

The thickness of the spider lines. - The diameters of the movable spider lines were measured by HALL, BURTON, and WATtS in terms of a revolution of the micrometer of the comparator referred to above.

Thread I is the movable thread nearest the micrometer head; II is in the middle. As has been stated, each interval, II - I and III - II, is equal approximately to $31^{\mathrm{R}} .5$. A thread of the engine micrometer was placed tangent to a thread of the Clark micrometer on each side of it. Each result for a diameter given below is the mean of 16 readings.

\begin{tabular}{|c|c|c|}
\hline I & II & III \\
\hline$r$ & $r$ & $r$ \\
0.252 & 0.220 & 0.216 \\
0.282 & 0.230 & 0.186 \\
0.297 & 0.241 & 0.226 \\
0.288 & 0.232 & 0.227 \\
0.260 & 0.218 & 0.220 \\
\hline 0.276 & 0.228 & 0.215 \\
\hline
\end{tabular}

$1^{r}$ of the comparator micrometer $=0^{\mathrm{R}} .05517$ Clark II, and in terms of $1^{R}$ of Clark II the above values become:

or in seconds of arc

$$
\begin{array}{ccc}
\text { I } & \text { II } & \text { III } \\
0^{\mathrm{R} .01523} & 0^{\mathrm{R}} .01258 & 0^{\mathrm{R}} .01186
\end{array}
$$

$$
0^{\prime \prime} .151 \quad 0^{\prime \prime} .125 \quad 0^{\prime \prime} .118
$$

$\mathrm{I}^{\mathrm{R}}=0^{\text {in }} .018763$ at $32^{\circ} \mathrm{F}$. (See Washington Observations for 1877, Appendix I, p. 10.) Then the diameters of the threads in inches and microns are:

$$
\begin{array}{ccc}
\text { I } & \text { II } & \text { III } \\
0^{\text {in }} .00028 & 0^{\text {in }} .00024 & 0^{\text {in }} .00023 \\
7 \mu & 6 \mu & 6 \mu
\end{array}
$$

For use in correcting measures of planetary diameters the mean of the above values in arc has been taken as the thickness of a thread-that is, $0^{\prime \prime} .131$.

(3) Investigation of the errors of the screw of Clark Micrometer II with the eyepiece microscope.-After experience with the eyepiece microscope furnished with the new Repsold micrometer constructed for the 26-inch equatorial it was decided to adapt the microscope to Clark Micrometer II and to make a further examination of the screw.

Mr. J. Rheinsold cut additional scores on the movable slide of Clark II and inserted wires at suitable intervals for the examination of the screw. Also, provision was made to clamp the eyepiece microscope in any desired position.

In order to keep the Repsold micrometer in use on the 26-inch, Clark Micrometer II was placed on a bench in the east office room of the great equatorial building. By a mirror skylight was reflected through a hole in the bench onto a ground glass plate which illuminated the field with a diffused light. The measurements were made by HaLl and Burton in March, April, May, 1916. 
The eyepiece microscope has a magnifying power of about 60 . It is provided with a pair of fixed threads, which are placed parallel to the micrometer threads and between which the latter are set.

The periodic error was found by measuring a thread interval on the movable micrometer slide approximately equal to $2^{\mathrm{R}} .25$ in terms of three portions of the micrometer screw. The respective results were:

$$
\begin{aligned}
& \stackrel{\mathbf{R}}{\mathbf{R}} \stackrel{\mathbf{R}}{\mathbf{R}} \stackrel{\mathbf{R}}{\mathbf{R}} \underset{\mathbf{R}}{\mathbf{R}} \cos u+0.0001 \sin u-0.0001 \cos 2 u-0.0000 \sin 2 u \\
& -0.0001 \cos u-0.0001 \sin u-0.0002 \cos 2 u-0.0001 \sin 2 u \\
& -0.0001 \cos u-0.0001 \sin u-0.0002 \cos 2 u+0.0000 \sin 2 u
\end{aligned}
$$

The periodic error is, therefore, negligible.

The progressive errors. - To determine the progressive errors, the space $85^{\mathrm{R}}-115^{\mathrm{R}}$ was taken as fundamental. First a wire interval on the micrometer slide equal approximately to $15^{\mathrm{R}}$ was employed to subdivide the space $55^{\mathrm{R}}-130^{\mathrm{R}}$.

A sample set of measures of the $15^{\mathrm{R}}$ intervals is as follows, four settings being made symmetrically on each wire that was brought under the microscope:

$$
\begin{aligned}
& \mathrm{R} \\
& \Delta+(70)-(55)=15.0113 \\
& \Delta+(85)-(70)=15.0140 \\
& \Delta+(100)-(85)=15.0152 \\
& \Delta+(115)-(100)=15.0070 \\
& \Delta+(130)-(115)=15.0058 \\
& \Delta+(140)-(125)=15.0035
\end{aligned}
$$

From the third and fourth equations $\Delta=15^{\mathrm{R}} .0111$ and the corrections for progressive error, to be added algebraically to the actual micrometer readings, are:

$$
\begin{array}{cc}
\mathbf{R} & \mathbf{R} \\
(55)=+0.0031 & (100)=-0.0041 \\
(70)=+0.0029 & (115)=0.0000 \\
(85)=0.0000 & (130)=+0.0053
\end{array}
$$

This same value of $\Delta, 15^{\mathrm{R}} .0111$, was used for the determination of (140) after (125) had been found by the trisection of the $15^{\mathrm{R}}$ spaces. It was not possible to bring $145^{\mathrm{R}}$ under the eyepiece microscope in connection with the threads $15^{\mathrm{R}}$ apart on the slide. 
The separate results for the $15^{R}$ spaces were, the unit being $0^{\mathrm{R}} .0001$ :

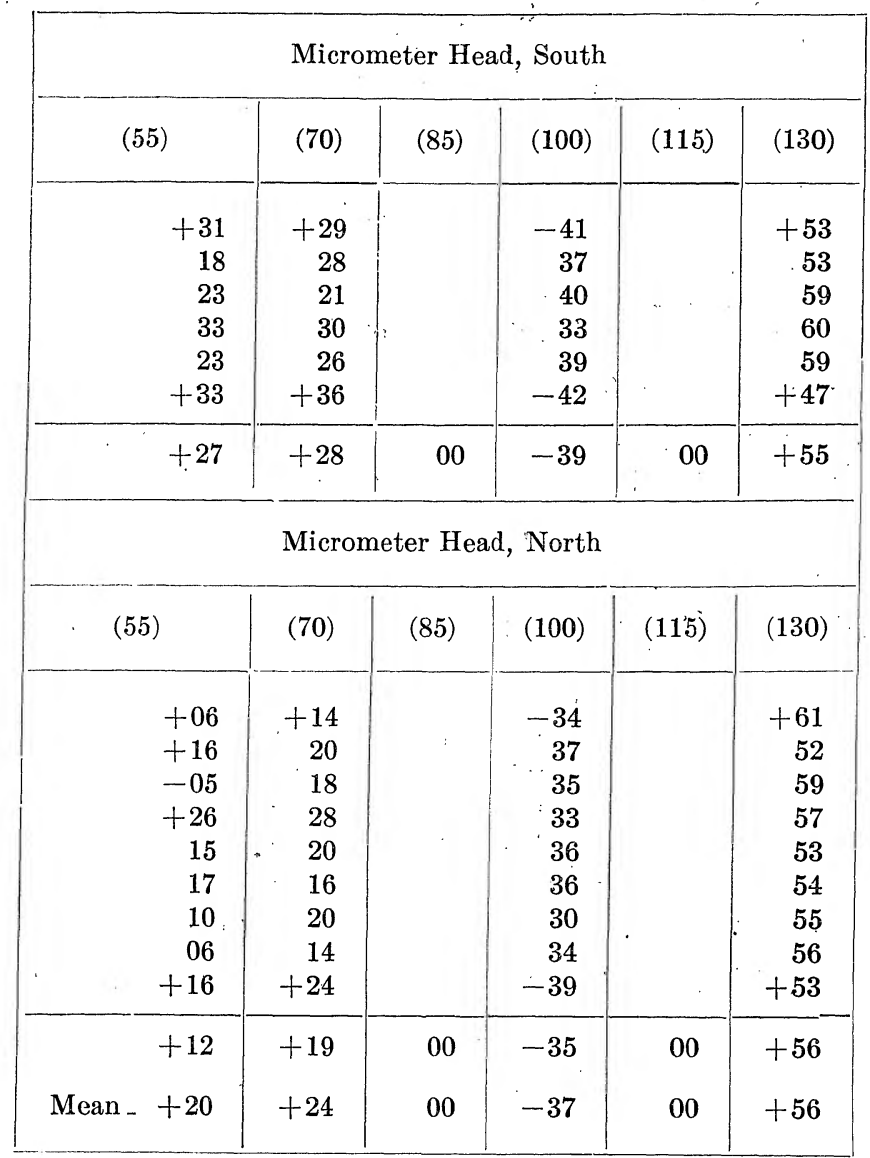


Employing the values just obtained, the $15^{\mathrm{R}}$ intervals were trisected by means of threads approximately $5^{\mathrm{R}}$ apart, giving:

\begin{tabular}{|c|c|c|c|c|c|c|c|c|c|}
\hline \multicolumn{10}{|c|}{ Micrometer Head, South } \\
\hline$(60)$ & $(65)$ & $(75)$ & $(80)$ & $(90)$ & $(95)$ & $(105)$ & (110) & $(120)$ & (125) \\
\hline+34 & +38 & +20 & +13 & -18 & -38 & -34 & -19 & +22 & +40 \\
\hline 33 & 35 & 15 & 13 & 24 & 35 & 19 & 09 & 12 & 27 \\
\hline 39 & 34 & 18 & 11 & 14 & 36 & 34 & 16 & 21 & 37 \\
\hline 29 & 30 & 21 & 17 & 16 & 32 & 29 & 20 & 23 & 34 \\
\hline+29 & +32 & +19 & +14 & -28 & -34 & -34 & -24 & +23 & +33 \\
\hline+33 & +34 & +19 & +14 & -20 & -35 & -30 & -18 & +20 & +34 \\
\hline \multicolumn{10}{|c|}{ Micrometer Head, North } \\
\hline$(60)$ & $(65)$ & $(75)$ & $(80)$ & $(90)$ & $(95)$ & (105) & (110) & $(120)$ & (125) \\
\hline+19 & +22 & +14 & +06 & -15 & -32 & -25 & -11 & +17 & +31 \\
\hline 17 & 21 & 15 & 06 & 16 & 29 & 24 & 13 & 21 & 37 \\
\hline 22 & 24 & 18 & 15 & 18 & 38 & 24 & 12 & 09 & 30 \\
\hline 19 & 23 & 18 & 10 & 23 & 33 & 22 & 09 & 09 & 26 \\
\hline+18 & ++18 & +19 & +15 & -13 & -33 & -29 & -15 & +12 & +34 \\
\hline+19 & +22 & +17 & +10 & -17 & -33 & -25 & -12 & +14 & +32 \\
\hline Mean_ + 26 & +28 & +18 & +12 & -18 & -34 & -28 & -15 & +17 & +33 \\
\hline
\end{tabular}


EQUATORIAL OBSERVATIONS, 1908-1926

Making use of (125) found by trisecting the $15^{\mathrm{R}}$ spaces, and of the individual values of $\Delta$ found from the $15^{\mathrm{R}}$ spaces, there were obtained for (140):

\begin{tabular}{|c|c|}
\hline Micrometer Head, South & Micrometer Head, North \\
\hline$(140)$ & $(140)$ \\
\hline+110 & +103 \\
104 & 96 \\
99 & 94 \\
102 & 97 \\
102 & 92 \\
+94 & 102 \\
+102 & 94 \\
& 105 \\
& +95 \\
\hline Mean $\ldots+98$ \\
\hline
\end{tabular}

Using (130) and (140), the following results were obtained for (135) and (145):

\begin{tabular}{|c|c|c|c|}
\hline $\begin{array}{l}\text { Head, South } \\
\text { (135) }\end{array}$ & $\begin{array}{l}\text { Head, North } \\
\text { (135) }\end{array}$ & $\underset{(145)}{\text { Head, South }}$ & $\underset{\text { (145) }}{\text { Head, North }}$ \\
\hline+71 & +79 & +123 & +103 \\
\hline 76 & 80 & 121 & 112 \\
\hline 79 & 78 & 118 & 105 \\
\hline 76 & 78 & 129 & 126 \\
\hline+73 & +75 & +114 & +114 \\
\hline+75 & +78 & +121 & +112 \\
\hline \multicolumn{2}{|c|}{ Mean_...... +76 } & \multicolumn{2}{|c|}{ Mean _..... +116 } \\
\hline
\end{tabular}


Then, the $5^{\mathrm{R}}$ intervals of the screw were each divided twice into five parts by means of threads on the micrometer slide having a distance apart of approximately $1^{\mathrm{R}}$. In this way were found the following results:

\begin{tabular}{|c|c|c|c|c|c|c|c|c|}
\hline & (66) & $(67)$ & (68) & (69) & (71) & $(72)$ & (73) & $(74)$ \\
\hline \multirow{2}{*}{$\begin{array}{l}\text { Head, South } \\
\text { Head, North } \\
\text { Mean }\end{array}$} & $\begin{array}{l}+35 \\
+23\end{array}$ & $\begin{array}{r}+30 \\
+17\end{array}$ & $\begin{array}{l}+28 \\
+12\end{array}$ & $\begin{array}{l}+29 \\
+21\end{array}$ & $\begin{array}{l}+30 \\
+20\end{array}$ & $\begin{array}{l}+20 \\
+21\end{array}$ & $\begin{array}{l}+22 \\
+16\end{array}$ & $\begin{array}{l}+25 \\
+11\end{array}$ \\
\hline & +29 & +24 & +20 & +25 & +25 & +20 & +19 & +18 \\
\hline & (76) & (77) & (78) & (79) & (81) & (82) & (83) & (84) \\
\hline \multirow{4}{*}{$\begin{array}{l}\text { Head, South } \\
\text { Head, North } \\
\text { Mean }\end{array}$} & +28 & +24 & +23 & +19 & +15 & +06 & +02 & +01 \\
\hline & +10 & +14 & +06 & +08 & +05 & +02 & +01 & +03 \\
\hline & +19 & +19 & +14 & +14 & +10 & +04 & +02 & +02 \\
\hline & (86) & (87) & (88) & (89) & $(91)$ & $(92)$ & (93) & (94) \\
\hline \multirow{4}{*}{$\begin{array}{l}\text { Head, South } \\
\text { Head, North } \\
\quad \text { Mean }\end{array}$} & -08 & -13 & -16 & -16 & -25 & -32 & -39 & -41 \\
\hline & -06 & -15 & -16 & -14 & -23 & -29 & -27 & -26 \\
\hline & -07 & -14 & -16 & -15 & -24 & -30 & -33 & -34 \\
\hline & $(96)$ & $(97)$ & (98) & (99) & (101) & (102) & (103) & (104) \\
\hline \multirow{4}{*}{$\begin{array}{l}\text { Head, South } \\
\text { Head, North } \\
\text { Mean }\end{array}$} & -25 & -19 & -21 & -29 & -32 & -33 & -36 & -36 \\
\hline & -40 & -40 & -41 & -37 & -32 & -29 & -29 & -29 \\
\hline & -32 & -30 & -31 & -33 & -32 & -31 & -32 & -32 \\
\hline & (106) & (107) & (108) & (109) & (111) & (112) & (113) & (114) \\
\hline \multirow{3}{*}{$\begin{array}{l}\text { Head, South } \\
\text { Head, North } \\
\text { Mean }\end{array}$} & -32 & -29 & -26 & -21 & -12 & -01 & -04 & -08 \\
\hline & -22 & -24 & -19 & -18 & -13 & -05 & -04 & +03 \\
\hline & -27 & -26 & -22 & -20 & -12 & -03 & -04 & -02 \\
\hline
\end{tabular}




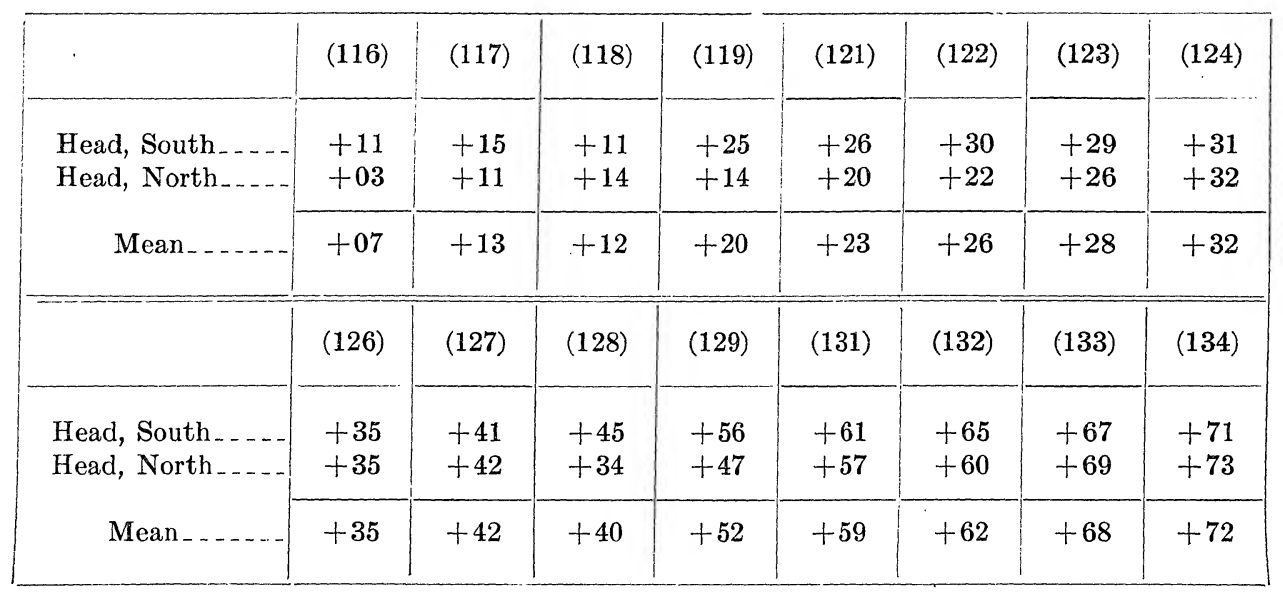

The table of progressive errors adopted for use is given below. In it (55) and (60) have each been taken as zero; also, in the case of the revolutions $65^{\mathrm{R}}-70^{\mathrm{R}}$, inclusive, the values obtained with the eyepiece microscope have been slightly modified to conform somewhat to the determinations secured with the measuring engine. To use the table of progressive errors, the coincidence of Wire I with $\mathrm{C}$, the middle fixed wire, should be approximately $68^{\mathrm{R}} .3$. Corrections for progressive error have been applied, but as shown in the table they are negligible in ordinary double distance measures where the mean of the readings is about 100 revolutions The fundamental interval of the screw is $115^{\mathrm{R}}-85^{\mathrm{R}}$. For diagram of scores for the wires see page 10 .

Adopted Progressive Errors of the Screw of Clark Micrometer II

\begin{tabular}{|c|c||c|c||c|c||c|c|}
\hline Rev. & Corr. & Rev. & Corr. & Rev. & Corr. & Rev. & Corr. \\
\hline & $\mathbf{R}$ & & $\mathrm{R}$ & & $\mathrm{R}$ & & $\mathbf{R}$ \\
\hline 55 & 0.0000 & 82 & +0.0004 & 101 & -0.0032 & 120 & +0.0017 \\
60 & 0.0000 & 83 & +0.0002 & 102 & -0.0031 & 121 & +0.0023 \\
65 & +0.0020 & 84 & +0.0002 & 103 & -0.0032 & 122 & +0.0026 \\
66 & +0.0021 & 85 & 0.0000 & 104 & -0.0032 & 123 & +0.0028 \\
67 & +0.0016 & 86 & -0.0007 & 105 & -0.0028 & 124 & +0.0032 \\
68 & +0.0012 & 87 & -0.0014 & 106 & -0.0027 & 125 & +0.0033 \\
69 & +0.0018 & 88 & -0.0016 & 107 & -0.0026 & 126 & +0.0035 \\
70 & +0.0022 & 89 & -0.0015 & 108 & -0.0022 & 127 & +0.0042 \\
71 & +0.0025 & 90 & -0.0018 & 109 & -0.0020 & 128 & +0.0040 \\
72 & +0.0020 & 91 & -0.0024 & 110 & -0.0015 & 129 & +0.0052 \\
73 & +0.0019 & 92 & -0.0030 & 111 & -0.0012 & 130 & +0.0056 \\
74 & +0.0018 & 93 & -0.0033 & 112 & -0.0003 & 131 & +0.0059 \\
75 & +0.0018 & 94 & -0.0034 & 113 & -0.0004 & 132 & +0.0062 \\
76 & +0.0019 & 95 & -0.0034 & 114 & -0.0002 & 133 & +0.0068 \\
77 & +0.0019 & 96 & -0.0032 & 115 & 0.0000 & 134 & +0.0072 \\
78 & +0.0014 & 97 & -0.0030 & 116 & +0.0007 & 135 & +0.0076 \\
79 & +0.0014 & 98 & -0.0031 & 117 & +0.0013 & 140 & +0.0100 \\
80 & +0.0012 & 99 & -0.0033 & 118 & +0.0012 & 145 & +0.0116 \\
81 & +0.0010 & 106 & -0.0037 & 119 & +0.0020 & & \\
& & & & & & & \\
\hline
\end{tabular}

(4) Value of one revolution of the screw of Clark Micrometer II.-The value of one revolution was found by Prof. T. J. J. See to be 
(See Publications of the Naval Observatory, Second Series, Vol. III, Pt. I, p. Avi; also Vol. VI, p. Axvi.)

The above value (A) of a revolution was used for the following observations as published in the Astronomical Journal, no corrections for errors of the screw being applied:

Satellites of Saturn, opposition of 1908, published in No. 621. Satellites of Uranus, oppositions of 1908, 1909, 1910; No. 627. Satellite of Neptune, opposition of 1908-09, 1909-10, No. 622. Asteroids, comets, Satellite VI of Jupiter, until October, 1910, Nos. 605, 606, 612, 613, 616, 618-619, 621, 622, 673-674. Instrumental constants, until March 31, 1911, No. 645.

A preliminary value of a revolution of the screw of Clark II was determined by HaLL from measures of the differences of declination of the stars $A$ and $Z$ in the cluster $h$ Persei. This value is

$$
R=9^{\prime \prime} .9337+0^{\prime \prime} .00006\left(\mathrm{~T}-50^{\circ} \mathrm{F}\right. \text {. }
$$

for the focal setting $1^{\text {in }} .270$. (See Astronomical Journal No. 645.)

Preliminary values of one revolution were determined also by FREDERICKSON, Eppes, and Burton from the same pair of stars by the same method. These determinations were very nearly the same as the result given above for (B).

For $1914.0 \Delta \delta$ of the stars $A$ and $Z$, of the cluster $h$ Persei was taken to be $1115^{\prime \prime} .45$ in the determination of this preliminary value.

This value (B) was used for the following observations as published in the Astronomical Journal, no corrections for screw errors being applied: Satellites of Uranus and Neptune, 1911, No. 648. Satellite of Neptune, 1911-12, No. 654. Satellites of Mars, 1909, No. 645. Asteroids, comets, Satellite VI of Jupiter, for the period from October, 1910, through June, 1915, Nos. 635-636, 649-650, 664, 665, 666, 673-674, 676, 693, 697, 698, 713.

The definitive value of a revolution of the screw of Clark Micrometer II, for the period May 20, 1908, to June 15, 1915, was found from measures with bright field of the differences of declination of three pairs of stars. As for the value (B), the stars were allowed to transit across the field, the declination settings being taken at the middle transit thread.

The three pairs of stars were:

1. $A$ and $Z$ in the cluster $h$ Persei-that is, B. D. $+56^{\circ} 543(8.0)$ and B. D. $+56^{\circ}$ $498(8.6)$.

2. B. D. $+23^{\circ} 495$ (8.3) and B. D. $+24^{\circ} 540$ (8.0), Pleiades stars.

3. B. D. $+24^{\circ} 550$ (8.8) and B. D. $+24^{\circ} 552$ (9.1), Pleiades stars.

The authorities for the places of the Perseus stars were:

1. Der Sternhaufen h Persei, von A. KRUEGer, Abdruck aus den Abhandlungen der Finnischen Societät der Wissenschaften, heliometer.

2 and 3. Volume IX, page 23, Observations de Poulkova, Gyldén and Nyrén, vertical circle.

4. Supplément III aux Observations de Poulkova, Romberg, meridian circle.

5. Contributions from the Observatory of Columbia University No. 24, stars 78 and 39, Young, 12 Rutherford plates. $1757-29-3$ 
6. Annalen der K. Universitäts-Sternwarte in Strassburg, zweiter Band, Katalog von 858 Sternen, meridian circle.

7. Astronomische Mittheilungen von der K. Sternwarte zu Göttingen, sechster Theil, stars $f$ and $c$, Schur, heliometer.

8. Astronomische Abhandlungen der Hamburger Sternwarte in Bergedorf, Band II, $N r$. Q , stars 312 and 122, Messow, 2 plates.

9. Naval Observatory, 9-inch meridian circle.

10. Naval Observatory, 6-inch meridian circle.

11. Naval Observatory, 9-inch meridian circle.

12. Naval Observatory, 6-inch meridian circle.

13. Publications de Poulkova, série II, Volume XI, page 9, mean of 3 heliometers. Reduced to 1914.0, the means for $s$ and $p$ become $s=1342^{\prime \prime} .72, p=33^{\circ} 49^{\prime} 28^{\prime \prime}$.

14. Yale Observatory, observed with heliometer by SмITH, at the request of Superintendent of the Naval Observatory. For 1914.0, $s=1342^{\prime \prime} .68, p=33^{\circ} 48^{\prime} 2^{\prime \prime}$.

15. Yale Observatory, observed with heliometer by SмIтн at the request of the Superintendent of the Naval Observatory. For 1915.0, $s=1342^{\prime \prime} .80, p=33^{\circ} 50^{\prime} 15^{\prime \prime}$.

With Newcomb's precession the difference of declination of the pair of stars in Perseus was reduced to 1914.0, giving the following results:

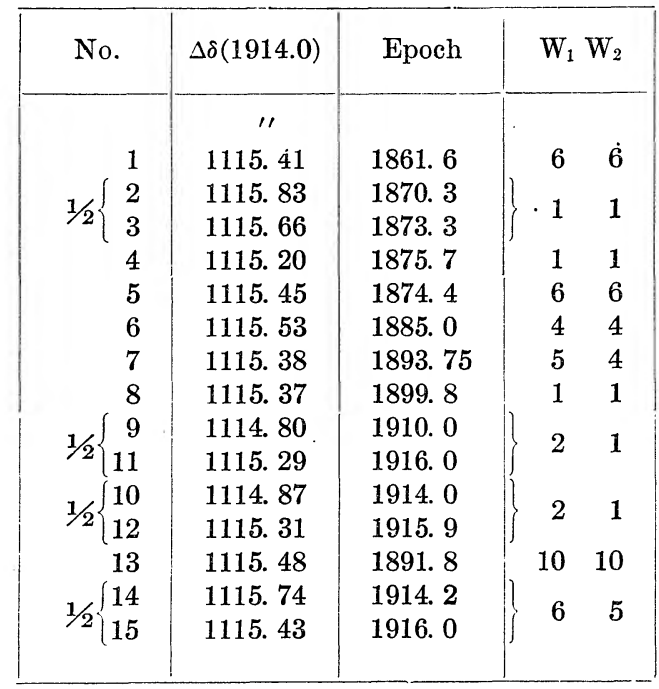

Weights were assigned as indicated under $W_{1}$ and $W_{2}$. The respective results are:

$$
\Delta \delta=1115^{\prime \prime} .43 \text { for } \mathrm{W}_{1} ; \Delta \delta=1115^{\prime \prime} .48 \text {, for } \mathrm{W}_{2}
$$

The epoch for each result is 1889.5 .

Since a preliminary value of $\Delta \delta$ for 1914.0 had been assumed to be $1115^{\prime \prime} .45$, there seemed to be no reason for changing it, and this value has been retained in the investigation of the micrometer screw; also, it has been assumed that the two Perseus stars have no relative proper motion in declination.

Dr. Edison Pettit has kindly communicated the following results for the yearly proper motions of these stars in declination obtained by Dr. HANNAH STEele PetTit:

$$
\text { B. D. }+56^{\circ} 543=-0^{\prime \prime} .014 ; \quad \text { B. D. }+.56^{\circ} 498=-0^{\prime \prime} .007
$$


Dr. A. van MaAnen has also found proper motions in declination for these stars: $-0^{\prime \prime} .016$ and $-0^{\prime \prime} .001$ per year, respectively.

Using the values of $\Delta \delta$ as tabulated on page 24 , BurTon formed equations of condition with two unknown quantities, $x$ and $\mu, x$ being the correction to be added to $1115^{\prime \prime} .40$ and $\mu$ the relative proper motion in declination per century. For the weights $\mathrm{W}_{1}, x=+0^{\prime \prime} .004, \mu=-0^{\prime \prime} .114$. For the weights $\mathrm{W}_{2}, x=+0^{\prime \prime} .051$, $\mu=+0^{\prime \prime} .009$. In the latter case the probable error of $x= \pm 0^{\prime \prime} .052$. This value of the probable error has been used in the investigation of the screw-i. e., the value of $\Delta \delta$ for 1914.0 was taken as $1115^{\prime \prime} .45 \pm 0^{\prime \prime} .052$.

For the stars of pair (2) - that is, B. D. $+23^{\circ} 495$ and B. D. $+24^{\circ} 540$ - the data were as follows, the weights being assigned arbitrarily:

\begin{tabular}{|c|c|c|c|}
\hline & $\Delta \delta(1914.0)$ & Epoch & Wt. \\
\hline & $\prime \prime$ & & \\
\hline First Yale triangulation, heliometer & 658. 39 & 1885.0 & 5 \\
\hline Second Yale triangulation, heliometer & 658.53 & 1901. 5 & 5 \\
\hline Naval Observatory, 6-inch meridian circle & 658.44 & 1913. 9 & 2 \\
\hline Naval Observatory, 9-inch meridian circle & 658. 67 & 1914. 0 & 2 \\
\hline Yale Observatory, heliometer, Sмгтн & 658. 53 & 1914. 2 & 4 \\
\hline Weighted mean .... & 658.50 & 1902.5 & \\
\hline
\end{tabular}

The probable error of the weighted mean was assumed to be $\pm 0^{\prime \prime} .10$. It was assumed, also, that these stars had no relative proper motion in declination.

The Catalogue of the Pleiades by F. HaYn gives for $1914.0, \Delta \delta=658^{\prime \prime} .46$, epoch about 1890. (See Nr. VI, des XXXVIII Bandes, der Abhandlungen der Math.-Phys. Klasse der Sächsischen Academie der Wissenschaften, Leipzig, 1921.) This was published after the investigation of the micrometer screw had been made.

The results of the Yale heliometer measures as communicated by Mr. SMith were for 1914.0

$$
p=19^{\circ} 1^{\prime} 28^{\prime \prime}, \quad s=696^{\prime \prime} .58
$$

For the stars of pair (3) - that is, B. D. $+24^{\circ} 550$ and B. D. $+24^{\circ} 552$ - the data used for $\Delta \delta$ were:

\begin{tabular}{|c|c|c|c|}
\hline & $\Delta \delta(1914.0)$ & Epoch & Wt. \\
\hline & 11 & & \\
\hline First Yale triangulation, heliometer & 590. 66 & 1885. 0 & 5 \\
\hline Second Yale triangulation, heliometer................ & 590. 88 & 1901. 5 & 5 \\
\hline Naval Observatory, 9-inch meridian circle & 591.04 & 1914. 0 & 2 \\
\hline Yale Observatory heliometer, Sмгтн & 590. 56 & 1914. 2 & 4 \\
\hline Weighted mean... & 590.75 & 1901.1 & \\
\hline
\end{tabular}

The weights were assigned arbitrarily. The probable error of the weighted mean was taken as $\pm 0^{\prime \prime} .15$.

The Pleiades Catalogue of HAYN gives for 1914.0, $\Delta \delta=590^{\prime \prime} .86$, epoch about 1890 . 
As communicated, Mr. Smith's measures were, for 1914.0, $p=7^{\circ} 3^{\prime} 13^{\prime \prime}$, $s=595^{\prime \prime} .06$.

It was assumed that the stars of this pair had no relative proper motion in declination.

Below are tabulated in groups the results of observations with bright field of the differences of declination of the three pairs of stars referred to. In all cases the measures were taken by allowing the stars to transit across the field, the settings being made on the middle fixed transit thread. The wire interval on the movable slide was employed which was most nearly equal to the step to be measured in passing from one known end star to the other known end star.

In the earlier observations of the Perseus pair the micrometer screw was set at a whole revolution, and one thread of the movable wire interval was placed by means of the box screw on the star that transited first. Then, with the micrometer screw, a second thread was placed on the star that followed.

In later measures both threads of a movable wire interval were placed successively on the stars of a step by means of the micrometer screw.

Usually five measures were taken of each step. The probable error of the mean of five measures of a step arising from the accidental errors of pointings is about \pm 7 in units of $0^{\mathrm{R}} .001$. The probable error made in determining an interval in revolutions between two movable wires is taken as \pm 1 , and the probable error of a reading of the screw is supposed to be \pm 1 . The progressive errors were applied, and the values of $R$ were reduced to the focal setting $1^{\text {in }} .280$.

Of the groups of observations which follow, the box screw was used in 1-7, Perseus pair. Eyepieces fitted with a totally reversing prism were used in groups $16,17,18,19,24,25,26,28$, Perseus pair, and in all groups of the Pleiades pairs. 
Perseus Pair, $R$ from Observations of $\Delta \delta$ by Transits

\begin{tabular}{|c|c|c|c|c|c|c|c|c|c|}
\hline & $\begin{array}{c}\mathbf{R} \\
\text { Observed }\end{array}$ & $\begin{array}{l}\text { Th. } \\
\text { F. }\end{array}$ & obs. & $\begin{array}{l}\text { Num- } \\
\text { ber } \\
\text { Steps }\end{array}$ & $\begin{array}{l}\text { Head } \\
\text { Up or } \\
\text { Down }\end{array}$ & $\begin{array}{l}\text { Num- } \\
\text { ber } \\
\text { Obsns. }\end{array}$ & Dates & $\begin{array}{c}\mathrm{R} \\
\text { Reduced to } 50^{\circ} \mathrm{F} \text {. }\end{array}$ & Wt. \\
\hline & " & $\circ$ & & & & & & & \\
\hline 1 & $9.9336 \pm 0.00030$ & 67.8 & Fn. & 2 & $\mathrm{u}, \mathrm{d}$ & 5 & 1909 -July $9,16,17,20,24 \ldots \ldots$ & $9.9327 \pm 0.00032$ & 9.9 \\
\hline 2 & 9. $9334 \pm 0.00067$ & 30.4 & Ep. & 2 & $\mathrm{u}$ & 3 & 1909-Dec. 27, 30; 1910-Mar. 4_. & $9.9344 \pm 0.00068$ & 2.2 \\
\hline 3 & 9. $9339 \pm 0.00070$ & 65.7 & Bn. & 2 & $\mathrm{u}, \mathrm{d}$ & 3 & $1910-$ July $19,20,21 \ldots$ & $9.9331 \pm 0.00070$ & 2.0 \\
\hline 4 & $9.9306 \pm 0.00045$ & 29.3 & $\mathrm{Hl}$. & 2 & $\mathrm{u}$ & 6 & 1909-Dec. 27, 30; 1910-Jan. 4, Feb. 13, 22, Mar. 18. & $9.9317 \pm 0.00047$ & 4.6 \\
\hline 5 & $9.9347 \pm 0.00030$ & 70.1 & Hl. & 2 & $\mathrm{u}$ & 12 & 1910 -July $14,19,20,21,21,23,23,27,27$, Aug. $9,20,20$ - & $9.9336 \pm 0.00032$ & 9.5 \\
\hline 6 & 9. $9332 \pm 0.00068$ & 41.3 & $\mathrm{Hl}$. & 2 & $\mathrm{~d}$ & 2 & 1910-Jan. 19, Mar. 8. & $9.9337 \pm 0.00068$ & 2.2 \\
\hline 7 & $9.9319 \pm 0.00071$ & 65.2 & Hl. & 2 & d & 2 & $1910-J u l y ~ 19,20$ & $9.9311 \pm 0.00071$ & 2. 0 \\
\hline 8 & $9.9339 \pm 0.00039$ & 60.5 & Ep. & 2 & $\mathrm{u}$ & 7 & $\begin{array}{l}\text { 1910-Sept. 15, 16, 17; 1911-Sept. 6, Oct. 13, 13, } \\
\text { Nov. } 10 .\end{array}$ & $9.9333 \pm 0.00040$ & 6. 3 \\
\hline 9 & $9.9336 \pm 0.00044$ & 36.0 & Ep. & 2 & $\mathrm{u}$ & 6 & $1911-N o v .13,13,16,16,22,26$ & $9.9343 \pm 0.00045$ & 4. 9 \\
\hline 10 & $9.9332 \pm 0.00050$ & 65.4 & Ep. & 2 & d & 4 & 1910-Sept. $15,16,17 ; 1911-$ Sept. $6 \ldots$ & 9. $9324 \pm 0.00051$ & 3.8 \\
\hline 11 & $9.9332 \pm 0.00057$ & 44.4 & Ep. & 2 & d & 3 & 1911-Nov. 10, 22, 26 & $9.9335 \pm 0.00057$ & 3.1 \\
\hline 12 & $9.9328 \pm 0.00046$ & 69.1 & $\mathrm{Bn}$. & 2 & $\mathrm{u}$ & 7 & 1910-Sept. 16,$20 ; 1913$-July $8,10,12,16,25 \ldots \ldots$ & $9.9318 \pm 0.00048$ & 4. 4 \\
\hline 13 & $9.9310 \pm 0.00053$ & 29.1 & Bn. & 2 & $\mathrm{u}$ & 5 & $\begin{array}{l}\text { 1911-Feb. 24, Mar. 6,8; 1912-Feb. 10; 1914-Mar. } \\
12 .\end{array}$ & $9.9321 \pm 0.00055$ & 3.3 \\
\hline 14 & 9. $9334 \pm 0.00047$ & 67.0 & Bn. & 2 & d & 7 & 1910 -Sept. $15,15,16 ; 1913$-July $8,25,26,30 \ldots \ldots$ & $9.9325 \pm 0.00048$ & 4.3 \\
\hline 15 & 9. $9320 \pm 0.00060$ & 31.0 & $\mathrm{Bn}$. & 2 & d & 4 & 1911-Feb. 28; Mar. 4, 8; 1914-Mar. 12 . . . & $9.9330 \pm 0.00061$ & 2.6 \\
\hline 16 & 9. $9353 \pm 0.00077$ & 29.8 & $\mathrm{Hl}$. & $: 2$ & d & 3 & 1912-Feb. 22, 28; Mar. 1...................... & $9.9364 \pm 0.00078$ & 1.7 \\
\hline 17 & 9. $9324 \pm 0.00076$ & 66.2 & Hl. & 2 & d & 3 & 1912-July 30, Aug. 6, 6 & $9.9316 \pm 0.00076$ & 1.7 \\
\hline 18 & $9.9332 \pm 0.00066$ & 65.4 & $\mathrm{Hl}$. & 2 & $\mathrm{u}$ & 4 & 1912-July 26,30 , Aug. 5, $5 \ldots \ldots \ldots$ & $9.9324 \pm 0.00066$ & 2.3 \\
\hline 19 & $9.9318 \pm 0.00126$ & 24.6 & $\mathrm{Hl}$. & 2 & $\mathrm{u}$ & 1 & 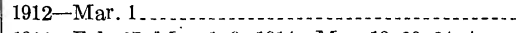 & $9.9331 \pm 0.00127$ & 0.6 \\
\hline 20 & $9.9308 \pm 0.00040$ & 38.4 & HI. & 2 & $\mathbf{u}$ & 8 & $\begin{array}{l}\text { 1911-Feb. 27, Mar. 1, 9; 1914-Mar. 13, 20, 24, A pr. } \\
9,10 .\end{array}$ & $9.9314 \pm 0.00040$ & 6.1 \\
\hline 21 & $9.9337 \pm 0.00036$ & 70.8 & $\mathrm{Hl}$. & 2 & $\mathbf{u}$ & 9 & $\begin{array}{l}\text { 1913-July } 7,16,16,28,28,29 \text {, Aug. 9, 14; 1914- } \\
\text { Mar. } 26 .\end{array}$ & $9.9326 \pm 0.00038$ & 7.0 \\
\hline 22 & $9.9339 \pm 0.00039$ & 39.0 & $\mathrm{Hl}$. & 2 & d & 8 & $\begin{array}{l}\text { 1911-Feb. 27, Mar. 1, 11; 1914-Mar. 13. 20, 24, } \\
\text { Apr. 9, } 10 .\end{array}$ & $9.9345 \pm 0.00040$ & 6.4 \\
\hline 23 & 9. $9351 \pm 0.00050$ & 71.0 & Hl. & 2 & $\mathrm{~d}$ & 4 & 1913-July 29, Aug. 9, 14; 1914-Mar. 26 ............ & $9.9340 \pm 0.00052$ & 3.7 \\
\hline 24 & $9.9354 \pm 0.00080$ & 68.8 & Bn. & 4 & $\mathrm{u}$ & 3 & 1912-Aug. 23, 27, Sept. 10 & $9.9344 \pm 0.00081$ & 1.5 \\
\hline 25 & $9.9304 \pm 0.00067$ & 68.6 & Bn. & 4 & d & 5 & 1912-Aug. $24,27,29$, Sept. $6,12 \ldots \ldots$ & $9.9294 \pm 0.00068$ & 2. 1 \\
\hline 26 & $9.9334 \pm 0.00100$ & 68.5 & $\mathrm{Hl}$. & 4 & $\mathrm{u}$ & 2 & 1913-Aug. 20, 26 & $9.9324 \pm 0.00100$ & 1.0 \\
\hline 27 & 9. $9284 \pm 0.00133$ & 46.2 & $\mathrm{Hl}$. & 4 & $\mathrm{u}$ & 1 & 1912-Mar. 17 & $9.9286 \pm 0.00133$ & 0.6 \\
\hline 28 & $9.9358 \pm 0.00101$ & 67.0 & $\mathrm{Hl}$. & 4 & d & 2 & 1913-Aug. 16, 21 & $9.9349 \pm 0.00102$ & 1.0 \\
\hline 29 & 9. $9308 \pm 0.00132$ & 35.0 & Hl. & 4 & d & 1 & 1912-Mar. 22 & $9.9316 \pm 0.00133$ & 0.6 \\
\hline \multirow[t]{6}{*}{30} & $9.9341 \pm 0.00094$ & 57.9 & Hl. & 5 & d & 3 & 1910 -Oct. $20,22,26$ & 9. $9337 \pm 0.00094$ & 1. 1 \\
\hline & 19. 9373 & 51.8 & Ep. & 2 & d & 1 & 1910-Mar. 3 & 19.9372 & \\
\hline & 19.9363 & 72.8 & Ep. & 5 & $d$ & 1 & 1910-Sept. 27 & 19.9351 & \\
\hline & 19.9297 & 61.1 & Ep. & 5 & $\mathrm{u}$ & 1 & 1910-Sept. 29 & 19.9291 & \\
\hline & 19.9366 & 59.6 & $\mathrm{Bn}$. & 5 & d & 1 & $1910-O c t .12$ & 19.9361 & \\
\hline & 19.9369 & 29.5 & Bn. & 5 & $\mathrm{u}$ & 1 & 1911-Feb. 10 & 19.9380 & \\
\hline
\end{tabular}

1 These values of $R$ from observations of $\Delta \delta$ of the Perseus Pair were, through an oversight, omitted in deriving the definitive value of a revolution of Clark II for the period May 20, 1908-June 15, 1915.

Pleiades Pair, B. D. $+23^{\circ} 495$ and B. D. $+24^{\circ} 540$

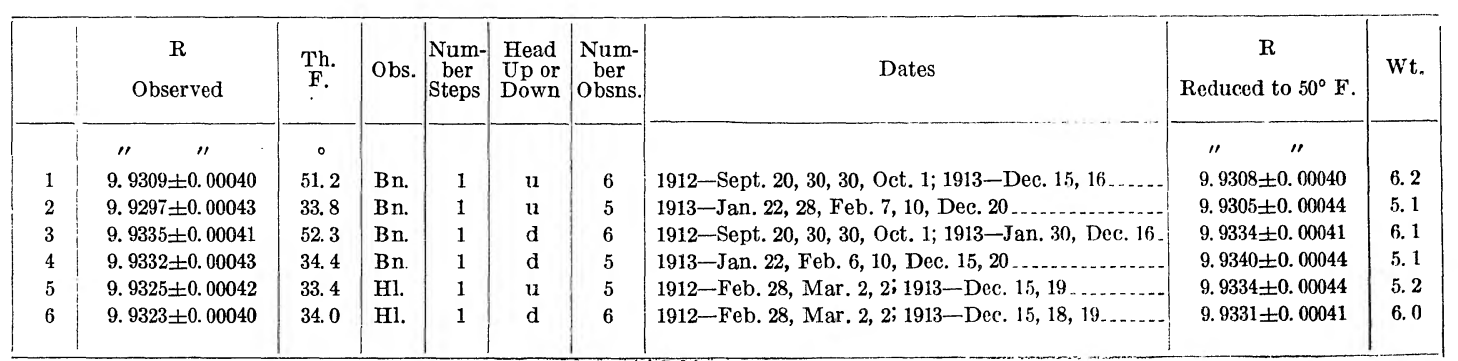


EQUATORIAL OBSERVATIONS, 1908-1926

Pleiades Pair, B. D. $+24^{\circ} 55^{\circ}$ and B. D. $+24^{\circ} 552$

\begin{tabular}{|c|c|c|c|c|c|c|c|c|c|}
\hline & $\begin{array}{c}\mathbf{R} \\
\text { Observed }\end{array}$ & $\begin{array}{l}\text { Th. } \\
\text { F. }\end{array}$ & Obs. & $\begin{array}{l}\text { Num- } \\
\text { ber } \\
\text { Steps }\end{array}$ & $\begin{array}{l}\text { Head } \\
\text { Up or } \\
\text { Down }\end{array}$ & $\begin{array}{c}\text { Num- } \\
\text { ber } \\
\text { Obsns. }\end{array}$ & Dates & $\begin{array}{c}\mathrm{R} \\
\text { Reduced to } 50^{\circ} \mathrm{F} \text {. }\end{array}$ & Wt. \\
\hline & $" \prime \prime$ & $\circ$ & & & & & & $" \prime \prime$ & \\
\hline 1. & $9.9337 \pm 0.00101$ & 52.8 & Bn. & 2 & $\mathrm{u}$ & 5 & 1912 -Oct. $15,26,28,29 ; 1913$-Jan. $30 \ldots \ldots$ & $9.9336 \pm 0.00101$ & 1.0 \\
\hline 2 & $9.9341 \pm 0.00101$ & 27. 7 & Bn. & 2 & u & 5 & 1913-Feb. $1,4,5 ; 1914$-Feb. $7,24 \ldots \ldots$ & $9.9353 \pm 0.00102$ & 1.0 \\
\hline 3 & 9. $9324 \pm 0.00101$ & 51.8 & $\mathrm{Bn}$. & 2 & $d$ & 5 & 1912-Oct. $9,26,28,29 ; 1913$-Jan. $22 \ldots \ldots$ & 9. $9323 \pm 0.00101$ & 1.0 \\
\hline 4 & $9.9320 \pm 0.00101$ & 25. 7 & Bn. & 2 & $\mathrm{~d}$ & 5 & 1913-Feb. $1,4,6 ; 1914$-Feb. 7,24 & 9. $9333 \pm 0.00102$ & 1.0 \\
\hline 5 & $9.9350 \pm 0.00088$ & 25. 6 & Hl. & 2 & $\mathrm{u}$ & 6 & 1912-Feb. $6,8,9 ; 1914-F e b .9,11,12 \ldots \ldots$ & $9.9363 \pm 0.00090$ & 1.2 \\
\hline 6 & $9.9326 \pm 0.00079$ & 26.0 & HI. & 2 & $d$ & 7 & 1912-Feb. 5, 8, 9, Mar. 7 ; 1914-Feb. 9, 11, 12 & $9.9339 \pm 0.00080$ & 1.6 \\
\hline
\end{tabular}

From the three pairs of stars the temperature coefficient $c$ was found to be

$$
c=+0^{\prime \prime} .0000525 \pm 0^{\prime \prime} .00000627
$$

This is the increase in the value of $R$ for a rise of $1^{\circ} \mathrm{F}$. of the thermometer. With this coefficient and its probable error the observed values of $R$ were reduced to $50^{\circ} \mathrm{F}$. Then the three pairs of stars give respectively for the value of a revolution of the screw of Clark Micrometer II at $5{ }^{\circ} \mathrm{F}$.:

$$
\begin{aligned}
& r \prime \prime \prime \prime \prime \\
& R=9.9329 \pm 0.00010 \\
& R=9.9325 \pm 0.00017 \\
& R=9.9342 \pm 0.00039
\end{aligned}
$$

With each of the probable errors as just written is to be combined the probable error arising from the probable error of each $\Delta \delta$. As has been stated the values of $\Delta \delta$ for 1914.0 were taken as:

$$
1115^{\prime \prime} .45 \pm 0^{\prime \prime} .052 ; \quad 658^{\prime \prime} .50 \pm 0 .{ }^{\prime \prime} 10 ; \quad 590^{\prime \prime} .75 \pm 0^{\prime \prime} .15
$$

In the case of each pair it was assumed that there was no relative proper motion in declination.

Then the final values of $R$ from the three pairs of stars are:

$$
\begin{aligned}
& R=9.9329 \pm 0.00047 \\
& R=9.9325 \pm 0.00152 \\
& R=9.9342 \pm 0.00255
\end{aligned}
$$

Combining the three results according to their probable errors there is obtained:

$$
R=9^{\prime \prime} .9329 \pm 0^{\prime \prime} .00044, \text { for focal scale } 1^{\text {in }} .280, \text { and } \mathrm{T}=50^{\circ} \mathrm{F} .
$$

Also the temperature coefficient is

$$
c=+0^{\prime \prime} .0000525 \pm 0^{\prime \prime} .00000627
$$

this being the increase in the value of $R$ for a rise of $1^{\circ} \mathrm{F}$. of the thermometer.

The above value of $R$ has been used from May 20, 1908, to June 15, 1915, the separators between the lenses being changed at the latter date.

For the observations taken during this period and printed in this volume the above mentioned value of $R$ has been used, also it has been used for observations printed in the journals except as already specified. That is,

$$
R=9^{\prime \prime} .9329+0^{\prime \prime} .0000525\left(\mathrm{~T}-50^{\circ} \mathrm{F} \text {. }\right)+0^{\prime \prime} .0255 \text { ( } 1^{\text {in }} .280 \text {-focal scale) }
$$

After the change of the separators between the lenses of the 26-inch equatorial on June 15, 1915, additional observations of $\Delta \delta$ by transits were taken in 1916 
with Clark Micrometer II, using a bright field as before, and measuring the same three pairs of stars. No change was made in the values of $\Delta \delta$ assumed for 1914.0.

On a number of nights the movable threads were displaced or broken, apparently by the buckling of the plate which carries the fixed threads. Therefore, it may be that there was some displacement of a movable thread which was not noticed by the observer.

The observations of 1916 may be tabulated as follows, for the reading $1^{\text {in }} .220$. of the focal scale:

Perseus Pair, $R$ from Observations of $\Delta \delta$ by Transits

\begin{tabular}{|c|c|c|c|c|c|c|c|}
\hline & $\begin{array}{c}\mathrm{R} \\
\text { Observed }\end{array}$ & $\begin{array}{l}\text { Th. } \\
\text { F. }\end{array}$ & Obs. & $\begin{array}{l}\text { Num- } \\
\text { ber } \\
\text { Steps }\end{array}$ & Head & $\begin{array}{c}\text { Num- } \\
\text { ber } \\
\text { Obsns. }\end{array}$ & Dates \\
\hline & $\prime \prime$ & $\circ$ & & & & & \\
\hline 1 & $9.9366 \pm 0.00095$ & 37.2 & Bn. & 5 & rt & 3 & 1916-Nov. 16, 18, 21. \\
\hline 2 & $9.9357 \pm 0.00057$ & 37.3 & $\mathrm{Bn}$. & 2 & $\mathrm{rt}$ & 3 & 1916-Nov. 16, 18, 21. \\
\hline 3 & $9.9351 \pm 0.00038$ & 52.6 & HI. & 2 & u & 9 & $\begin{array}{l}\text { 1916-Sept. } 30 \text {, Oct. } 17,23,24,28 \text {, Nov. } \\
1,7,11,20 \text {. }\end{array}$ \\
\hline 4 & $9.9341 \pm 0.00115$ & 50.8 & HI. & 5 & $\mathrm{u}$ & 2 & 1916 -Nov. 7,11 \\
\hline 5 & 9. $9358 \pm 0.00062$ & 52.0 & Hl. & 4 & $\mathrm{u}$ & 6 & 1916-Sept. 30, Oct. 17, 23, 24, 28, Nov. 1. \\
\hline 6 & 9. $9342 \pm 0.00066$ & 64.2 & $\mathrm{Hl}$. & 4 & $\mathrm{u}$ & 5 & 1916-Sept. $23,26,28$, Oct. 4,6 . \\
\hline 7 & 9. $9353 \pm 0.00047$ & 65.2 & H1. & 2 & $\mathrm{u}$ & 5 & 1916-Sept. 23, 26, 28, Oct. 4, 6 . \\
\hline
\end{tabular}

Pleiades Pair, B. D. $+23^{\circ} 495$ and B. D. $+24^{\circ} 540$

\begin{tabular}{|c|c|c|c|c|c|c|c|}
\hline & $\begin{array}{c}\mathrm{R} \\
\text { Observed }\end{array}$ & $\begin{array}{l}\text { Th. } \\
\text { F. }\end{array}$ & Obs. & $\begin{array}{l}\text { Num- } \\
\text { ber } \\
\text { Steps }\end{array}$ & Head & $\begin{array}{l}\text { Num- } \\
\text { ber } \\
\text { Obsns. }\end{array}$ & Dates \\
\hline & $\prime \prime \quad 11$ & $\circ$ & & & & & \\
\hline 1 & 9. $9329 \pm 0.00036$ & 49.5 & Hl. & 1 & $\mathrm{u}$ & 8 & $\begin{array}{l}\text { 1916-Sept. } 30 \text {, Oct. } 17,24 \text {, Nov. } 1,3,7 \text {, } \\
11,20 \text {. }\end{array}$ \\
\hline 2 & $9.9327 \pm 0.00037$ & 60.5 & $\mathrm{Hl}$. & 1 & $\mathrm{u}$ & 7 & 1916-Sept. 23, 23, 25, 26, Oct. 4, 6, 19. \\
\hline 3 & $9.9305 \pm 0.00098$ & 48. 1 & $\mathrm{Hl}$. & 2 & $\mathrm{u}$ & 3 & 1916-Nov. $7,11,20$. \\
\hline 4 & $9.9342 \pm 0.00101$ & 40.4 & Bn. & 2 & $\mathrm{u}$ & 3 & 1916-Nov. 10, 16, 21. \\
\hline
\end{tabular}

Pleiades Pair, B.D. $+24^{\circ} 550$ and B. D. $+24^{\circ} 552$

\begin{tabular}{|c|c|c|c|c|c|c|c|}
\hline & $\begin{array}{c}\mathrm{R} \\
\text { Observed }\end{array}$ & Th. & Obs. & $\begin{array}{l}\text { Num- } \\
\text { ber } \\
\text { Steps }\end{array}$ & Head & $\begin{array}{l}\text { Num- } \\
\text { ber } \\
\text { Obsns. }\end{array}$ & Dates \\
\hline $\begin{array}{l}1 \\
2\end{array}$ & $\begin{array}{l}\prime \prime \prime \prime \\
9.9358 \pm 0.00079 \\
9.9339 \pm 0.00100\end{array}$ & $\begin{array}{c}\circ \\
49.1 \\
59.1\end{array}$ & $\begin{array}{l}\mathrm{Hl} \text {. } \\
\mathrm{Hl} \text {. }\end{array}$ & $\begin{array}{l}2 \\
2\end{array}$ & $\begin{array}{l}\mathrm{u} \\
\mathrm{u}\end{array}$ & $\begin{array}{l}5 \\
3\end{array}$ & $\begin{array}{l}\text { 1916-Sept. } 30 \text {, Oct. } 23,24, \text { Nov. } 1,3 . \\
\text { 1916-Sept. } 25,26 \text {, Oct. } 4 \text {. }\end{array}$ \\
\hline
\end{tabular}

Combining groups $1,2,3,4,5$ of the Perseus Pair,

and from groups 6 and 7 ,

(a) $R=9^{\prime \prime} .9354 \pm 0^{\prime \prime} .00026$ at $48^{\circ} .0 \mathrm{~F}$.

(b) $R=9^{\prime \prime} .9349 \pm 0^{\prime \prime} .00038$ at $64^{\circ} .9 \mathrm{~F}$.

Combining groups 1, 3, 5 of the first Pleiades Pair,

(c) $R=9^{\prime \prime} .9328 \pm 0^{\prime \prime} .00032$ at $48^{\circ} .4 \mathrm{~F}$. 
Group 2 gives

(d) $R=9^{\prime \prime} .9327 \pm 0^{\prime \prime} .00037$ at $60^{\circ} .5 \mathrm{~F}$.

By an intercomparison of the results $(a),(b),(c),(d)$ as just written and taking account of the two groups of the second Pleiades Pair as tabulated is obtained the temperature coefficient

$$
c=-0^{\prime \prime} .0000180 \pm 0^{\prime \prime} .0000202
$$

to be added algebraically to the value of $R$ for a rise of the thermometer of $1^{\circ} \mathrm{F}$.

Then, reducing the observed values of $R$ as tabulated to $50^{\circ} \mathrm{F}$, the three pairs of stars give, respectively:

$$
\begin{gathered}
\prime \prime \prime \prime \prime \\
R=9.9354 \pm 0.00023 \\
R=9.9328 \pm 0.00026 \\
R=9.9352 \pm 0.00062
\end{gathered}
$$

With the above probable errors are to be combined the probable errors of each $\Delta \delta$; that is, $\pm 0^{\prime \prime} .052, \pm 0^{\prime \prime} .10, \pm 0^{\prime \prime} .15$, giving

and finally

$$
\begin{aligned}
& R=9.9354 \pm 0.00052 \\
& R=9.9328 \pm 0.00153 \\
& R=9.9352 \pm 0.00260
\end{aligned}
$$

for $50^{\circ} \mathrm{F}$. and focal setting $1^{\text {in }} .220$.

After the separators between the lenses were changed the Clark Micrometer II was used only occasionally, when it was necessary to remove the Repsold micrometer from the instrument.

After 1915, June 15, the value of $R$ as used was:

$$
\left.R=9^{\prime \prime} .9351+0^{\prime \prime} .0000525\left(\mathrm{~T}-50^{\circ} \mathrm{F} .\right)+0^{\prime \prime} .0255 \text { ( } 1^{\text {in }} .220-\text { focal scale }\right)
$$

that is, the temperature coefficient of the value (C) was employed, as it had been determined from a long series of observations.

For $50^{\circ} \mathrm{F}$. the value (C) of $R$ before change of separators was $9^{\prime \prime} .9329$ for the focal setting $1^{\text {in }} .280$. Reduced to $1^{\text {in }} .220$, for comparison with the determination (D), this result is $9^{\prime \prime} .9344$. Therefore, by changing the separation of the lenses the focal length of the telescope was shortened $0^{\text {in }} .027$.

(5) The position circle of Clark Micrometer II.-This position circle is used also with the Warner and Swasey micrometer. The circle is on a plate which is attached to a cylinder, and this cylinder forms the outer sleeve of either of the micrometers just mentioned.

The circle is divided to $0^{\circ} .5$. By the aid of two small reading glasses the verniers are read directly to $0^{\circ} .02$, and estimated to $0^{\circ} .01$. It is not possible to clamp the micrometer quite firmly in position angle. From this cause any setting in position angle is subject to a probable error which is estimated to be $\pm 0^{\circ} .005$.

In order to avoid applying corrections for eccentricity both verniers were read by all the observers except FrEDERICKson.

On December 5, 1911, the sleeves and collars of Clark Micrometer II were taken apart by the instrument maker, and were found to be gummed. When the micrometer was assembled the verniers were interchanged; that is, Vernier I came opposite position sircle divisions which before this date had been read by Vernier II. 


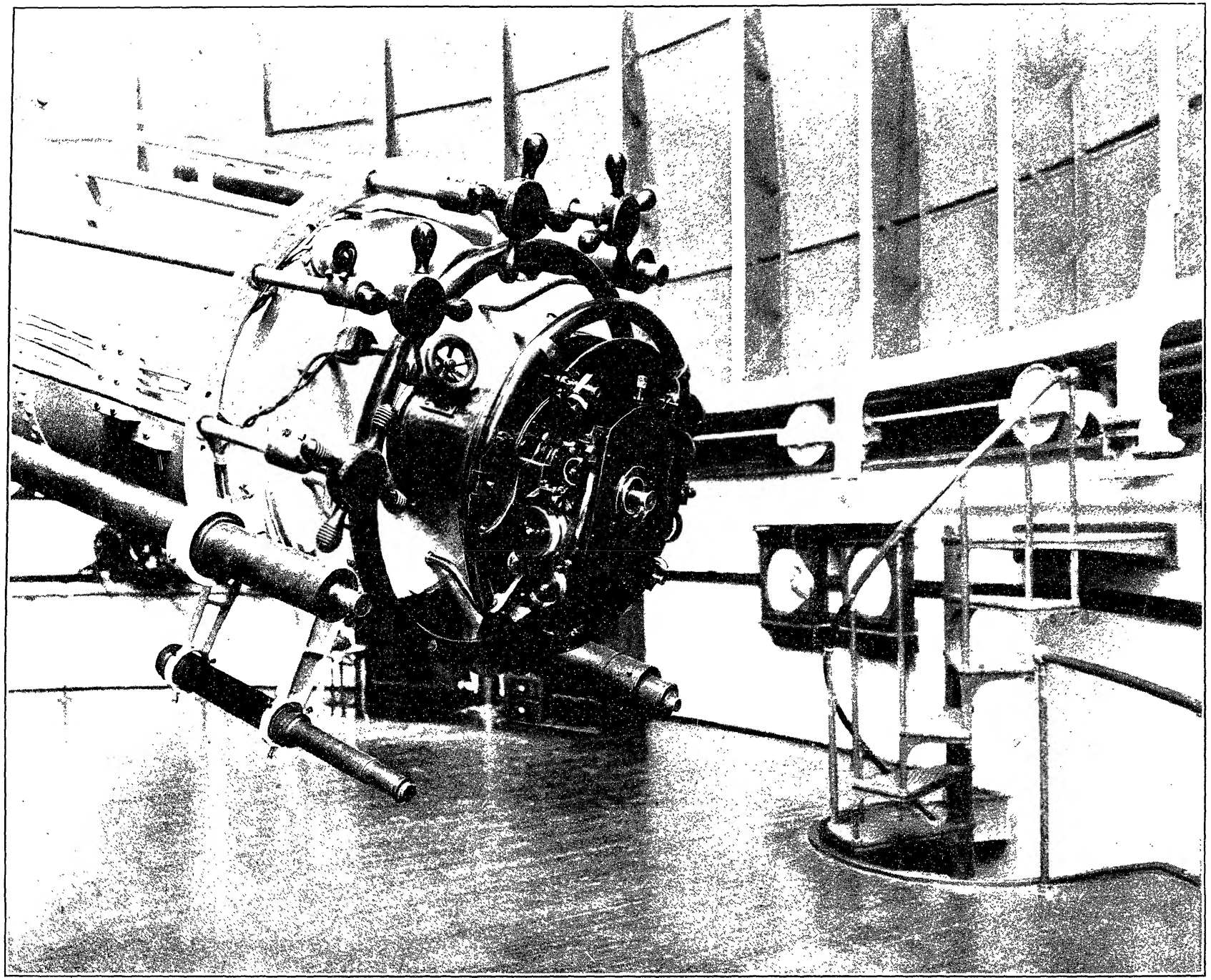

THE EYE END OF THE 26-INCH EQUATORIAL WITH THE REPSOLD MICROMETER 
THE WARNER AND SWASEY MICROMETER OF THE 26-INCH EQUATORIAL

Nothing in addition to the investigation given in Volume VI of the Naval Observatory Publications, Second Series, pages Axvir and seq., has been done in the way of examining the screw of the Warner and Swasey micrometer. From the measures printed in Volume VI the screw seems to be a good one.

In the winter of 1910-11 it was necessary to send away for repairs Clark Micrometer II, and to attach the Warner and Swasey micrometer to the 26 -inch equatorial. A moderate number of observations were taken with it of the satellites of Saturn. There was not a good arrangement for lighting the spider threads, so that all the observations were made with bright field.

The screw of the Warner and Swasey micrometer is on one side of the box. Near the micrometer head the screw passes through the box, which serves as a nut. The other end of the screw butts against a hardened steel block which is adjustable in the direction of the screw. There is no spring. The slide carrying the movable threads moves like a nut on the screw.

From observations by HALL and BurTon in two steps of the difference of declination of the Perseus stars $A$ and $Z$ in the cluster $h$ Persei the value of a revolution was found to be

$$
R=10^{\prime \prime} .5752
$$

at the mean temperature $32^{\circ} \mathrm{F}$., and with the focal scale set at $3^{\text {in }} .170$.

The value of $R$ thus determined was used for the reduction of the 1910-11 observations of the satellites of Saturn. No corrections were applied for periodic or progressive errors.

For the determination of $R$ the stars were allowed to transit across the field, and the pointings were taken at the long fixed thread in the middle of the field. The observations follow. For $1914.0 \Delta \delta$ was taken as $1115^{\prime \prime} .45$.

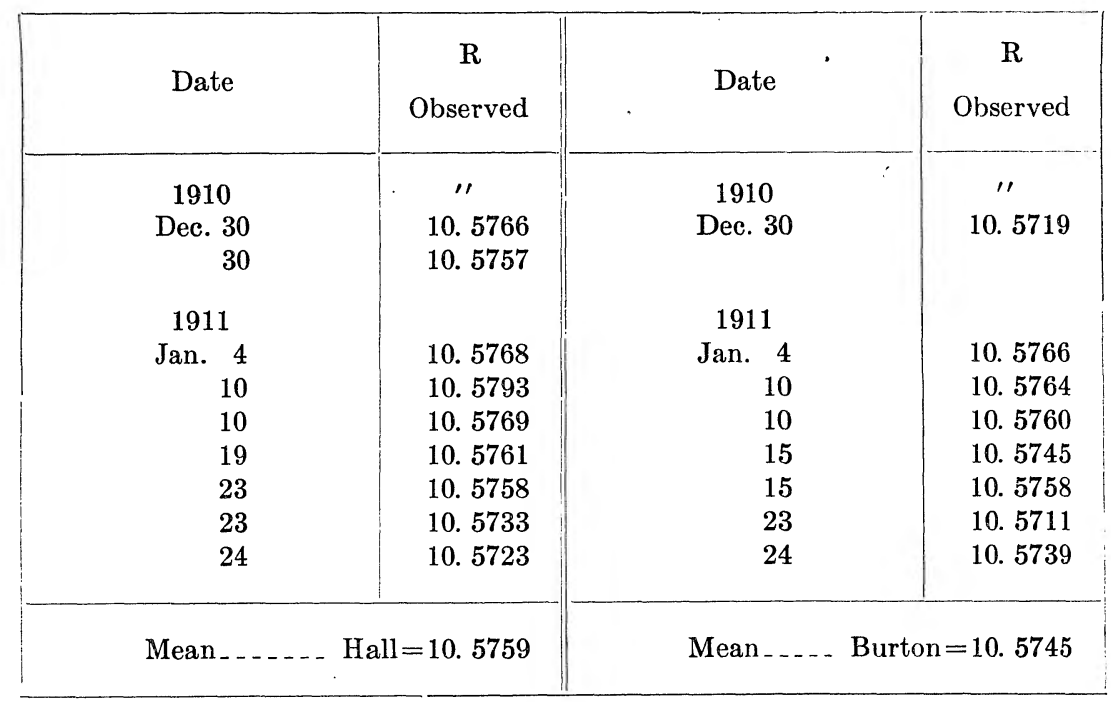

THE REPSOLD MICROMETER OF THE 26-INCH EQUATORIAL

In the session of Congress of 1910-11 the appropriation for apparatus and instruments for the Naval Observatory was increased in order to provide for the purchase of a new filar micrometer for the 26 -inch equatorial. 
The plans for this instrument were carefully considered by the Observatory staff, and it was ordered from C. L. Berger \& Sons, of Boston, to be constructed by A. Repsold \& Sons, of Hamburg. The micrometer was received August 2, 1913.

The new micrometer weighs 81 pounds, while the micrometer Clark II weighs 18 pounds. Therefore it seemed necessary to obtain a new tailpiece and draw tube. These parts were made at the Washington Navy Yard and received May 28, 1914. They are teel and weigh 65 pounds. The old tailpiece and draw tube are brass and weigh 36 pounds. At the navy yard was made also a new hand ring, larger

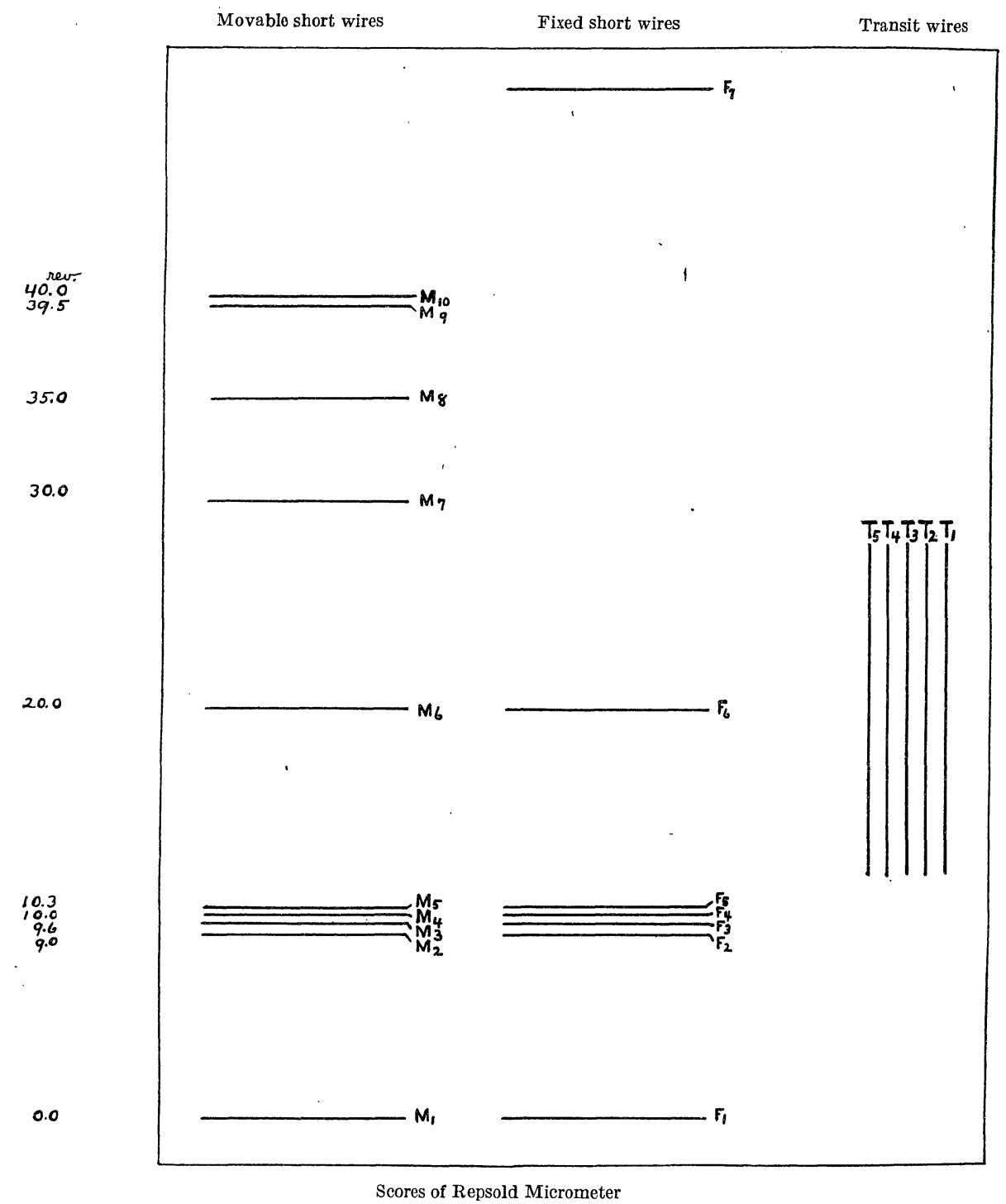

than the old one, to be attached to the end plate of the telescope in place of the old ring.

On account of the increased weight at the eye end it was necessary to fit two lead rings to the telescope tube, near the object-glass end, in order to balance the instrument. These rings are about $2 \frac{1}{2}$ feet from the object glass. The new micrometer was attached to the instrument June 30, 1914. 


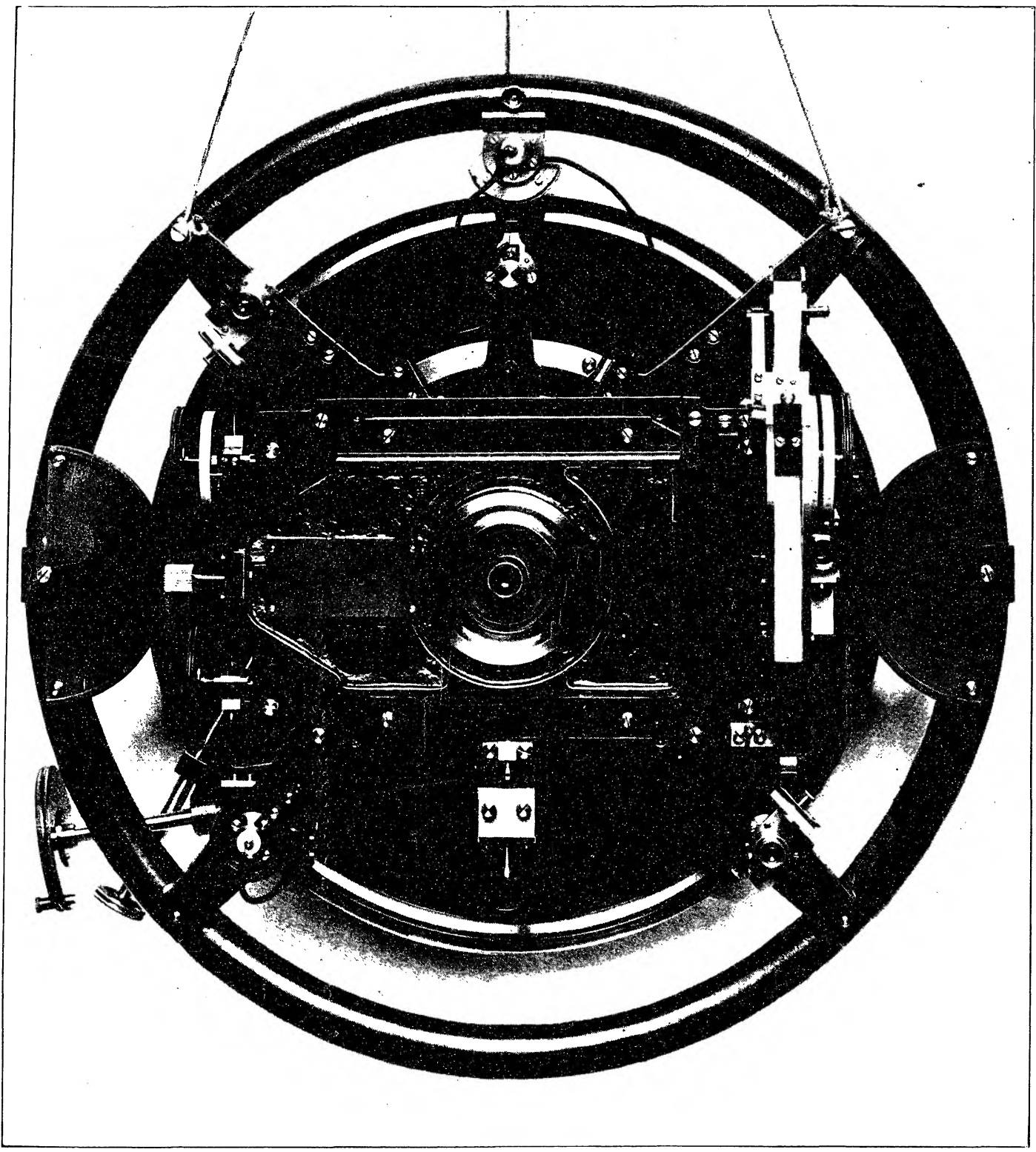

THE REPSOLD MICROMETER OF THE 25-INCH EQUATORIAL 
The general characteristics of a Repsold filar micrometer are shown on page 529 of the Handbuch der Astronomischen Instrumentenkunde by L. Ambronn. A brief description of the instrument constructed for the Naval Observatory is given by Dr. J. A. RePsold in the Astronomische Nachrichten, Nr. 5062.

The micromter is made of cast iron and steel. The position circle is of platinum and iridium, about 16 inches in diameter, and graduated to $0^{\circ} .1$. There are two low-power microscopes with which $0^{\circ} .01$ can be estimated easily and quickly. For special purposes the circle can be read to $0^{\circ} .0001$ by means of the micrometer screws of the microscopes.

The field of the micrometer is 75 by $45 \mathrm{~mm}$. The eyepiece has a double slide. One revolution of the micrometer screw equals $1 \mathrm{~mm}$., approximately, or about $20^{\prime \prime} .8$. The extent of the motion of the middle moveable wire is $40 \mathrm{~mm}$. For the spider lines scores are cut in nickel strips which are let into the cast-iron plates.

(1) Scores of the Repsold micrometer. $-\mathrm{M}_{1}$ and $\mathrm{F}_{1}$ are the movable and fixed wire scores nearest the micrometer head. The micrometer reading increases as the movable wires approach the head. When the coincidence of $\mathrm{M}_{6}$ and $\mathrm{F}_{6}$ is 20.0 revolutions and the head which changes the coincidence is set at zero, as in the case of the progressive error investigation, the coincidences of the movable wires with $\mathrm{F}_{6}$ are as given at the left of the line which indicates the position of the score.

The intervals in revolutions between the fixed wire scores are:

$$
\begin{array}{lll}
\mathrm{F}_{1}-\mathrm{F}_{2}=9.0 & \mathrm{~F}_{3}-\mathrm{F}_{4}=0.4 & \mathrm{~F}_{5}-\mathrm{F}_{6}=9.7 \\
\mathrm{~F}_{2}-\mathrm{F}_{3}=0.6 & \mathrm{~F}_{4}-\mathrm{F}_{5}=0.3 & \mathrm{~F}_{6}-\mathrm{F}_{7}=30.0
\end{array}
$$

The intervals between the scores for movable and fixed short wires are shown on the same scale.

The transit wire scores are $41 / 2 \mathrm{~mm}$. apart and are represented on about $2 / 9$ the scale used for short wire scores.

The short wires are $45+\mathrm{mm}$. in length and the transit wires $75+\mathrm{mm}$., both dimensions represented on about $2 / 9$ the scale used for short wire scores.

The heads of the micrometer screw are celluloid. There are also two steel printing wheels carrying raised figures, so that both the whole revolution and the decimal part can be impressed on a Morse fillet. The printing wheels are mounted on a shoulder fixed to the micrometer box. No pressure is exerted on the micrometer screw when the impressions are made. Thus a setting of the micrometer screw can be read in the ordinary way, or can be impressed on the Morse fillet.

The spring against which the micrometer screw works is carried on a separate slide rod. The office of the spring is to push the end of the micrometer screw which is opposite the heads against a jewel set in the end of a cylindrical plug. This plug can be moved through half a micrometer revolution, thus changing the coincidence of a fixed and movable wire by that amount.

It is necessary to observe with the micrometer head down or horizontal when the box screw is used. Otherwise, the weight of the heavy micrometer box can not be moved by the spring against which the box screw works. The heads of the box screw and micrometer screw are symmetrically situated on opposite sides of the micrometer box. The two screws are of the same pitch, and the heads by which these screws are turned are of the same size.

The micrometer is provided with an eyepiece microscope of about 60 magnifying power, and there is a suitable arrangement of movable threads for determining 
the periodic and progressive errors of the screw. The eyepiece slides can be clamped when the microscope is used.

The bright field illumination has been described on page 9 .

As to the bright wires, special care was taken by the Repsolds to make the illumination symmetrical. One 3.8-volt, 2-candlepower, small Mazda lamp furnishes light for both the long and short wires. The light passes through three thin plates of colored glass set in an ebonite ring. A brass shutter with little windows revolves about the ring, so as to give light for the short wires, or for the long wires, or for all the wires. To change the color of the threads the ebonite ring is changed. The light for the threads goes through lenses, two being used for the short threads and one for the long threads. After leaving the lenses light for the short threads is reflected by two mirrors, one at each end of the long axis of the micrometer box. There is a window in each end of the box for the passage of the light. The mirrors are mounted on the hand ring by which a rapid motion in position angle is given to the micrometer.

For the long wires the light passes through a lens mounted in the sleeve of the micrometer and is reflected back and forth by mirrors mounted inside the sleeve.

A crushed carbon rheostat is placed at the eye end of the micrometer for the control of the illumination of the bright wires. The heads of the micrometer screw are lighted from the lamp that illuminates the threads, by means of a mirror placed underneath the laimp. The current can be short-circuited around the rheostat, so as to brighten the lamp for an instant, for reading the heads.

A second small lamp, of the same voltage and candlepower as the first, furnishes light for the two microscopes by which the position circle is read.

The two small lamps on the micrometer are in parallel. Current is furnished from contact rings against which two brushes rub.

August 10, 1917, all the currents on the instrument except the chronograph circuit were taken from two small transformers, and this arrangement has been used continuously since that date to step down the commercial 110-volt alternating current. The chronograph circuit is 12 volts, furnished from storage batteries.

October 11, 1920, the tangent motion of the micrometer in position angle was modified by Mr. J. RheinBold, so as to have the tangent screw work against a spring held in a box. March 25, 1921, Mr. Rheinbold attached phosphor bronze springs to the brushes which carry current to the micrometer lamps.

With the Repsold micrometer were furnished three Kellner eyepieces, each provided with a reversing prism. The respective equivalent focal lengths of these eyepieces are approximately 1 inch, $3 / 4$ inch, $1 / 2$ inch, corresponding to magnifying powers of $390,520,779$ diameters.

(2) Investigation of the errors of the screw of the Repsold micrometer.-By means of the eyepiece microscope a preliminary examination of the screw was made in 1913 . The micrometer was placed on a bench, and light was reflected from a mirror and passed through a ground-glass plate underneath the micrometer, to light the threads.

The periodic error.-With the eyepiece microscope the screw of the Repsold micrometer was examined by HaLl, Burton, Watts, and Bower for periodic error. The micrometer was on the telescope and the field was lighted by skylight. The pairs of movable threads used were approximately $0^{\mathrm{R}} .3$ and $0^{\mathrm{R}} .5$, apart. 


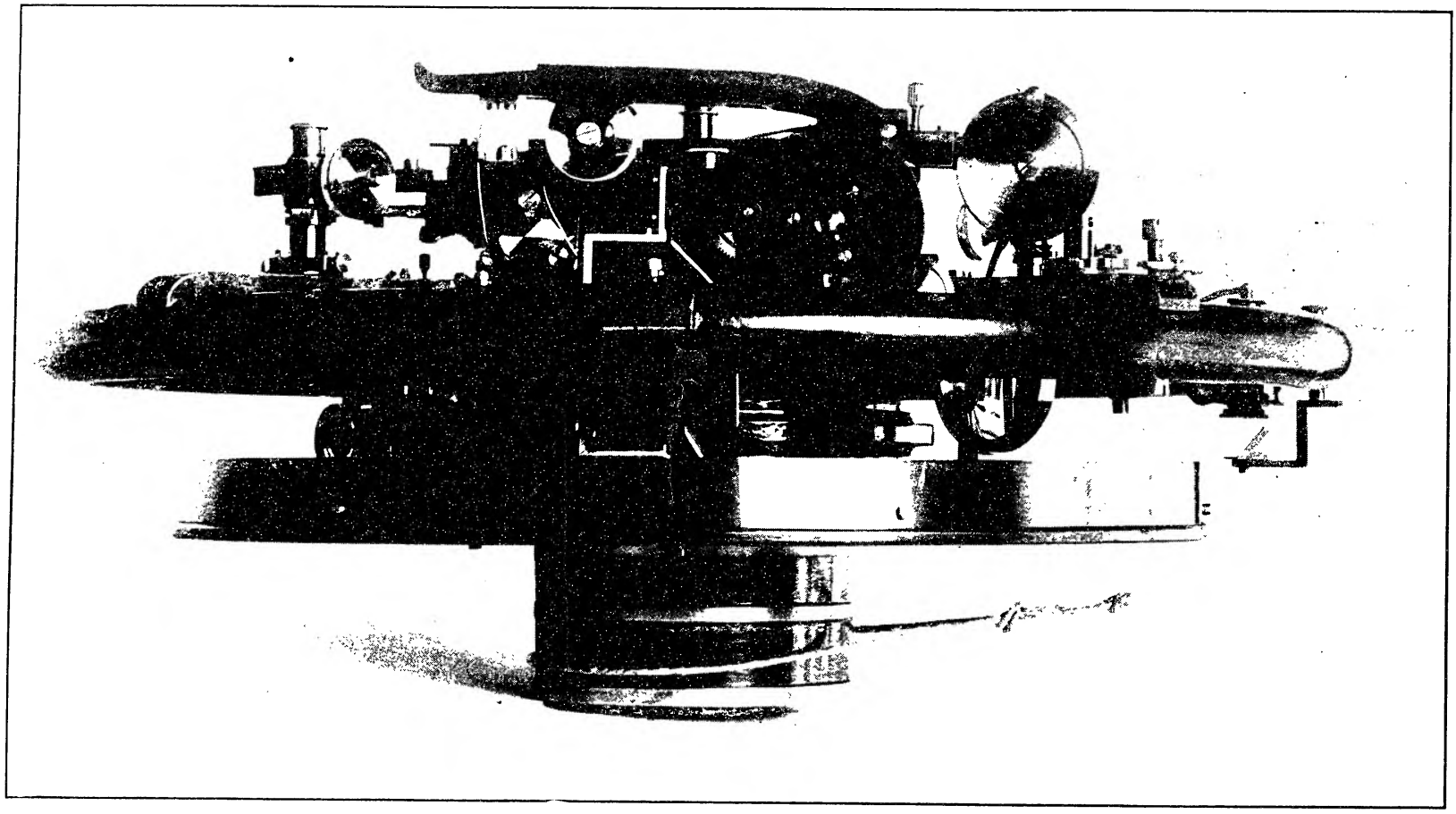

SIDE VIEW OF THE REPSOLD MICROMETER 
With the pair of wires $0^{\mathrm{R}} .5$ apart the periodic error was found to be:

1. 1913 , November 19 to 26 :

$+0^{\mathrm{R}} .0001 \cos u+0^{\mathrm{R}} .0001 \sin u-0^{\mathrm{R}} .0000 \cos 2 u+0^{\mathrm{R}} .0004 \sin 2 u$

2. 1915 , November 1 to 13 :

$$
+0^{\mathrm{R}} .0000 \cos u-0^{\mathrm{R}} .0000 \sin u
$$

3. 1921 , October 13 to 27 :

$-0^{\mathrm{R}} .0001 \cos u+0^{\mathrm{R}} .0000 \sin u$

With the pair of wires $0^{\mathrm{R}} .3$ apart was obtained:

4. 1921, October 20 to November 4:

$$
-0^{\mathrm{R}} .0000 \cos u-0^{\mathrm{R}} .0002 \sin u+0^{\mathrm{R}} .0001 \cos 2 u+0^{\mathrm{R}} .0000 \sin 2 u
$$

As usual, the determinations were made by measuring in terms of the screw and at different parts of it the interval between the pair of threads employed. Thus, in 3 , above, observed by Bower, $11^{\mathrm{R}}, 12^{\mathrm{R}}, 20^{\mathrm{R}}, 21^{\mathrm{R}}, 30^{\mathrm{R}}, 31^{\mathrm{R}}$ were the starting points, and beginning with each $1 / 10$ of a revolution the thread interval was measured in terms of the screw, going forward and back through each revolution. In terms of the screw the interval between the threads was found to be:

$$
\text { from } \begin{aligned}
11^{\mathrm{B}} \text { and } 12^{\mathrm{R}}, \text { interval } & =0^{\mathrm{R}} .4872 \\
20 \text { and } 21, & =0.4874 \\
30 \text { and } 31, & =0.4873
\end{aligned}
$$

\begin{tabular}{|c|c|c|c|c|c|c|c|c|c|c|}
\hline & $\begin{array}{c}R \\
0.0\end{array}$ & $\begin{array}{c}R \\
0.1\end{array}$ & $\begin{array}{c}\mathrm{R} \\
0.2\end{array}$ & $\begin{array}{c}\mathrm{R} \\
0.3\end{array}$ & $\begin{array}{c}\mathrm{R} \\
0.4\end{array}$ & $\begin{array}{c}\mathrm{R} \\
0.5\end{array}$ & $\begin{array}{c}\mathrm{R} \\
0.6\end{array}$ & $\begin{array}{c}\mathrm{R} \\
0.7\end{array}$ & $\begin{array}{c}\mathrm{R} \\
0.8\end{array}$ & $\begin{array}{c}\mathrm{R} \\
0.9\end{array}$ \\
\hline $11^{\mathrm{R}} \cdot 0-11^{\mathrm{R}} \cdot 9$ & $-5^{5}$ & $-5^{5}$ & $-0^{5}$ & +2 & $-0^{5}$ & +2 & $-0^{5}$ & $-0^{5}$ & +2 & +2 \\
\hline $12.0-12.9$ & -3 & $-5^{5}$ & +2 & $-0^{5}$ & -3 & $-0^{5}$ & $-0^{5}$ & $-10^{5}$ & +2 & $-0^{5}$ \\
\hline $20.0-20.9$ & -3 & -3 & $-0^{5}$ & +2 & +7 & +2 & $+4^{5}$ & +2 & $+4^{5}$ & +2 \\
\hline $21.0-21.9$ & $-0^{5}$ & $-5^{5}$ & $+4^{5}$ & -3 & +2 & $-0^{5}$ & $+4^{5}$ & $-0^{5}$ & $-5^{5}$ & +2 \\
\hline $30.0-30.9$ & +2 & -8 & $-0^{5}$ & +2 & -3 & $+4^{5}$ & +2 & $+4^{5}$ & -3 & $-0^{5}$ \\
\hline $31.0-31.9$ & -8 & $-0^{5}$ & $-0^{5}$ & $+4^{5}$ & +2 & +2 & +2 & $+4^{5}$ & -3 & $-0^{5}$ \\
\hline Observed means_..... & -3 & -5 & +1 & +1 & +1 & +2 & +2 & 0 & 0 & +1 \\
\hline Comp. periodic error & -1 & -1 & 0 & 0 & +1 & +1 & +1 & 0 & 0 & -1 \\
\hline $\mathrm{O}-\mathrm{C}_{-}$ & -2 & -4 & +1 & +1 & 0 & +1 & +1 & 0 & 0 & +2 \\
\hline
\end{tabular}

The observed quantities for determining the periodic error, the computed periodic error. and the residuals in the sense observed minus computed are exhibited as follows, the unit being $0^{\mathrm{R}} .0001$. The observed quantities are the intervals as read at each $1 / 10$ of a revolution minus the respective intervals as given above. 
The determination 4 of the periodic error was by HaLL. The revolutions used were $3^{\mathrm{R}} \cdot 0-3^{\mathrm{R}} \cdot 9,5^{\mathrm{R}} \cdot 0-5^{\mathrm{R}} \cdot 9,14^{\mathrm{R}} \cdot 0-14^{\mathrm{R}} \cdot 9,21^{\mathrm{R}} \cdot 0-21^{\mathrm{R}} \cdot 9$, and $29^{\mathrm{R}} \cdot 0-29^{\mathrm{R}} \cdot 9$ The mean value of an interval was found to be $0^{\mathrm{R}} .30474$. The results are:

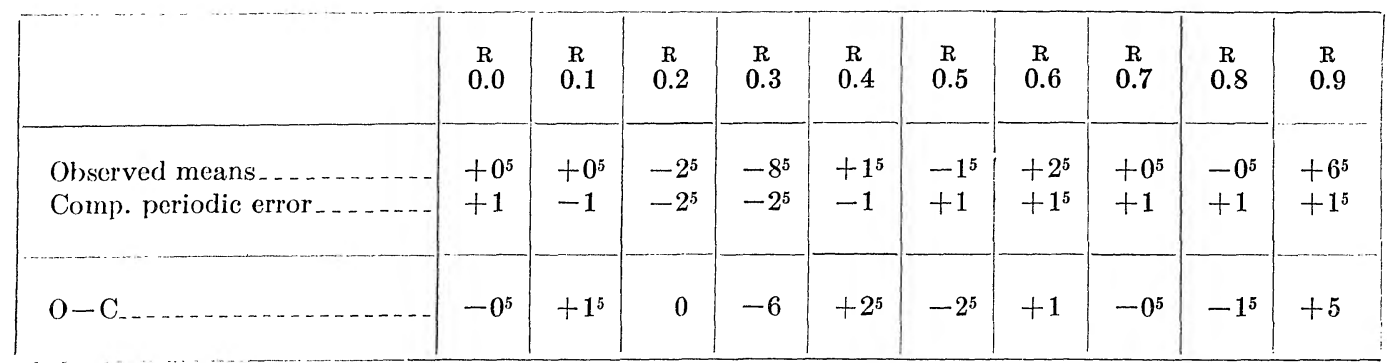

In June and August, 1926, the periodic error of the screw of the Repsold micrometer was redetermined by HALL with the eyepiece microscope, the thread interval approximately equal to $1 / 2^{\mathrm{R}}$ being measured by daylight in terms of the screw. The result was:

$$
-0.0000 \cos u+0.0001 \sin u
$$

The progressive errors.-The progressive errors were determined for every fifth revolution of the screw by the method used for a linear scale. The readings were made in 1915, 1917, and 1921 by HALL, Burtọ, and Bower. The micrometer was on the telescope, the eyepiece microscope was used, and the field was lighted from the sky.

The screw can be used through about 40 revolutions. Approximately $1^{\mathrm{R}}=20^{\prime \prime} .8$. The space $5^{\mathrm{R}}-35^{\mathrm{R}}$ was taken as fundamental. The spaces were subdivided by means of threads on the movable slide arranged by the makers for that purpose, measures being taken of the thread intervals in terms of the micrometer screw. The measures were made symmetrically, forward and back, each result being the mean of eight readings. The probable error of the mean of eight determinations of a thread interval in terms of the screw is $\pm 0^{\mathrm{R}} .0002$.

Examples of actual measures follow:

November 24,1915 , the fundamental space $5^{\mathrm{R}}-35^{\mathrm{R}}$ was bisected by means of the movable threads approximately $15^{\mathrm{R}}$ apart, giving as results:

$$
\begin{gathered}
R \\
14.9904+(20)-(5)=\Delta \\
14.9894+(35)-(20)=\Delta
\end{gathered}
$$

(20) is the error of $20^{\mathrm{R}}$, to be added algebraically to the micrometer reading. (5) and (35) have each been assumed zero. Then, the true value of the thread interval is $14^{\mathrm{R}} .9899$ and $(20)=-0^{\mathrm{R}} .0005$. The probable error of $(20)=\frac{2}{\sqrt{2}}$, and the weight of this determination is taken as 2 . In the table of results for the progressive errors, page $3 \dot{8}$, the probable error of any one of the results is

$\frac{2}{\sqrt{\text { wt. of determination }}}$ 
November 30,1915 , the fundamental interval $5^{\mathrm{R}}-35^{\mathrm{R}}$ was twice trisected with threads approximately $10^{\mathrm{R}}$ apart, so that there were 16 determinations of each thread interval, giving as the means:

$$
\begin{aligned}
& \mathrm{R} \\
& 10.0017^{5}+(15)-(5)=\Delta \\
& 10.0005^{5}+(25)-(15)=\Delta \\
& 10.0021+(35)-(25)=\Delta
\end{aligned}
$$

From these equations $\Delta=10^{\mathrm{R}} \cdot 0014^{2 / 3},(15)=-3,(25)=+6 . \quad$ (15) and (25) each has the weight 3 , and the probable error of each is $\frac{2}{\sqrt{3}}$.

May 15, 1917, with the pair of threads $5^{\mathrm{R}}$ apart, the spaces $5^{\mathrm{R}}-15^{\mathrm{R}}$ and $25^{\mathrm{R}}-35^{\mathrm{R}}$ were bisected. The measures give the following results, each result for a thread interval being the mean of four determinations:

$$
\begin{array}{cc}
\mathrm{R} & \stackrel{\mathrm{R}}{\mathrm{R}} \mathrm{r} \\
4.9780+(10)-(5)=\Delta, & 4.9787^{5}+(30)-(25)=\Delta \\
4.9780+(15)-(10)=\Delta, & 4.9787^{5}+(35)-(30)=\Delta
\end{array}
$$

Making use of the final values of (15) and (25), that is, -5 and +3 . respectively, it is found that $(10)=-2^{5},(30)=+1^{5}$, each with the weight 1 and the probable error \pm 2 .

May 15,1917 , the space $30^{\mathrm{R}}-40^{\mathrm{R}}$ was bisected with the pair of threads approximately $5^{\mathrm{R}}$ apart, giving:

$$
\begin{aligned}
& \mathrm{R} \\
& 4.9782^{5}+(35)-(30)=\Delta \\
& 4.9777^{5}+(40)-(35)=\Delta
\end{aligned}
$$

Making use of the final value of (30), which is $+1^{5}$, it is found that $(40)=+3^{5}$, with a weight $1 / 4$ and a probable error \pm 4 .

No corrections have been applied for the progressive or periodic errors of the screw of the Repsold micrometer.

The following table exhibits the result of the determination of progressive errors, the coincidence of $M_{6}$ and $F_{6}$ being $20^{R} .0$, and the head which changes the coincidence being set at zero. 


\begin{tabular}{|c|c|c|c|c|c|c|c|c|}
\hline \multirow{4}{*}{ 要 } & $\dot{z}$ & 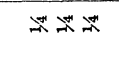 & 요제 & 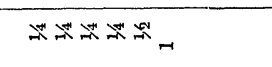 & 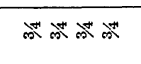 & 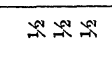 & 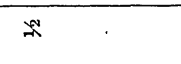 & 芦 \\
\hline & & 等虽虽 & 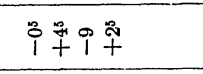 & 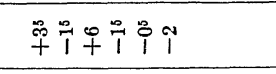 & 芰少辛早辛 & 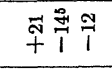 & $\stackrel{m}{+}$ & 守 \\
\hline & 容 & 可品百 & 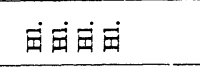 & 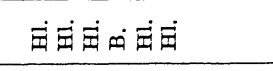 & 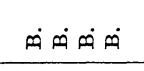 & 画画畐 & 画 & \\
\hline & 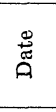 & 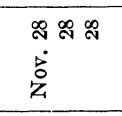 & 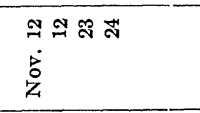 & 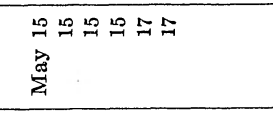 & 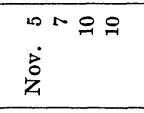 & 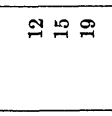 & \& & \\
\hline \multirow{4}{*}{ क्ष् } & $\dot{H}$ & . & พxล ล & 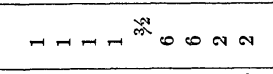 & m心 & ส ก ล & & $\infty$ \\
\hline & & & 077 & 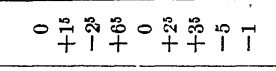 & $7 ¥ 0 \stackrel{\leftrightarrow}{+}$ & 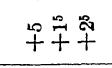 & & $\stackrel{x^{2}}{+}$ \\
\hline & $\begin{array}{l}\text { Lे } \\
0 \\
0\end{array}$ & & 宙画百 & 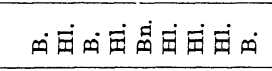 & $\dot{\varphi} \dot{\varphi} \dot{\varphi} \dot{m}$ & 画画白 & & \\
\hline & 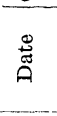 & & 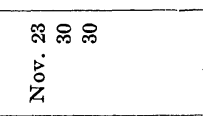 & 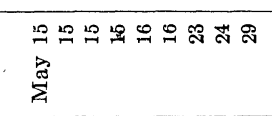 & $\begin{array}{l}\text { 2n } 90 \\
\dot{0} \\
\dot{4}\end{array}$ & 녹요용 & & \\
\hline \multirow{4}{*}{ 慈 } & $\dot{B}$ & st & $\infty$ & $\infty \infty \infty \cdots$ & $\infty$ & m & 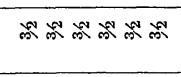 & J゙ \\
\hline & & î & 乎电 & 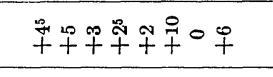 & +20 & 卆梁个 & 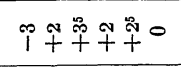 & $\stackrel{m}{+}$ \\
\hline & 范 & 昂 & 画甶 & 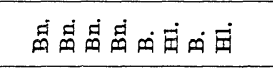 & $\dot{\varphi} \dot{\varphi} \dot{\varphi}$ & 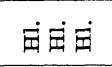 & 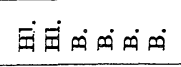 & \\
\hline & 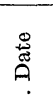 & $\begin{array}{l}\infty \\
\stackrel{\infty}{0} \\
\dot{\vec{a}} \\
z\end{array}$ & $\begin{array}{l}\text { 飠 } \\
\dot{0} \\
\dot{0}\end{array}$ & 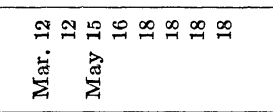 & 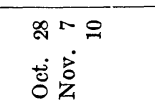 & $\begin{array}{l}\text { मिलo } \\
\dot{\vec{\alpha}}\end{array}$ & 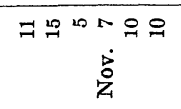 & \\
\hline \multirow{5}{*}{ 产 } & $\dot{B}$ & & a a & 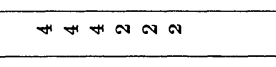 & लลNลN & a a a a & $\mathrm{N} N$ & F \\
\hline & & & pi & 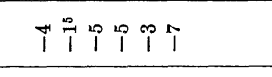 & 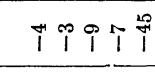 & ifipo & 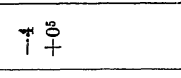 & $i$ \\
\hline & 范 & & 宙宙 & 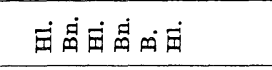 & $\dot{\varphi} \dot{\varphi} \dot{\varphi} \dot{\varphi} \dot{\varphi}$ & 的亩画画 & 可㦴 & \\
\hline & 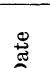 & & 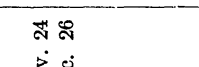 & 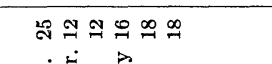 & 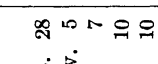 & 8010 & $\Rightarrow \stackrel{2}{2}$ & \\
\hline & $\tilde{\Omega}$ & & 尝 苛 & 密密 惫 & 宽雚 & 总 & & \\
\hline \multirow{4}{*}{ 㫤 } & $\dot{\vec{B}}$ & का & ๓ & 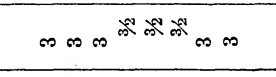 & ๓ & 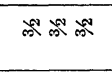 & 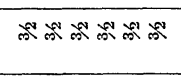 & 㮍 \\
\hline & & $\circ$ & iक⿱艹亡 & 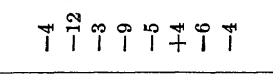 & pqi & 인 & Tipipi & $i$ \\
\hline & 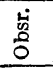 & $\dot{\ddot{m}}$ & 画甶百 & 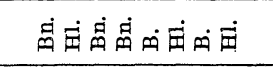 & $\dot{\varphi} \dot{\varphi} \dot{\varphi}$ & 㐫畐亩 & 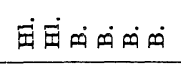 & \\
\hline & $\stackrel{8}{\sharp}$ & 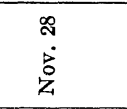 & 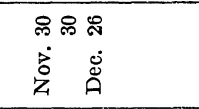 & 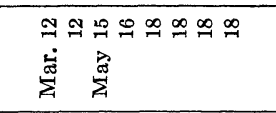 & 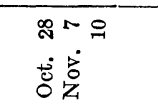 & $\begin{array}{l}20 \mathrm{~N} \\
\dot{8} \\
\dot{8}\end{array}$ & 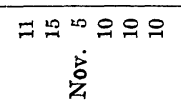 & \\
\hline \multirow{4}{*}{$\widehat{\varrho}$} & $\dot{B}$ & & กา & 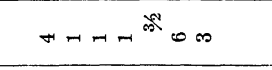 & wo & लब & & $\because$ \\
\hline & & & 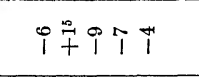 & 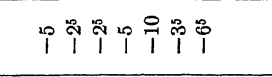 & ip i i i & i千 & & $i$ \\
\hline & 㟧 & & 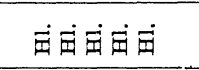 & 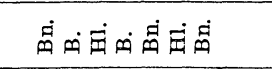 & $\dot{\infty} \dot{\varphi \dot{\varphi} \dot{\varphi}}$ & 亩吕开 & & \\
\hline & 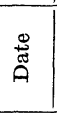 & & 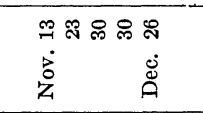 & 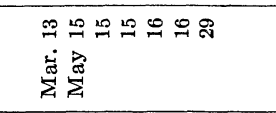 & $\begin{array}{l}\text { m9ㅇㅇㅁ } \\
\dot{8} \\
\dot{3}\end{array}$ & 꼭요 & & \\
\hline \multirow{4}{*}{$\widehat{\varrho}$} & $\dot{H}$ & ג゙ボ & 저 & $-x^{-1}$ का & 小" & $x$ & $\stackrel{m}{m}$ & 茎 \\
\hline & & 总苾早 & 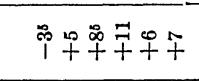 & $\stackrel{\circ}{7} \underset{+}{\infty} \circ \stackrel{\sharp}{+}$ & ザ十卋芰早早 & 蛋索 & $\stackrel{3}{7}$ & $\stackrel{\infty}{+}$ \\
\hline & 范 & 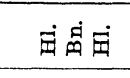 & 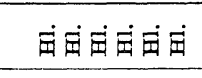 & 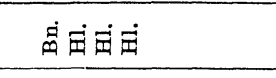 & $\dot{\infty} \dot{\varphi} \dot{\varphi} \dot{\varphi} \dot{\varphi}$ & 可开苗 & 苟 & \\
\hline & คั๊ & 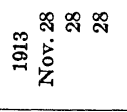 & 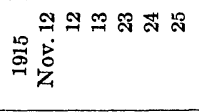 & 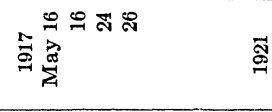 & 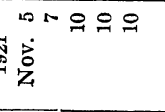 & 곡욤ㅇ & 8 & $\begin{array}{l}\vec{B} \\
\overrightarrow{\mathrm{B}} \\
\overrightarrow{\mathrm{E}}\end{array}$ \\
\hline
\end{tabular}


In August, 1926, the screw of the Repsold micrometer was again examined for progressive errors by means of the eyepiece microscope. As before, suitable thread intervals were measured by daylight in terms of the micrometer screw, each result being the mean of four readings. The weights are homogeneous with those of the preceding table. The measures were by HaLL.

The table of results follows, the coincidence of $\mathrm{M}_{6}$ and $\mathrm{F}_{6}$ being $20^{\mathrm{R}} 0$, and the head which changes the coincidence being set at zero.

Progressive Errors of Repsold Micrometer, 1926. Unit $0^{R} .0001$

\begin{tabular}{|c|c|c|c|c|c|c|c|c|c|c|c|c|c|c|c|c|c|c|c|c|}
\hline 1926 & (0) & Wt. & 1926 & (10) & Wt. & 1926 & (15) & Wt. & 1926 & (20) & Wt. & 1926 & (25) & Wt. & 1926 & (30) & Wt. & 1926 & (40) & Wt. \\
\hline Aug. 24 & +1 & $1 / 4$ & Aug. 23 & -8 & 1 & Aug. 17 & -10 & $3 / 4$ & Aug. 17 . & -11 & 1 & Aug. 17 & +3 & $3 / 4$ & Aug. 23 & -6 & 1 & Aug. 24 & 0 & $3 / 4$ \\
\hline 26 & +3 & 14 & $\therefore \quad 24$ & -6 & 1 & 17 & -21 & $3 / 4$ & 17 & -7 & 1 & 17 & -4 & $3 / 4$ & 24 & -3 & 1 & 27 & +1 & $3 / 4$ \\
\hline 27 & +2 & $1 / 4$ & 26 & -3 & 1 & 23 & -9 & $3 / 4$ & 23 & -3 & 1 & 23 & -2 & $3 / 4$ & 26 & -4 & 1 & 27 & +6 & $1 / 4$ \\
\hline 29 & +10 & $1 / 4$ & 29 & -11 & 1 & 23 & -5 & $3 / 4$ & 23 & -5 & 1 & 23 & -3 & $3 / 4$ & 27 & +2 & 1 & 29 & +12 & $1 / 4$ \\
\hline 31 & +4 & $1 / 4$ & 29 & -7 & 1 & $\begin{array}{l}24 \\
31\end{array}$ & $\begin{array}{r}-15 \\
-2\end{array}$ & $\begin{array}{l}3 / 4 \\
3 / 4\end{array}$ & 24 & -8 & 1 & $\begin{array}{l}24 \\
31\end{array}$ & $\begin{array}{r}-13 \\
0\end{array}$ & $\begin{array}{l}3 / 4 \\
34\end{array}$ & 29 & +1 & 1 & 31 & -6 & $1 / 4$ \\
\hline & & & & & & 31 & -7 & $3 / 4$ & & & & 31 & -4 & $3 / 4$ & & & & & & \\
\hline Mean,wt & +4 & $11 / 4$ & & -7 & 5 & & -10 & $51 / 4$ & & -7 & 5 & & -3 & $51 / 4$ & & -2 & 5 & & +3 & $11 / 4$ \\
\hline
\end{tabular}

(3) Value of one revolution of the screw of the Repsold micrometer.-The new Repsold micrometer was attached to the 26-inch equatorial June 30, 1914 . It was necessary to remove it occasionally and use Clark Micrometer II in its place.

Before changing the separators between the lenses, on June 15, 1915, a few measures by transits with a bright field of the difference of declination of the arc $A-Z$ in Perseus were observed for a preliminary value of one revolution of the screw.

The results are tabulated below, reduced to the focal setting $0^{\text {in }} .810$. With a provisional temperature coefficient the values of $R$ are also reduced to $50^{\circ} \mathrm{F}$. The coefficient is

$$
c=+0^{\prime \prime} .000066 \pm 0^{\prime \prime} .0000565 \text {, }
$$

which is the increase in the value of one revolution for a rise of $1^{\circ} \mathrm{F}$. of the thermometer.

The value of $\Delta \delta$ of the stars $A-Z$ for 1914.0 was taken to be $1115^{\prime \prime} .45 \pm 0^{\prime \prime} .052$.

Perseus Pair, $R$ from Observations of $\Delta \delta$ by Transits

\begin{tabular}{|c|c|c|c|c|c|c|c|}
\hline & $\begin{array}{c}\mathrm{R} \\
\text { Observed }\end{array}$ & $\begin{array}{l}\text { Th. } \\
\text { F. }\end{array}$ & Obs. & $\begin{array}{l}\text { Num- } \\
\text { ber } \\
\text { Steps }\end{array}$ & Dates & $\begin{array}{c}\mathrm{R} \\
\text { Reduced to } 50^{\circ} \mathrm{F} \text {. }\end{array}$ & Wt. \\
\hline & $\prime \prime \prime \prime$ & $\circ$ & & & & 111 & \\
\hline 1 & $20.8423 \pm 0.00144$ & 61.3 & $\mathrm{Hl}$. & 2 & 1914-Sept. 30, 30 $\ldots$ & $20.8421 \pm 0.00146$ & 4. 7 \\
\hline 2 & $20.8354 \pm 0.00144$ & 37. 7 & $\mathrm{Bn}$. & 2 & 1915-Jan. 25, Mar. 10_- & $20.8357 \pm 0.00146$ & 4. 7 \\
\hline 3 . & $20.8357 \pm 0.00101$ & 71.4 & Bn. & 2 & $\begin{array}{l}\text { 1914-Aug. 31, 31, Sept. } \\
\text { 16, } 23 \text {. }\end{array}$ & $20.8352 \pm 0.00109$ & 8.4 \\
\hline
\end{tabular}


Then for $50^{\circ} \mathrm{F}$.

$$
R=20^{\prime \prime} .8372 \pm 0^{\prime \prime} .00075
$$

Combining with this probable error the probable error assumed for the Perseus Pair, that is, $\pm 0^{\prime \prime} .052$, the result is

$$
R=20^{\prime \prime} .8372 \pm 0^{\prime \prime} .00123
$$

for $50^{\circ} \mathrm{F}$. and focal setting $0^{\text {in }} .810$, before the separators between the lenses were changed on June 15, 1915.

After the insertion of new separators between the lenses of the object glass on June 15, 1915, measurements of differences of declination with bright field were made with the Repsold micrometer of the three pairs observed with Clark Micrometer II. The values of $\Delta \delta$ already assumed for 1914.0 were retained. These were:

1. For the Perseus Pair,

$$
\text { B. D. }+56^{\circ} 543(8.2) \text { and B. D. }+56^{\circ} 498(8.6), 1115^{\prime \prime} .45 \pm 0^{\prime \prime} .052
$$

2. For the Pleiades Pair,

$$
\text { B. D. }+23^{\circ} 495(8.3) \text { and B. D. }+24^{\circ} 540(8.0), 658^{\prime \prime} .50 \pm 0^{\prime \prime} .10
$$

3. And for the Pleiades Pair,

$$
\text { B. D. }+24^{\circ} 550(8.8) \text { and B. D. }+24^{\circ} 552(9.1), \quad 590^{\prime \prime} .75 \pm 0^{\prime \prime} .15
$$

From an examination of the pointings with a thread interval on the movable micrometer slide the probable error of a single measure of $\Delta \delta$ of two stars by means of the thread interval and the screw is $\pm 0^{\mathrm{R}} .0081$. The probable error of the mean of five measures is $\pm 0^{\mathrm{R}} .0036$. Any reading of the screw is supposed to have the probable error $\pm 0^{\mathrm{R}} .0003$. The determination of a thread interval in terms of the screw is supposed to be without error.

The observed values of $R$ are tabulated below in groups; each group is reduced to $50^{\circ} \mathrm{F}$. with the temperature coefficient

$$
c=+0^{\prime \prime} .000022 \pm 0^{\prime \prime} .0000191
$$

determined from an intercomparison of the observations of the arcs. Also, each observed value of $R$ is reduced to the reading $0^{\text {in }} .810$ of the focal scale. 
Perseus Pair, $R$ from Observations of $\Delta \delta$ by Transits.

\begin{tabular}{|c|c|c|c|c|c|c|c|c|}
\hline & $\begin{array}{c}\mathrm{R} \\
\text { Observed }\end{array}$ & $\begin{array}{l}\text { Th. } \\
\text { F. }\end{array}$ & Obs. & $\begin{array}{c}\text { Num- } \\
\text { ber } \\
\text { Steps }\end{array}$ & $\begin{array}{c}\text { Num- } \\
\text { ber } \\
\text { Obsns. }\end{array}$ & Dates & $\begin{array}{c}\mathrm{R} \\
\text { Reduced to } 50^{\circ} \mathrm{F} \text {. }\end{array}$ & Wt. \\
\hline & 111 & ○ & & & & & $11 \quad 11$ & \\
\hline 1 & $20.8213 \pm 0.00331$ & 36.5 & $\mathrm{Hl}$. & 5 & 1 & 1917-Jan. $2 \ldots$ & $20.8216 \pm 0.00332$ & 0.9 \\
\hline 2 & $20.8335 \pm 0.00080$ & 29. 6 & $\mathrm{Hl}$. & 2 & 7 & $\begin{array}{l}\text { 1916-Dec. 6, 13; 1917- } \\
\text { Jan. 11, 19, 19, 26, Feb. } \\
21 .\end{array}$ & $20.8339 \pm 0.00089$ & 12. 5 \\
\hline 3 & $20.8358 \pm 0.00080$ & 69.8 & Hl. & 2 & 8 & $\begin{array}{c}\text { 1916-July 29, Aug. 9, 16, } \\
\text { 16, 19, 26, Sept. 9, } 16 .\end{array}$ & $20.8354 \pm 0.00089$ & 12. 7 \\
\hline 4 & $20.8370 \pm 0.00101$ & 68.5 & Hl. & 4 & 13 & $\begin{array}{l}\text { 1915-Aug. 23, Sept. 1, 3, } \\
\text { 13, 14, 23, 24; 1916- } \\
\text { Aug. 9, 16, 19, 26, Sept. } \\
9,16 .\end{array}$ & $20.8366 \pm 0.00107$ & 8. 7 \\
\hline 5 & $20.8346 \pm 0.00060$ & 73.5 & $\mathrm{Bn}$. & 2 & 12 & $\begin{array}{l}\text { 1915-June 28, July 24, } \\
\text { Aug. 13, 14; 1917-July } \\
\text { 23, 28, Aug. 1, 1, 28, 28, } \\
\text { Sept. 1, 1. }\end{array}$ & $20.8341 \pm 0.00075$ & 17. 8 \\
\hline 6 & $20.8362 \pm 0.00070$ & 42.0 & Bn. & 2 & 9 & $\begin{array}{l}\text { 1916-Dec. 13; 1917-Jan. } \\
\text { 20, Feb. 7, 17, 17, Mar. } \\
\text { 10, 15, Sept. 11, } 11 .\end{array}$ & $20.8364 \pm 0.00072$ & 19. 5 \\
\hline
\end{tabular}

.. Pleiades Pair, B. D. +23० 495 and B. D. $+24^{\circ} 540$

\begin{tabular}{|c|c|c|c|c|c|c|c|c|}
\hline & $\begin{array}{c}\mathbf{R} \\
\text { Observed }\end{array}$ & Th. & Obs. & $\begin{array}{l}\text { Num- } \\
\text { ber } \\
\text { Steps }\end{array}$ & $\begin{array}{l}\text { Num- } \\
\text { ber } \\
\text { Obsns. }\end{array}$ & Dates & $\begin{array}{c}\mathrm{R} \\
\text { Reduced to } 50^{\circ} \mathrm{F} \text {. }\end{array}$ & Wt. \\
\hline & $\prime \prime$ & 。 & & & & & $\prime \prime$ & \\
\hline 1 & $20.8345 \pm 0.00152$ & 71.5 & $\mathrm{H} 1$. & 2 & 6 & $\begin{array}{c}\text { 1915-Sept. 10, 15; 1917- } \\
\text { Aug. } 3,18,20,24 .\end{array}$ & $20.8340 \pm 0.00157$ & 4. 0 \\
\hline 2 & $20.8312 \pm 0.00158$ & 51.6 & $\mathrm{Hl}$. & 2 & 5 & $\begin{array}{l}\text { 1915-Sept. 22, Oct. 11, } \\
\text { 21, 23, Dec. } 2 \text {. }\end{array}$ & $20.8312 \pm 0.00158$ & 4. 0 \\
\hline 3 & $20.8341 \pm 0.00178$ & 43. 4 & $\mathrm{Hl}$. & 1 & 1 & 1916 -Dec. 2 & $20.8342 \pm 0.00179$ & 3. 1 \\
\hline 4 & $20.8264 \pm 0.00178$ & 39.2 & Bn. & 2 & 4 & $\begin{array}{l}\text { 1915-Nov. 24, 27, } 30 ; \\
\text { 1917-Jan. 20. }\end{array}$ & $20.8266 \pm 0.00179$ & 3. 1 \\
\hline 5 & $20.8343 \pm 0.00175$ & 63. 2 & Bn. & 2 & 4 & $\begin{array}{l}\text { 1917-Aug. 3, Sept. 1, 11, } \\
13 \text {. }\end{array}$ & $20.8340 \pm 0.00177$ & 3. 2 \\
\hline
\end{tabular}

Pleiades Pair, B. D. +24 550 and B. D. $+24^{\circ} 552$

\begin{tabular}{|c|c|c|c|c|c|c|c|c|}
\hline & $\begin{array}{c}\mathbf{R} \\
\text { Observed }\end{array}$ & $\begin{array}{c}\text { Th. } \\
\text { F. }\end{array}$ & Obs. & $\begin{array}{c}\text { Num- } \\
\text { ber } \\
\text { Steps }\end{array}$ & $\begin{array}{l}\text { Num- } \\
\text { ber } \\
\text { Obsns. }\end{array}$ & Dates & $\begin{array}{c}\mathrm{R} \\
\text { Reduced to } 50^{\circ} \mathrm{F} \text {. }\end{array}$ & Wt \\
\hline & II & 0 & & & & & $\prime \prime$ & \\
\hline 1 & $20.8279 \pm 0.00192$ & 55. 4 & $\mathrm{Hl}$. & 2 & 4 & 1915 -Oct. $12,12,21,23$ & $20.8278 \pm 0.00192$ & 2.7 \\
\hline 2 & $20.8320 \pm 0.00195$ & 70.0 & $\mathrm{Hl}$. & 2 & 4 & 1917-Aug. 3, 18, 20, 24_.. & $20.8316 \pm 0.00199$ & 2.5 \\
\hline 3 & $20.8302 \pm 0.00192$ & 63. 2 & $\mathrm{Bn}$. & 2 & 4 & $\begin{array}{l}\text { 1917-Aug. 3, Sept. 1, 11, } \\
13 \text {. }\end{array}$ & $20.8299 \pm 0.00194$ & 2. 7 \\
\hline 4 & $20.8308 \pm 0.00190$ & 38.8 & Bn. & 2 & 4 & $\begin{array}{l}\text { 1915-Nov. } 27,30 ; 1917- \\
\text { Oct. } 31 \text {, Nov. } 2 \text {. }\end{array}$ & $20.8310 \pm 0.00191$ & 2. 7 \\
\hline
\end{tabular}

The three pairs give

$$
\begin{aligned}
& R=20.8351 \pm 0.00037 \\
& R=20.8321 \pm 0.00076 \\
& R=20.8300 \pm 0.00097
\end{aligned}
$$


Compounding with the probable errors just written the probable errors of the respective $\Delta \delta^{\prime}$ s there result

$$
\begin{gathered}
{ }^{\prime \prime} \\
\pm 0.00103 \\
\pm 0.00325 \\
\pm 0.00538
\end{gathered}
$$

Then the value of a revolution is

$$
R=20^{\prime \prime} .8347 \pm 0^{\prime \prime} .00097
$$

for $50^{\circ} \mathrm{F}$. and the reading $0^{\text {in }} .810$ of the focal scale.

The temperature coefficient is

$$
c=+0^{\prime \prime} .000022 \pm 0^{\prime \prime} .0000191
$$

which is the change in the value of $R$ for a rise of $1^{\circ} \mathrm{F}$. of the thermometer.

Then, for the reduction of observations taken after June 15, 1915, the value of $R$ employed has been

$$
R=20^{\prime \prime} .8347+0^{\prime \prime} .000022\left(\mathrm{~T}-50^{\circ} \mathrm{F} .\right)+0^{\prime \prime} .0535\left(0^{\text {in }} .810 \text {-focal scale }\right)
$$

As there were only a few observations taken for the screw value of the Repsold micrometer before the change of the separators between the lenses, the value of $R$ last found, $20^{\prime \prime} .8347$, was corrected for the change caused by the separators of $0^{\text {in }} .027$ in the focal length shown by the two series of observations for the screw of Clark Micrometer II. This correction is $-0^{\prime \prime} .0014$, making the preceding value of $R$,

$$
R=20^{\prime \prime} .8333 \pm 0^{\prime \prime} .00097
$$

for focal scale reading $0^{\text {in }} .810$. Combining with this the value

$$
R=20^{\prime \prime} .8372 \pm 0^{\prime \prime} .00172
$$

obtained before the change of separators is found

$$
R=20^{\prime \prime} .8348 \pm 0^{\prime \prime} .00076
$$

for scale reading $0^{\text {in }} .810$, or

$$
R=20^{\prime \prime} .8332 \pm 0^{\prime \prime} .00076
$$

for scale reading $0^{\text {in }} .840$ and temperature $50^{\circ} \mathrm{F}$.

This result, $R=20^{\prime \prime} .8332$, was used for the reduction of observations made before the change of separators, with the temperature coefficient

$$
c=+0^{\prime \prime} .000027 \pm 0^{\prime \prime} .0000182
$$

found by combining the temperature coefficients determined before and after the change of separators.

In $1919,1920,1921,1923$, and 1924 observations near the meridian were made with bright field of transits of equatorial stars across the short micrometer wires, to determine the value of a revolution of the micrometer screw. The observers were Hall, Burton, and Bower. From a discussion by Burton the results, reduced to $50^{\circ} \mathrm{F}$. and the focal setting $0^{\text {in }} .810$, are 


\begin{tabular}{|l|c|c|c|c|}
\hline Obsr. & Interval & $\begin{array}{c}\mathbf{R} \\
\text { Observed }\end{array}$ & Interval & $\begin{array}{c}\mathbf{R} \\
\text { Observed }\end{array}$ \\
\hline & & $\prime \prime$ & & $\prime \prime$ \\
Hl. & $\mathbf{s}$ & $20.8314 \pm 0.0006$ & 42 & $20.8355 \pm 0.0013$ \\
Bn. & 85 & $20.8352 \pm 0.0005$ & 27 & $20.8398 \pm 0.0025$ \\
B. & 78 & $20.8356 \pm 0.0006$ & 39 & $20.8433 \pm 0.0011$ \\
\hline
\end{tabular}

The values found from the short intervals seem to differ systematically from those determined from the long intervals.

Uniting the results of each observer according to the respective probable errors,

\begin{tabular}{|l|c|}
\hline Obsr. & $\mathrm{R}$ \\
Observed \\
\hline & "' \\
\hline Hl. & $20.8321 \pm 0.0005$ \\
Bn. & $20.8354 \pm 0.0005$ \\
B. & $20.8374 \pm 0.0005$ \\
\hline
\end{tabular}

and for the mean of the three observers

$$
R=20^{\prime \prime} .8350 \pm 0^{\prime \prime} .0003
$$

for $50^{\circ} \mathrm{F}$. and the focal setting $0^{\text {in }} .810$.

(4) Eccentricity of the position circle of the Repsold micrometer.-With the Repsold micrometer, as with the Clark Micrometer II, both microscopes were read, or verniers in the case of Clark II, in order to avoid applying a correction for eccentricity.

Soon after the Repsold micrometer was received the circle was examined, in order to be sure that the eccentricity was small.

Determinations of the eccentricity were made by HaLL and WATTS July 22.5, 1914, and by Bower October 18.1 and 19.2, 1921. These readings were reduced by Bower by the usual formula

$$
\alpha+\cos Z\left(2 \frac{e}{r} \sin E\right)+\sin Z\left(\frac{2 e}{r} \cos E\right)=n_{c}
$$

The readings were treated in the sense microscope $B$ minus microscope $A$. Microscope A is near the micrometer heads. It is adjustable in the direction of the circle reading, so as to make the two microscopes $180^{\circ}$ apart. This adjustment was made after the readings taken on July 22.5, 1914.

The two determinations of eccentricity are as follows, the unit being $0^{\circ} .0001$; $n_{\mathrm{o}}$ is the mean of the readings $(\mathrm{B}-\mathrm{A})$, which are taken symmetrically, forward and back. 


\begin{tabular}{|c|c|c|c|c|c|c|c|c|c|c|c|}
\hline \multicolumn{6}{|c|}{ Hall and Watts; observers } & \multicolumn{6}{|c|}{ Bower, observer. $\quad \mathrm{T} .=66^{\circ} \mathrm{F}$. } \\
\hline$Z$ & $n_{o}$ & $n \cos Z$ & $n \sin Z$ & $n_{\mathrm{o}}$ & $(\mathrm{O}-\mathrm{C})$ & $Z$ & $n_{\mathrm{o}}$ & $n \cos Z$ & $n \sin Z$ & $n_{\mathrm{c}}$ & $(\mathrm{O}-\mathrm{C})$ \\
\hline o & & & & & & 0 & & & & & \\
\hline 0 & +437 & +437.0 & 0.0 & +437 & 0 & 0 & -18 & -18.0 & 0.0 & -19 & +1 \\
\hline 30 & 428 & +370.6 & +214.0 & +417 & +11 & 30 & -45 & -39.0 & -22.5 & -43 & -2 \\
\hline 60 & 389 & +194.5 & +336.9 & +402 & -13 & 60 & -68 & -34.0 & -58.9 & -63 & $-\overline{5}$ \\
\hline 90 & 401 & 0.0 & +401.0 & +396 & +5 & 90 & -65 & 0.0 & -65.0 & -72 & +7 \\
\hline 120 & 399 & -199.5 & +345.5 & +399 & 0 & 120 & -65 & +32.5 & -56.3 & -69 & +4 \\
\hline 150 & 420 & -363.7 & +210.0 & +412 & +8 & 150 & -58 & +50.2 & -29.0 & -54 & -4 \\
\hline 180 & 413 & -413.0 & 0.0 & +430 & -17 & 180 & -30 & +30.0 & 0.0 & -31 & +1 \\
\hline 210 & 460 & -398.4 & -230.0 & +449 & +11 & 210 & -11 & +9.5 & +5.5 & -7 & -4 \\
\hline 240 & 457 & -228.5 & -395.8 & +464 . & -7 & 240 & +21 & -10.5 & -18.2 & +13 & +8 \\
\hline 270 & 485 & 0.0 & -485.0 & +471 & +14 & 270 & +22 & 0.0 & -22.0 & +22 & 0 \\
\hline 300 & 456 & +228.0 & -394.9 & +467 & -11 & 300 & +11 & +5.5 & -9.5 & +19 & -8 \\
\hline 330 & +454 & +393.2 & -227.0 & +455 & -1 & 330 & +9 & +7.8 & -4.5 & +4 & +5 \\
\hline Sums_ & 5,199 & +20.2 & -225.3 & & 0 & Sums_. & -297 & +34.0 & -280.4 & & +3 \\
\hline & $=+433.2$ & $\frac{e}{r}=$ & & $E=174^{\circ}$ & & & 0 & $\frac{e}{r}=$ & & $=173$ & \\
\hline
\end{tabular}

\begin{tabular}{|c|c|c|c|c|c|}
\hline \multicolumn{3}{|c|}{ Bower, observer } & \multicolumn{3}{|c|}{$\mathrm{T} .=69^{\circ} .5 \mathrm{~F}$} \\
\hline$Z$ & $n_{\mathrm{o}}$ & $n \cos Z$ & $n \sin Z$ & $n_{\mathrm{c}}$ & $(0-C)$ \\
\hline \multicolumn{6}{|l|}{ o } \\
\hline 0 & -28 & -28.0 & 0.0 & -31 & +3 \\
\hline 30 & -65 & -56.3 & -32.5 & -61 & -4 \\
\hline 60 & -84 & -42.0 & -72.7 & -82 & -2 \\
\hline 90 & -86 & 0.0 & -86.0 & -88 & +4 \\
\hline 120 & -77 & +38.5 & -66.7 & -79 & +2 \\
\hline 150 & -54 & +46.8 & -27.0 & -56 & +2 \\
\hline 180 & -30 & +30.0 & 0.0 & -25 & -5 \\
\hline 210 & +3 & -2.6 & -1.5 & +4 & -1 \\
\hline 240 & +30 & -15.0 & -26.0 & +25 & +5 \\
\hline 270 & +26 & 0.0 & -26.0 & +32 & -6 \\
\hline 300 & +22 & +11.0 & -19.1 & +22 & 0 \\
\hline 330 & +2 & +1.7 & -1.0 & -1 & +3 \\
\hline Sums_- & -341 & -15.9 & -358.5 & & -1 \\
\hline & -28.4 & $\frac{e}{r}=2$ & & $=182^{\circ}$ & \\
\hline
\end{tabular}


In the first determination by BowER the telescope was west of the pier, object glass north, and the $5^{\circ}$ mark on the circle was straight down. In his second determination the telescope was east of the pier, object glass north, and the $185^{\circ}$ mark on the circle was straight down. The box screw was turned up.

In the above results microscope $\mathrm{B}$ minus microscope $\mathrm{A}=180^{\circ}+\alpha$, or $(\mathrm{B}-\mathrm{A})=$ $180^{\circ}+\alpha . \quad E$ is the position on the circle of the line joining the center of the circle to the center of the microscopes, $r$ is the radius of the circle, and $e$ is the distance from the center of the circle to the center of the microscopes.

THE INSTRUMENTAL CONSTANTS OF THE 26-INCH EQUATORIAL

Instrumental constants with Clark Micrometer II.-The notation for the instrumental constants is that given in Appendix III, Volume IV, Publications of the Naval Observatory, Second Series. During the period October 20, 1908 to March 24,1914 , the constants were determined according to the methods given in the appendix referred to. Clark Micrometer II was attached to the instrument during this period. The constants are

$\eta=$ the distance of the instrumental pole westward from the true pole, measured along the six-hour circle. $\xi=$ the distance of the instrumental pole above the true pole, measured along the meridian.

$i_{1}=$ the inclination of the axes. The angle between the polar axis produced northward and the declination axis produced through the telescope tube is $i_{1}+90^{\circ}$. This is the observed angle as affected by the flexure of the declination axis.

$i_{1}$ as here defined equals the $i_{1}$ of Chauvenet, who takes $i_{1}=i-\epsilon \sin \phi, 90^{\circ}-i$ being the angle between the polar axis produced northward and the declination axis produced away from the tube, not including the effect of the flexure of the declination axis, and $\epsilon$ being the maximum flexure of the declination axis, positive when the end extending away from the tube bends downward. Here $\phi=$ the instrumental latitude.

$c=$ the collimation. The angle between the optical axis of the telescope produced through the objective and the declination axis produced through the tube is $c+90^{\circ}$.

$\epsilon=$ the maximum flexure of the declination axis, positive when the end joining the tube bends downward, opposite in sign to Chauvenet's definition of $\epsilon$.

$e=$ the maximum flexure of the telescope tube, positive when the objective end of the tube bends the more. $f=$ torsion of telescope tube.

The constants as determined with Clark Micrometer II are as follows:

The Instrumental Constants, Clark Micrometer II

\begin{tabular}{|c|c|c|c|c|c|c|c|c|}
\hline Date & Obs. & Th. & $\boldsymbol{\eta}$ & $i_{1}-c$ & $\xi$ & $\epsilon \cos \phi$ & $c$ & $e \cos \phi$ \\
\hline 1908 & & 0 & ." & " & $"$ & " & " & " \\
\hline Oct. 20 & $\mathrm{Hl}$. & 48.9 & +113 & -62.8 & -48.8 & & & \\
\hline Nov. 17 & $\mathrm{Hl}$. & 44.8 & & & & +102.2 & +123.9 & +5.2 \\
\hline 1909 & & & & & & & & \\
\hline Feb. 6 & Hl. & 42.0 & +107.8 & -59.4 & -51.5 & & & \\
\hline 14 & $\mathrm{Hl}$. & 41.9 & & & & +96.8 & +121.3 & +3.0 \\
\hline Mar. 20 & Fn. & 42.7 & & & & +86.0 & +111.6 & -1.7 \\
\hline 20 & Fn. & 37.0 & +111.8 & -62.3 & -48.4 & & & \\
\hline Apr. 2 & Ep. & 42.9 & & & & +93.3 & +118.1 & +5.2 \\
\hline & Ep. & 46. 8 & +108.2 & -60.8 & -54.5 & & & \\
\hline 6 & Fn. & 63 & +109.6 & -56.6 & -56.2 & & & \\
\hline 6 & Ep. & 63.0 & +110.8 & -57.6 & -59.4 & & & \\
\hline 12 & Fn. & 61.8 & & & & +93.8 & +116.2 & +5.7 \\
\hline May 5 & $\mathrm{Hl}$. & 63 & +111.2 & -61.2 & -53.9 & & & \\
\hline 7 & Hl. & 63.3 & & & & +90.6 & +115.0 & +1.8 \\
\hline 10 & Ep. & 60 & +107.6 & -62.9 & -56.1 & & & \\
\hline 10 & Ep. & 58.8 & & & & +95.4 & +115.3 & +3.9 \\
\hline 11 & Fn. & 57.5 & +111.2 & -60.2 & -53.6 & & & \\
\hline 11 & Fn. & 57.3 & & & & +91.5 & +114.9 & +3.3 \\
\hline
\end{tabular}


The Instrumental Constants, Clark Micrometer II-Continued

\begin{tabular}{|c|c|c|c|c|c|c|c|c|}
\hline Date & Obs. & $\begin{array}{l}\text { Th. } \\
\text { F. }\end{array}$ & $\eta$ & $i_{1}-c$ & $\xi$ & $\epsilon \cos \phi$ & . & $e \cdot \cos \phi$ \\
\hline 1909 & & 。 & ", & " & " & ": & " & " \\
\hline Jıne 11 & $\mathrm{Hl}$. & 70.5 & +109.8 & -59.6 & -54.0 & & & \\
\hline 14 & Hl. & 68.7 & & & & +92.5 & +113.0 & +4.1 \\
\hline 17 & Fn. & 72 & & & & +91.5 & +111.7 & +5.2 \\
\hline 18 & Fn. & 74. 8 & +110.3 & -59.4 & -57.6 & & & \\
\hline 18 & Ep. & 64 & & & & +91.5 & +112.3 & -0.4 \\
\hline · $\quad 19$ & Ep. & 69 & +109.6 & -59.7 & -58.5 & & & \\
\hline 30 & Ep. & 79.1 & +108.2 & -59.8 & -56.9 & & & \\
\hline 30 & Ep. & 80 & & & & +87.1 & +110.1 & +5.7 \\
\hline July 2 & Fn. & 78. 9 & +110.3 & -59.3 & -56.0 & +88.1 & +111.0 & -0.3 \\
\hline Sept. 2 & Ep. & 65.0 & +112.6 & -60.0 & -67.0 & & & \\
\hline $\begin{array}{l}6 \\
7\end{array}$ & $\begin{array}{l}\text { Ep. } \\
\text { Hl. }\end{array}$ & $\begin{array}{l}65.0 \\
67.6\end{array}$ & & -60.4 & -66.1 & +86.4 & +108.8 & +5.1 \\
\hline 10 & HI. & 67. 7 & +112.1 & & & +84.3 & +110.2 & +5.0 \\
\hline 28 & Ep. & 59.0 & +108.1 & -57.6 & -71.4 & & & \\
\hline 28 & Ep. & 55.0 & & & & +93.9 & +117.3 & +1.9 \\
\hline 29 & Fn. & 59.5 & & & & +87.1 & +112.6 & +5.8 \\
\hline $\begin{array}{ll} & 30 \\
\text { Oct. } & 28\end{array}$ & $\begin{array}{l}\text { Fn. } \\
\text { Ep. }\end{array}$ & $\begin{array}{l}62.2 \\
40.0\end{array}$ & +110.3 & -60.9 & -69.4 & $+08 \quad 4$ & & \\
\hline 29 & Ep. & 41.0 & +111.9 & -60.8 & -62.2 & +98.4 & +118.6 & +7.0 \\
\hline $\begin{array}{c}\text { Dec. } 1 \\
1910\end{array}$ & Ep. & 43.0 & +113.1 & -60.6 & -64.1 & +89.4 & +114.8 & +6.1 \\
\hline $\begin{array}{ll}\text { Jan. } \quad 7 \\
7\end{array}$ & $\begin{array}{l}\text { Ep. } \\
\text { Ep. }\end{array}$ & $\begin{array}{l}28 \\
24\end{array}$ & +111.5 & -59.8 & -63.9 & & & \\
\hline 25 & Hl. & 29.5 & +111.2 & -60.6 & -57.2 & $\begin{array}{r}+91.8 \\
+84.9\end{array}$ & $\begin{array}{l}+116.9 \\
+111.3\end{array}$ & $\begin{array}{l}+5.9 \\
+6.8\end{array}$ \\
\hline Mar. 21 & Ep. & 46.0 & +109.8 & -58.8 & & $\begin{array}{r}+92.1 \\
\end{array}$ & +114.4 & $\begin{array}{r}+0.0 \\
+0.6\end{array}$ \\
\hline 23 & Ep. & 61.0 & +114.9 & -60.4 & -61.0 & & & \\
\hline 25 & HI. & 70.7 & +114.4 & -62.8 & -61.5 & +92.4 & +113.6 & -0.1 \\
\hline June 23 & Ep. & 83.3 & +112.7 & -55.9 & -69.8 & +96.3 & +117.3 & +3.0 \\
\hline Aug. 19 & Hl. & 71. 2 & +113.3 & -57.6 & -68.2 & & & \\
\hline Sept. 7 & $\mathrm{Hl}$. & 77 & +109.8 & -58.6 & -68.9 & +97.4 & +116.0 & +1.9 \\
\hline $\begin{array}{ll}\text { Oct. } & 10 \\
& 10-11\end{array}$ & $\begin{array}{l}\text { Ep. } \\
\text { Ep. }\end{array}$ & $\begin{array}{l}59.6 \\
65.2\end{array}$ & +114.0 & -58.8 & -75.3 & +91.4 & +113.7 & +1.3 \\
\hline 1911 & & & & & & & & \\
\hline $\begin{array}{lr}\text { Jan. } & 30 \\
\text { Feb. } & 4\end{array}$ & Ep. & 35. 7 & & & & +91.9 & +116.3 & +7.7 \\
\hline Apr. 24 & $\begin{array}{l}\text { Ep. } \\
\text { Ep. }\end{array}$ & $\begin{array}{l}42.8 \\
51\end{array}$ & $\begin{array}{l}+114.8 \\
+113.3\end{array}$ & -59.0 & $\begin{array}{l}-63.5 \\
-68.9\end{array}$ & & & \\
\hline July $14-15$ & Ep. & 75.2 & +113.3 & -58.7 & -68.9 & $\begin{array}{l}+88.4 \\
+83.9\end{array}$ & $\begin{array}{l}+112.8 \\
+111.4\end{array}$ & $\begin{array}{l}+3.9 \\
+4.6\end{array}$ \\
\hline $\begin{array}{r}17 \\
\text { Sept. } 18\end{array}$ & Ep. & 71.8 & +112.6 & -59.1 & -72.2 & & & \\
\hline $\begin{array}{c}\text { Sept. } 18 \\
1912\end{array}$ & Ep. & 65 & +113.6 & -59.7 & -73.4 & +87.7 & +111.2 & +2.9 \\
\hline $\begin{array}{l}\text { Feb. } \\
13\end{array}$ & Bn. & 24.4 & +114.6 & -64.7 & -60.2 & & & \\
\hline Mar. $\begin{array}{l}13 \\
25\end{array}$ & $\begin{array}{l}\text { Bn. } \\
\text { Bn. }\end{array}$ & $\begin{array}{l}24.3 \\
35.7\end{array}$ & • & & & $\begin{array}{r}+81.4 \\
+82.1\end{array}$ & $\begin{array}{l}+113.3 \\
+1096\end{array}$ & $\begin{array}{l}+2.7 \\
+1.9\end{array}$ \\
\hline 26 & $\mathrm{Bn}$. & 49.8 & +112.8 & -61.5 & -66.3 & & +109.0 & \\
\hline July $15^{1}$ & $\mathrm{Bn}$. & 77 & +113.8 & -59.0 & -69.5 & +92.6 & +115.3 & +1.5 \\
\hline $\begin{array}{c}\text { Dec. } 12^{1} \\
1913\end{array}$ & Bn. & 26 & +114.9 & -64.0 & -70.7 & +89.2 & +117.4 & +3.5 \\
\hline Feb. $12^{2}$ & Bn. & 22 & +113.9 & -63.5 & -63.7 & +83.0 & +115.3 & +6.8 \\
\hline June $29^{2}$ & Br: & 73 & +114.9 & -60.8 & -70.5 & +89.9 & +114.4 & -1.2 \\
\hline $\begin{array}{c}\text { Nov. } 24 \\
1914\end{array}$ & $\mathrm{Bn}$. & 46 & +117.4 & -59.9 & -74.8 & $\begin{array}{r}+92.6 \\
+92.6\end{array}$ & $\begin{array}{r}11 \pm . \\
+115.5\end{array}$ & +3.8 \\
\hline Feb. 16 & Bn. & 20 & it 116.4 & -60.6 & -72.4 & +74.1 & +108.1 & +2.2 \\
\hline Mar. 24 & $\mathrm{Bn}$. & 41 & +115.5 & -60.1 & -72.6 & +89.6 & +113.4 & +2.4 \\
\hline
\end{tabular}




\begin{tabular}{|c|c|c|c|c|c|c|c|c|}
\hline Date & $\begin{array}{l}\text { Th. } \\
\text { F. }\end{array}$ & $f$ & Obs. & \multicolumn{2}{|c|}{ Date } & $\begin{array}{l}\text { Th. } \\
\text { F. }\end{array}$ & $f$ & Obs. \\
\hline \multirow{2}{*}{$\begin{array}{c}1909 \\
\text { June } 12\end{array}$} & $\circ$ & $\circ$ & & \multicolumn{2}{|c|}{1910} & 。 & 。 & \\
\hline & & +0.010 & Ep. & July & 8 & 78. 6 & +0.008 & Hl. \\
\hline 14 & 82 & 0.009 & Fn. & & 8 & 85.4 & 0.016 & Bn. \\
\hline 20 & 83 & 0.016 & Ep. & & 12 & 83. 6 & 0.016 & Hl. \\
\hline 20 & 83 & 0.012 & Fn. & & 13 & 83.8 & 0.015 & Bn. \\
\hline 23 & 75 & 0.017 & Ep. & & 18 & 75.2 & 0.014 & Hl. \\
\hline 23 & 75 & 0.014 & Fn. & & 18 & 77. 8 & 0.015 & Bn. \\
\hline Sept. 15 & 72.4 & 0.009 & Fn. & Aug. & 3 & 80.1 & 0.015 & Ep. \\
\hline 15 & 73.0 & 0.015 & Ep. & & 7 & 74. 2 & 0.012 & Ep. \\
\hline 1910 & & & & & 7 & 74. 4 & 0.015 & $\mathrm{Bn}$. \\
\hline July 7 & 75.6 & 0.015 & Hl. & & 8 & 74.0 & 0.012 & Ep. \\
\hline 7 & 80.8 & +0.015 & Bn. & & 8 & 74. 4 & +0.016 & $\mathrm{Bn}$. \\
\hline
\end{tabular}

For application to observations during the period October 20, 1908-March 24, 1914, tables were formed with the following assumed values of the constants:

$$
\begin{aligned}
\xi & =-0^{\circ} .0152 \text { to August } 21,1909 \\
\xi & =-0^{\circ} .0180 \text { from August } 21,1909 \\
\eta & =+0^{\circ} .0308 \\
c & =+0^{\circ} .0318 \\
i_{1} & =+0^{\circ} .0152 \\
e \cos \phi & =+0^{\circ} .0010(\phi=\text { instrumental latitude) } \\
f & =+0^{\circ} .014
\end{aligned}
$$

On August 20.9, 1909, the lower side door on the east side of the iron pier was left open, and was hit by the elevating floor. This may be the reason for the change in the value of $\xi$.

Instrumental constants, Repsold micrometer.-Observing was begun with the Repsold micrometer in July, 1914.

Attempts to determine the constants by the methods of Appendix III, Volume IV, were made December 15 and 16 of the year 1914 with the following results:

\begin{tabular}{|r|c|c|c|c|c|c|c|}
\hline Date & $\begin{array}{c}\text { Th. } \\
\text { F. }\end{array}$ & \multicolumn{1}{|c|}{$\eta$} & $i_{1}-c$ & $\xi$ & $\epsilon \cos \phi$ & $c$ & $e \cos \phi$ \\
\hline 1914 & $\circ$ & $\prime \prime$ & $\prime$ & $\prime \prime$ & $\prime \prime$ & $\prime \prime$ & " \\
Dec. 15 & 18.4 & & & & +99.7 & +125.5 & +8.8 \\
16 & 22.8 & +114.5 & -59.6 & -84.7 & & & \\
\hline
\end{tabular}

During these observations the micrometer box seemed to slip a trifle when the micrometer was reversed. On this account, and on account of endwise play in the declination axis when the telescope is placed under the pier, the processes of Appendix III were discontinued, and methods described in the Spherical and Practical Astronomy of Chauvenet were used. However, the notation of Appendix III was retained, as written for the Clark Micrometer II.

The box screw of the Repsold micrometer was turned all the way up during the observation of constants, and the micrometer was set in two positions $180^{\circ}$ apart. Observations were taken on both sides of the pier.

$\epsilon$, the flexure of the declination axis, was found from observations of meridian transits above and below the pole of ephemeris stars of considerable polar distance, the hour circle being read at each observation of transits, and transits being observed on both sides of the pier. 
By combining observations of the same star taken at upper and lower culmination there results

$$
\epsilon \cos \phi=\frac{1}{4}\left[\left(\tau_{\mathrm{U}}^{\mathrm{E}}-\tau_{\mathrm{U}}{ }^{\mathrm{W}}\right)+\left(\tau_{\mathrm{L}}^{\mathrm{E}}-\tau_{\mathrm{L}}^{\mathrm{W}}\right)-\left(t_{\mathrm{U}^{\mathrm{E}}}^{\mathrm{E}}-t_{\mathrm{U}^{\mathrm{W}}} \mathrm{W}\right)-\left(t_{\mathrm{L}}^{\mathrm{E}}-t_{\mathrm{L}} \mathrm{W}\right)\right]
$$

where $\tau=$ the true hour angle of the star and $t=$ the instrumental hour angle, at upper and lower culmination (indicated by subscripts), and for the telescope east of pier and west of pier (indicated by superscripts).

$\xi$ and $e$ were determined by setting on stars on the meridian and reading the declination circle. In the summer of 1909 the illumination of the declination circle had been improved, so that it could be used for this purpose.

For the torsion $f$ of the telescope tube the following results were found by HALL and BuRTON, to which weights were arbitrarily assigned:

\begin{tabular}{|l|c|c|}
\hline & $f$ & Wt. \\
& & \\
1. Telescope parallel to equator & +0.0276 & 2 \\
2. Telescope in meridian & +0.0255 & 1 \\
3. Telescope in meridian & +0.0241 & 2 \\
4. Telescope in meridian & +0.0240 & 1 \\
5. Telescope in meridian & +0.0261 & 1 \\
6. From parallels & +0.0280 & 2 \\
\hline Mean & +0.0260 & \\
\hline Note.-The telescope was horizontal except in (6).
\end{tabular}

An additional determination of the torsion, $f$, was made December 24, 1926, by Burton, the telescope being in the meridian and horizontal as in (2) to (5). The result was $f=+0^{\circ} .020$; thermometer $35^{\circ} \mathrm{F}$.

For the determinations of $f,(2)$ to (5), the following method, proposed by Burton, was employed.

Let two spirit levels be secured to the micrometer box, one the long way of the box and the other parallel to the telescope tube. Then, when each level bubble is in the center of the scale

$$
f=\left\{\frac{1}{4}\left[p^{\mathrm{E}_{\mathrm{n}}}-p_{\mathrm{s}}^{\mathrm{E}_{\mathrm{s}}}+p^{\mathrm{w}_{\mathrm{s}}}-p^{\mathrm{w}_{\mathrm{n}}}\right]-90^{\circ}\right\} \sin \phi-i_{1}
$$

where the values of $p$ are readings of the position circle when the telescope is east of the pier and object glass north, east of the pier and object glass south, west of pier and object glass south, and west of pier and object glass north, respectively; $\phi=$ the instrumental latitude and $i_{1}=$ the inclination of the axes.

The telescope having been placed very nearly in the instrumental meridian and as nearly horizontal as possible, the hour circle may be read and the index correction applied to the readings; the values of $p$ may then be corrected for the amount the telescope is out of the instrumental meridian. The variation of $p$ is $15^{\prime \prime} \cos \phi$ per second of hour angle in time, or $0^{\circ} .003243$ for the 26 -inch equatorial. The position circle is read to $0^{\circ} .0001$ by means of the two microscopes, and settings are made on two consecutive circle divisions with each microscope to correct for run. Knowing the value of a division of the level mounted parallel to the micrometer box the position circle readings may also be corrected for the deviation of the level bubble from the center of the scale. 
There is also a torsion $f^{1}$ which may be supposed to be caused by a weight attached $90^{\circ}$ in position angle from the declination axis. The value of $f^{1}$ is practically negligible but may be obtained by taking parallels, or by a method which also gives $f$, found in Appendix III, Volume IV, Publications of the Naval Observatory, Second Series.

For the value (6) in the preceding table the parallels were taken in different parts of the sky, and the other constants, neglecting $f^{1}$, were applied before determining $f$.

For (1)-(5) a level was clamped to the micrometer box. With the tangent screw of the position circle the bubble was brought nearly to the centre of the vial, and the level and the position circle were read. The telescope was horizontal.

For (1) the telescope was placed in the plane of the equator of the instrument above and below the pier, object glass east and object glass west. -No application of the other instrumental constants is necessary except $i_{1}$.

For (2) to (5), inclusive, no application of the other constants is necessary except $i_{1}$ and $\xi$, the latter being needed to get the instrumental latitude $\phi$. Since $i_{1}=i-\epsilon \sin \phi$, the constant $i_{1}$ also depends upon $\phi$. The value of $\phi$ may be obtained independently of $\xi$ by the method given in Appendix III, Volume IV.

As determined with the Repsold micrometer the instrumental constants, other than $f$, were

The Instrumental Constants, Repsold Micrometer

\begin{tabular}{|c|c|c|c|c|c|c|c|c|c|c|c|}
\hline Date & Obs. & $\begin{array}{l}\text { Th. } \\
\text { F. }\end{array}$ & $\eta$ & $i_{1}-c$ & $\xi$ & $\epsilon \cos \phi$ & $c$ & $e \cos \phi$ & $\Delta t$ & & $\Delta p$ \\
\hline 1915 & & $\circ$ & " & " & " & " & 11 & & $s$ & $\therefore$ & " \\
\hline Oct. 21 & Bn. & 65.3 & & & -94.4 & & & +1.1 & & +2 & 22 \\
\hline Nov. 30 & Bn. & 32.8 & +121.8 & -59.0 & & & & & & & \\
\hline $\begin{array}{ll}\text { Dec. } & 7 \\
1916 & \end{array}$ & Bn. & 34.1 & +114.2 & -57.6 & & $\therefore$ & +121.0 & & -1.5 & & \\
\hline $\begin{array}{ll}\text { Jan. } & 24 \\
& 31\end{array}$ & $\begin{array}{l}\text { Bn. } \\
\text { Bn. }\end{array}$ & $\begin{array}{l}41.3 \\
62.2\end{array}$ & +114.9 & -57.4 & -91.2 & & & +2.2 & & +2 & 20 \\
\hline $\begin{array}{ll}\text { Feb. } & 3 \\
& 7\end{array}$ & $\begin{array}{l}\mathrm{Bn} \text {. } \\
\mathrm{Bn} .\end{array}$ & $\begin{array}{l}26.7 \\
35.6\end{array}$ & $\begin{array}{l}+118.8 \\
+110.9\end{array}$ & $\begin{array}{l}-59.5 \\
-56.8\end{array}$ & & +97.5 & $\begin{array}{l}+124.0 \\
+121.0\end{array}$ & & $\begin{array}{l}-1.6 \\
-1.4\end{array}$ & & \\
\hline May 10 & $\mathrm{Bn}$. & 67.2 & +120.8 & -59.8 & & & +121.0 & & -1.6 & & \\
\hline 17 & Bn. & 58.7 & +119.3 & -55.0 & & +109.5 & +121.0 & & -1.8 & & \\
\hline & $\begin{array}{l}\text { Bn. } \\
\text { Hl. }\end{array}$ & $\begin{array}{l}71.4 \\
67.8\end{array}$ & +111.0 & -57.6 & -90 & & +122.5 & +10.9 & -1.7 & +0 & 14 \\
\hline 23 & $\mathrm{Bn}$. & 74.3 & +119.1 & -61.1 & & & +115.0 & & -2.0 & & \\
\hline $\begin{array}{c}\text { July } \quad 6 \\
1917\end{array}$ & $\mathrm{Bn}$. & 74.5 & +117.0 & -58.2 & & +93.0 & +121.0 & & -1.2 & & \\
\hline June 4 & $\mathrm{Bn}$. & 62 & & & -88.6 & & & +3.7 & & +0 & 17 \\
\hline Sept. 20 & $\mathrm{Hl}$. & 66.8 & & & -94.2 & & & -1.0 & & +0 & 18 \\
\hline $\begin{array}{c}\text { Oct. } 13 \\
1919\end{array}$ & $\mathrm{Bn}$. & 45. 7 & +113.3 & -56.7 & & +99.0 & +122.3 & & -1.7 & & \\
\hline $\begin{array}{c}\text { Apr. } 18 \\
1920\end{array}$ & $\mathrm{Bn}$. & 43. 1 & +122.6 & -59.9 & -83.0 & +98.1 & +116.1 & +4.9 & +12.9 & +0 & 15 \\
\hline $\begin{array}{ll}\text { July } & 22 \\
& 28\end{array}$ & $\begin{array}{l}\text { B. } \\
\text { B. }\end{array}$ & $\begin{array}{l}75 \\
68\end{array}$ & +110.3 & -58.2 & -91.8 & +102.0 & +120.6 & +4.7 & +12.7 & +0 & 11. 8 \\
\hline 1922 & & & & & & & & & & & \\
\hline $\begin{array}{c}\text { Aug. } \quad 5 \\
1926\end{array}$ & B. & 71 & +116.2 & -54.8 & -89.2 & +97.5 & +118.2 & +3.1 & -1.1 & +0 & 44. 2 \\
\hline Sept.-Oct. & $\mathrm{Bn}$. & $71-41$ & +111.9 & -48.3 & -94.5 & +86.4 & +105.4 & -0.3 & -1.4 & +0 & 49 \\
\hline
\end{tabular}

Verniers of declination circle adjusted occasionally. 
$\Delta t$ is the index correction of the hour circle. $\Delta p$ is the index correction of the declination circle, which reads north polar distances on the east side of the pier and south polar distances on the west side.

For application to observations tables were formed, the values of the constants being taken to be

$$
\begin{aligned}
\xi & =-0^{\circ} .0255 \\
\eta & =+0^{\circ} .0324 \\
c & =+0^{\circ} .0336 \\
i_{1} & =+0^{\circ} .0174 \\
e \cos \phi & =+0^{\circ} .0010 \\
f & =+0^{\circ} .0260
\end{aligned}
$$

Parallels.-For a considerable period parallels were determined by trailing stars, as had been the previous practice.

Usually the stars were near the equator and near the meridian, and the telescope was east of the pier-that is, the parallels were taken near the position of the standard parallel as defined in Appendix III of Volume IV.

- As is seen from the tabulation of instrumental constants, these constants change but little, so that they can be taken to hold for a long time.

The observed parallels were reduced by the formula of Appendix III to the standard parallel, telescope east, on the meridian and on the equator by the formula

$$
p_{\mathrm{m}}^{\mathbf{e}_{\mathrm{m}}}=p_{1}+\Delta p_{1}+\lambda
$$

in which $p$ is the observed parallel, $\Delta p_{1}$ is the correction for differential refraction, and $\lambda$ is the correction for instrumental constants.

By this method it was necessary to set a thread on a star with the declination slow motion. In the summer of 1909 the gears actuated by the slow motion were changed by Mr. FEcker, Superintendent of the Warner and Swasey Instrument Shop, so that the accuracy of a pointing was considerably improved.

As the Clark Micrometer II does not have a double slide eyepiece, the parallels were generally taken on the long wires, usually on the middle wire. A few parallels were observed by trailing on the short wires, to determine whether they were perpendicular to the long wires.

The difference from perpendicularity was less than the errors of observation, and no correction for this difference has been applied in the few cases when the short wires were used for position angles or for differences of right ascension and declination.

After reduction to standard parallels, the results were tabulated and taken in groups, these groups usually covering considerable intervals of time, since it was evident that the parallels changed but little.

Beginning with 1914 parallels were usually taken near the position of the telescope where an observation was made. The parallel thus determined was reduced to the standard, and then the mean of a group was changed back by means of the instrumental constants to apply to the observation. In this way an error in the constants would have only a differential effect.

After the Repsold micrometer was attached to the 26-inch equatorial the middle short fixed wire was used for a time for measuring position angles when the distances were small. This micrometer is provided with a double slide eyepiece, 
and the box screw has a smooth, fine motion, making it easy to test the position angle settings. For parallel determinations the stars were trailed along the short wire used in measuring angles.

Beginning with November, 1918, at the suggestion of BuRToN, use was made in parallel determinations of the accurately divided position circle of the Repsold nicrometer. For a long wire an approximate setting was made with the declination slow motion, when the star entered the field; then an accurate setting was made on the star by means of the tangent motion of the position circle, and the circle microscopes were read. When the star was leaving the field, another setting on the star was made with the tangent motion of the position circle, and the microscopes were read a second time. Before the observation the circle was set approximately at the parallel.

For a short wire, the circle was set approximately at the parallel and the microscopes were read. When it entered the field the star was bisected with the wire by means of the box screw. On leaving the field the star was set on the wire by means of the tangent motion of the position circle, and the microscopes were read a second time.

For a complete parallel determination the star was usually made to cross the field five times, both for a long wire and a short wire.

Experiments were made by Bower with a method of determining parallels used by Dr. H. STRUve, and described in Königsberg Observations, Band 41, s. 4; also described in Publications of the United States Naval Observatory, Second Series, Volume IV-Appendix III, pages F 20, F 21.

It was found desirable to modify slightly the process used by STRUVE, as follows: The micrometer was set at approximately the correct parallel, and the position circle was read. With the driving clock stopped the star was allowed to transit across the field. Readings on the star were taken with the middle movable micrometer wire when the star entered the field and when it left the field. The difference of the micrometer readings and the time of transit across the field gave data for correcting the approximate setting of the position circle. Usually the star was allowed to transit across the field five times.

Beginning with July, 1919, Bower determined the parallel of the middle movable wire by this method. Almost all of BowER's observations of comets and asteroids were measures of rectangular coordinates with movable and fixed short wires. The respective inclinations of these threads were determined by coincidences, in order to have the mean of the parallels of wires used for observation.

Beginning with February, 1923, HALL used the middle short movable thread for settings in position angle when the distances were small, the parallel on this wire being determined by the method just described.

April 1, 1925, BuRToN was reassigned to the equatorial division, after which date his measures of position angle were made with the middle movable short wire.

For a number of BuRToN's parallel determinations with this short wire the position circle was set approximately on the parallel, and the circle microscopes were read. This movable wire was pointed on the star when it entered the field. As the star was leaving the field the movable wire was placed on the star a second 
time by means of the slow-motion screw of the position circle, after which the circle microscopes were read a second time.

The mean of the two circle readings furnished the true parallel. Four transits of the star were taken for the determination of a parallel, when a prism eyepiece was used.

During the following periods some use was made of eyepieces provided with reversing prisms for the determination of parallels:

February, 1911; October, November, December, 1912; January, February, March, April, May, June, 1913; December, 1913; January, February, March, 1914.

Beginning with June, 1925, all parallel determinations by BuRToN were taken with prism eyepieces except two determinations on a short wire of Clark Micrometer II when AF 54 (power 183) was used.

Probably all parallel determinations should be made with prism eyepieces, and all observations when the objects are sufficiently bright so that the loss of light on account of the prism does no harm.

No systematic corrections have been applied to parallel determinations or to any other observations.

In the spring of 1911 six new eyepieces were purchased from STEINHEIL, of Munich. Three were achromatic, of the type called A. F. by StEinHeiL, having equivalent focal lengths of $54 \mathrm{~mm}$., $27 \mathrm{~mm}$., and $20 \mathrm{~mm}$., respectively, corresponding to magnifying powers of 183,367 , and 495 . Three of the eyepieces were orthoscopic, called A. L. by Steinheil, having equivalent focal Iengths of $27 \mathrm{~mm}$., $20 \mathrm{~mm}$., $9 \mathrm{~mm}$., corresponding to magnifying powers of $367,495,1,100$. The orthoscopic eyepieces were provided with totally reflecting prisms for use in eliminating systematic errors of observation and could be used either with or without the prisms.

Personal equation in distance measures.-A number of measures of differences in declination between faint stars in the cluster $h$ Perse $i$ were made with the Repsold micrometer for determination of personal equation in distance measures. A difference, $\Delta \delta$, was measured in one step and also in several steps, with the driving clock running; $\Delta \delta$ being measured in preference to the distance $s$ in order to eliminate errors of the driving clock. The following results of the measures do not appear to justify a personal equation correction and have not been used: 


\begin{tabular}{|c|c|c|c|c|c|c|c|c|c|}
\hline $\begin{array}{c}\text { Date, } \\
\text { W. M. T. } \\
\end{array}$ & Obs. & $\begin{array}{l}\Delta \delta \text { (ene } \\
\text { step) }\end{array}$ & $\begin{array}{l}\text { Num- } \\
\text { ber of } \\
\text { Meas- } \\
\text { ures }\end{array}$ & $\begin{array}{l}\Delta \delta(\text { sum }) \\
.\end{array}$ & $\begin{array}{l}\text { Num- } \\
\text { ber of } \\
\text { Steps }\end{array}$ & $\begin{array}{l}\text { Num- } \\
\text { ber of } \\
\text { Meas- } \\
\text { ures } \\
\text { in } \\
\text { each } \\
\text { Step }\end{array}$ & Illumination & Power & Seeing \\
\hline 1915 & & & & & & & & & \\
\hline $\begin{array}{c}\text { Oct. } 12.4 \\
1918\end{array}$ & Bn. & 3. 407 & 4 & 3. 420 & 3 & 4 & Red wires & 388 & Good. \\
\hline Aug. $\quad 20.5$ & Bn. & 4. 344 & 8 & 4. 343 & 4 & 8 & Brt. field & 367 & Poor. \\
\hline 23. 4 & $\mathrm{Bn}$. & 3. $991^{\prime \prime}$ & 8 & 3. 981 & 4 & 8 & Brt. field & 367 & Fair. \\
\hline . $\quad 24.4$ & $\mathrm{Bn}$ : & 4. 346 & 8 & 4. 344 & 5 & 8 & Brt. field & 367 & Fair. \\
\hline Sept. 4.6 & $\mathrm{Hl}$ & 4. 341 & 4 & 4. 343 & 5 & 4 & Brt. field & 367 & Fair. \\
\hline 9.4 & $\mathrm{Hl}$. & 4. 345 & 8 & 4. 340 & 5 & 4 & Brt. field & 367 & Poor-fair. \\
\hline$\quad 12.4$ & Hl. & 4. 351 & 8 & 4. 347 & 5 & 4 & Brt. field & 367 & $\left\{\begin{array}{l}\text { Poor. } \\
\text { Haze and clouds }\end{array}\right.$ \\
\hline : 14.4 & $\mathrm{Hl}$. & 4. 345 & 12 & 4. 346 & 5 & 8 & Brt. field & 367 & Fair. \\
\hline Oct. $\quad 8.4$ & $\mathrm{Hl}$. & 4. 345 & 8 & 4. 336 & 5 & 4 & Red wires & 367 & Good. \\
\hline$\therefore \quad 8.4$ & $\mathrm{Hll:}$ & 4. 351 & 8 & 4. 346 & 5 & 4 & Red wires & 367 & Good. \\
\hline$\quad 10.4$ & $\mathrm{Hl}$. & 4. 346 & 8 & 4. 333 & 5 & 4 & Red wires & 367 & Fair. \\
\hline 14.4 & Bn. & 4. 346 & 8 & 4. 352 & 5 & 4 & Red wires & 367 & Fair. \\
\hline$\quad 14.4$ & $\mathrm{Hl}$. & 4. 340 & 8 & 4. 340 & 5 & 4 & Red wires & 367 & Fair-poor. \\
\hline$\quad 15.3$ & $\mathrm{Hl}$. & 4. 347 & 8 & 4. 346 & 5 & 4 & Red wires & 367 & Fair. \\
\hline 15.3 & H1. & $4 \cdot 344$ & 8 & 4. 357 & 5 & 4 & Red wires & 367 & $\left\{\begin{array}{l}\text { Fair-poor. } \\
\text { Clouds. }\end{array}\right.$ \\
\hline 16.4 & $\mathrm{Bn}$. & 4. 340 & 8 & 4. 347 & 5 & 4 & Red wires & 367 & Poor. \\
\hline 16. 4. & $\mathrm{Bn}$. & 4. 347 & 8 & 4. 351 & 5 & 4 & Red wires & 367 & Fair. \\
\hline 18.4 & Hl. & 4.345 & 8 & 4. 350 & 5 & 4 & Red wires & 367 & Fair-poor. \\
\hline Nov. 7.4 & Hl. & 4. 342 & 8 & 4. 352 & 5 & 4 & Red wires & 495 & Fair. \\
\hline
\end{tabular}

II. THE 12-INCH EQUATORIAL

A description of the 12-inch equatorial and accessories may be found in Publications of the United States Naval Observatory, Second Series, Volume VI, and part of the following data is taken therefrom.

The 12-inch objective (clear aperture 11.98 inches or $304.3 \mathrm{~mm}$.) made by Alvan Clark \& Sons has been in use since December 19, 1895. The focal length is approximately 15 feet. The distance between the crown and flint lenses, measured along the line joining their centers, is $0^{\text {in }} .0391 \pm$ as deduced by Prof. William Harkness.

The pier is situated 172 feet south and 276 feet east of the center of the clock room, the point which indicates the position of the observatory. The top of the pier is $461 / 2$ feet from the ground, and 2 feet below the floor under the instrument.

The mounting was constructed by SAEGMÜLLER.

The column is of cast iron and rises to a height of 8 feet above the floor. The casting which carries the polar axis is provided with means for adjustment in altitude and azimuth. The polar and declination axes are of steel. The polar axis is 3 feet long and 3 inches in diameter; the declination axis $31 / 2$ feet long and $21 / 2$ inches in diameter.

The tube is composed of seven sections of rolled sheet steel, in addition to a cast steel central section attached to the declination axis. It tapers from a diameter of 15 inches in the center to a diameter of 12 inches at the end. It contains diaphragms with apertures large enough to avoid cutting off the outer edge of the 
field of view of the low-power Huygenian eyepieces. Its length, excluding the draw tube, is 169 inches.

The hour and declination circles are graduated on silver to $30^{s}$ and $5^{\prime}$ respectively, and may be read to $1^{\mathrm{s}}$ in hour angle and $10^{\prime \prime}$ in declination by means of verniers. The diameter of the hour circle is $14 \% \frac{1}{16}$ inches and the diameter of the declination circle is $17 \% / 16$ inches.

The finder has an aperture of $4 \frac{1}{16}$ inches and a focal length of $461 / 2$ inches. The finder eyepiece has a magnifying power of 35 diameters and a field of view of $11 / 2^{\circ}$. In 1926 the finder was moved about $7 \frac{1}{2}$ inches toward the objective end of the 12-inch, leaving about 5 inches between the finder and the focal plane of the 12-inch. It was also made easier of adjustment in $\alpha$ and $\delta$ by relocating the finder posts and adding an extra screw to hold the finder more firmly in place. These changes were made by Mr. A. G. ILSE.

Attached to the south side of the column is a pair of dials, designed by Prof. William HARKNEss for approximate settings in right ascension and declination.

The driving clock has a double conical pendulum governor and is driven by a weight which is wound by hand. The driving clock has apparently never been satisfactory and a number of attempts have been made to improve it. The conical pendulum seems to be too small to govern the speed. Also the space within the column is only about $13 \frac{3}{4}$ inches in diameter and is too small for a much larger pendulum.

In July, 1916, a small transformer was placed in the 110-volt commercial lighting circuit and the voltage was reduced thereby, so that 3 to 4 volt lamps, each giving about 2 candlepower, could be used on the instrument. New brushes were made by Mr. ILsE to carry the current which lights the circles.

The micrometer was made by SAEgmüLler. On the fixed plate are five spider threads, called transit threads, or long threads, about $9^{\mathrm{s}} .1$ apart as determined by an equatorial star. At right angles to these and on the same plate is a short thread. The slide which is moved by the micrometer screw carries three short threads which are parallel to the fixed short thread.

The periodic and progressive errors of the screw are small and no corrections for them have been applied. The value of a revolution has been taken as $22^{\prime \prime} .8944$, from determinations by Professor See and Mr. Hammond.

It has been customary to use the micrometer in the position head up to prevent the pull of the spring against which the screw works from being counteracted by gravity, but in the determination of constants by the methods of Appendix III, Volume IV the micrometer was used both head up and head down.

During 1921-22 the 12-inch was equipped with an amplifier (Barlow lens), and an additional low power negative eyepiece (designated by $\mathrm{A}$ in Table II); also with adapters to render most of the negative eyepieces available for use with the amplifier. This apparatus practically doubles the focal length of the objective, thus increasing the magnifying powers of the large-field eyepieces. A large $90^{\circ}$ prism in a suitable mounting was secured at the same time for viewing objects near the zenith. These optical attachments, planned by Mr. Peters especially for visitors, were constructed by Mr. M. E. KAHLER and have proved to be convenient and satisfactory. 
INTRODUCTION

Following are data in regard to the eyepieces:

TABLE I.-Positive Eyepieces, 12-inch Equatorial

\begin{tabular}{|l|c|c|c|c|}
\hline Eyepiece & Power & Field & Maker & Type \\
\cline { 2 - 4 } & & \multicolumn{1}{|c|}{} & & \\
I & 115 & 21.0 & M. E. Kahler & Kellner. \\
II & 160 & 16.0 & M. E. Kahler & Kellner. \\
III & 235 & 12.4 & M. E. Kahler & Kellner. \\
IV & 335 & 8.0 & M. E. Kahler & Kellner. \\
V & 500 & 6.1 & M. E. Kahler & Kellner. \\
VI & 705 & 4.7 & M. E. Kahler & Kellner. \\
\hline
\end{tabular}

The magnifying powers in Table I are the means of determinations by Professor SEE and Mr. HAMmond, with the Ramsden dynameter.

TABLE II.-Negative Eyepieces, 12-inch Equatorial

\begin{tabular}{|c|c|c|c|c|}
\hline Eyepiece & Power & Field & Maker & Type \\
\hline & & , & & \\
\hline I & 37 & 66 & M. E. Kahler & Airy-Huygenian. \\
\hline II & 50 & 50 & M. E. Kahler & Airy-Huygenian. \\
\hline III & 85 & 33 & M. E. Kahler & Airy-Huygenian. \\
\hline IV & 118 & 26.5 & M. E. Kahler & Airy-Huygenian. \\
\hline $\mathrm{V}$ & 196 & 15. 6 & M. E. Kahler & Airy-Huygenian. \\
\hline VI & 258 & 9.2 & M. E. Kahler & Airy-Huygenian. \\
\hline VII & 314 & 6.8 & M. E. Kahler & Airy-Huygenian. \\
\hline VIII & 571 & 4.5 & M. E. Kahler & Airy-Huygenian. \\
\hline IX & 790 & 3.0 & M. E. Kahler & Airy-Huygenian. \\
\hline A & $\left\{\begin{array}{r}-162 \\
324^{1}\end{array}\right.$ & $\begin{array}{l}33.0 \\
16.2\end{array}$ & M. E. Kahler & Airy-Huygenian. \\
\hline
\end{tabular}

1 With amplifier.

The magnifying powers in Table II were determined with the Ramsden dynameter, the first 9 by Professor SEE and the last 2 by Mr. BOWER.

There are also two solar eyepieces-one Herschel prismatic, and one polarizing (John A. Brashear, No. 16).

The chronograph with the Hipp spring governor having produced a number of unsatisfactory records, it was decided to use a conical pendulum instead of the spring. The necessary changes in the chronograph were made by Mr. Rheinbold, and the chronograph records were somewhat improved. However, on account of further trouble this chronograph was replaced in 1926 by a Bausch and Lomb chronograph made after the Saegmüller pattern.

In $1926 \mathrm{Mr}$. ILSE attached a pair of weight-carrying rods to the telescope tube near the eye end in order that weights for balancing the instrument could be added upon removing the micrometer. Formerly the instrument was balanced, with respect to the declination axis only, by adjusting weights at the objective end. The weights may now be quickly and easily adjusted, and the operation of putting on and taking off the micrometer has been simplified.

$A$ double slide rheostat has been fastened to the tube at the eye end for regulating the two micrometer lamps; also a third contact ring was added to the $1757-29-5$ 
micrometer. One rheostat controls the lamp which illuminates the long threads; the other controls the lamp which illuminates the short threads, so that each set of threads may be illuminated independently of the other, or the two sets may be equalized in brightness. The same effect was before obtained roughly with one rheostat and two adjustable shutters, one for each lamp. The color of the threads when illuminated is red. Asteroids as faint as the eleventh magnitude may be observed. The estimated magnitude of Wratislavia observed in January, 1911, was 11.2.

Efforts to determine the constants of the 12-inch give results so discordant as to indicate some instability about the instrument; perhaps an insecurity in the clamps. Although no corrections on account of constants have been applied to the observations, the present practice of orienting the micrometer according to the parallel near the place of an observation practically eliminates the effect of the constants.

Following are the results of determinations of constants, the notation being the same as defined for the 26-inch (see p. 45):

The Instrumental Constants, 12-inch Equatorial

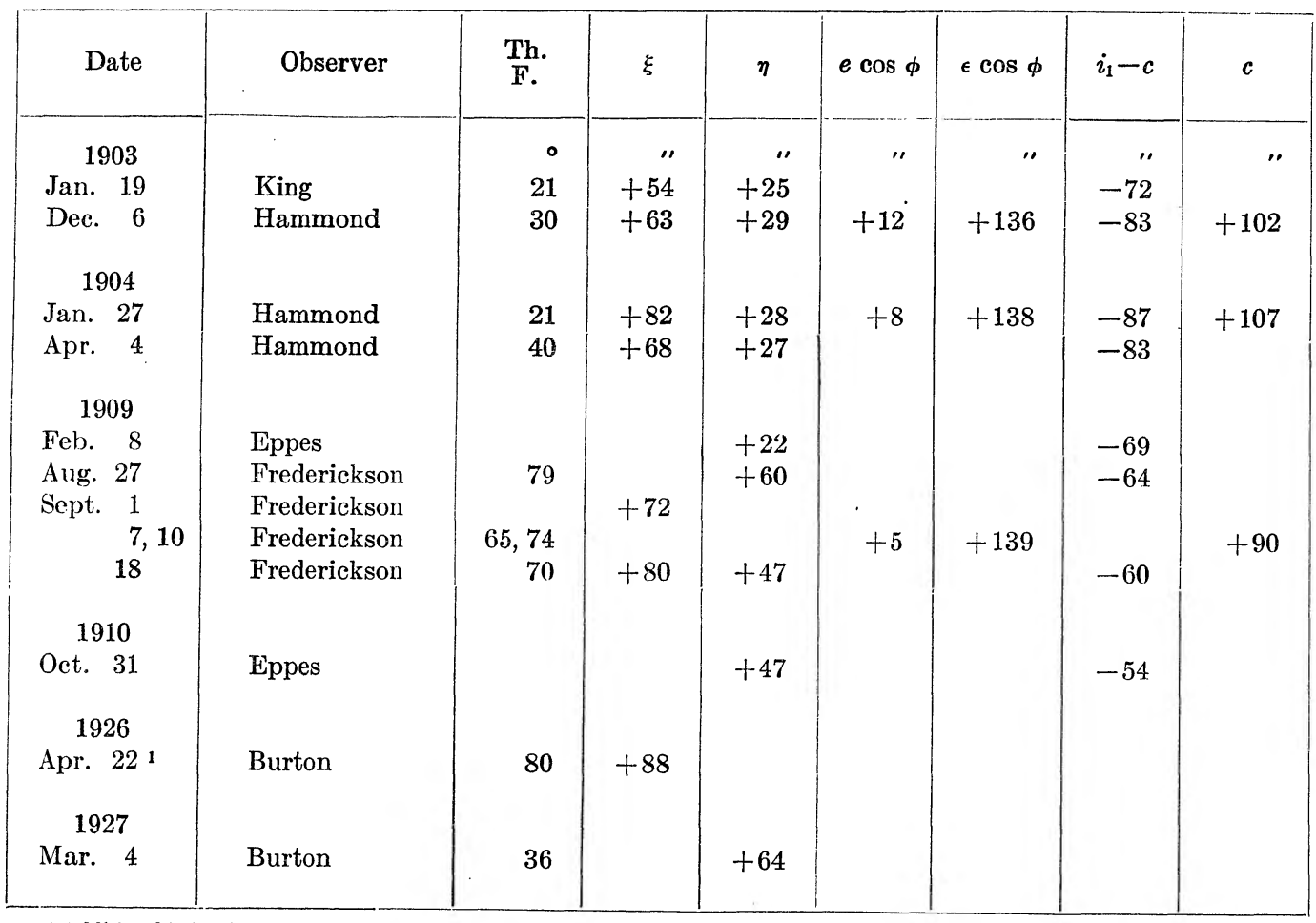

1 Additional balancing weights placed on instrument in 1926 prior to Apr. 22.

The last value of $\xi$ was determined by Professor SchaeberLe's method as described in the Astronomische Nachrichten No. 2374, and Campbell's Elements of Practical Astronomy, pages 215-217. The necessary apparatus was constructed by Mr. Ilse. 


\section{OBSERVATIONS AND REDUCTIONS}

The observations are arranged in sections as follows:
A. Observations of Satellites.
B. Observations of Diameters of Planets and Widths of Saturn's Rings.
C. Observations of Asteroids.
D. Observations of Comets.
E. Observations of Occultations.
F. Observations of Solar Eclipses and Transit of
Mercury.

G. Observations of Eclipses of Satellites of Jupiter and Saturn.

H. Observations of Double Stars.

I. Observations of Miscellaneous Stars, Novie, and Nebulæ.

J. Miscellaneous Observations.

The observations of each object are, for the most part, arranged in chronological order.

Corrections for differential refraction, and for the effect of instrumental constants, except for the 12-inch equatorial, were applied to the observations, and special corrections were applied when necessary.

Methods of correcting equatorial observations for differential refraction and instrumental constants may be found in Publications of the United States Naval Observatory, Second Series, Volume IV, Appendix III (Washington, 1905).

Discussions of satellite observations have been published in the Astronomical Journal as follows:

\begin{tabular}{|c|c|c|c|c|}
\hline Object & Author & A. J. & Period of Observations & Observer \\
\hline Satellites of Mars & Hall & No. 645 & $\begin{array}{l}1909 \text { Aug. } 23 \text {-Oct. } 16 \\
1908 \text { June } 4 \text {-Aug. } 2\end{array}$ & HI. \\
\hline Satellites of Uranus & Hall & 627 & $\begin{array}{l}1909 \text { Apr. 23-July } 20 \\
1910 \text { July 5-Aug. } 9\end{array}$ & Hl. \\
\hline Satellites of Uranus & Eppes & 648 & 1911 June 1-Sept. 13 & $\begin{array}{l}\text { Ep. } \\
\text { Bn. }\end{array}$ \\
\hline Satellite of Neptune & Hall & 654 & $\begin{array}{l}1911 \text { Jan. 28-Mar. } 31 \\
1911 \text { Jan. 30-Mar. } 30\end{array}$ & $\begin{array}{l}\mathrm{Hl} . \\
\mathrm{Bn} .\end{array}$ \\
\hline Satellite of Neptune & $\begin{array}{l}\text { Burton } \\
\text { Hall }\end{array}$ & 654 & 1911 Dec. 18-1912, Apr. 11 & $\mathrm{Bn}$. \\
\hline Satellites of Mars & $\begin{array}{l}\text { Lamson } \\
\text { Bower }\end{array}$ & 873 & 1924 July 19-Sept. 24 & $\begin{array}{l}\text { Hl. } \\
\text { B. }\end{array}$ \\
\hline
\end{tabular}

\section{A. OBSERVATIONS OF SATELLITES}

The observations are grouped in order of the distances of the planets from the Sun, beginning with the satellites of Mars and ending with the satellite of Neptune.

The Satellites of Mars.- The satellites of Mars have been observed as follows:

Phobos (at 6 Oppositions)

\begin{tabular}{|c|c|c|c|}
\hline Observed & Coordinates & $\begin{array}{l}\text { Number } \\
\text { of Obser- } \\
\text { vations }\end{array}$ & Observer \\
\hline 1909 Aug. 23-Oct. 16 & $\Delta \alpha \cos \delta, \Delta \delta$ & 53,56 & $\mathrm{Hl}$. \\
\hline 1911 Nov. 2-Dec. 19 & $\Delta a, \Delta d$ & $\begin{array}{r}24,26 \\
0,1\end{array}$ & $\begin{array}{l}\mathrm{Hl} \text {. } \\
\mathrm{Bn} .\end{array}$ \\
\hline 1913 Dec. $20-1914$ Jan. 15 & $\Delta a, \Delta d$ & 14,17 & $\mathrm{Bn}$. \\
\hline $1922\left\{\begin{array}{l}\text { May 29-May } 30 \\
\text { June 3-July } 6\end{array}\right.$ & $\begin{array}{l}\Delta \alpha \cos \delta, \Delta \delta \\
p, s\end{array}$ & $\begin{array}{l}3,4 \\
5,5\end{array}$ & $\begin{array}{l}\mathrm{Hl} . \\
\mathrm{Hl} \text {. }\end{array}$ \\
\hline 1924 July $19-$ Sept. 24 & $p, s$ & $\begin{array}{l}38,38 \\
26,25\end{array}$ & $\begin{array}{l}\text { Hl. } \\
\text { B. }\end{array}$ \\
\hline $1926\left\{\begin{array}{l}\text { Oct. } 4-\text { Dec. } 10 \\
\text { Oct. } 4 \text {-Dec. } 2\end{array}\right.$ & $\begin{array}{l}\Delta \alpha \cos \delta, \Delta \delta \\
p, s\end{array}$ & $\begin{array}{l}26,27 \\
15,15\end{array}$ & $\begin{array}{l}\mathrm{Bn} . \\
\mathrm{Hl} .\end{array}$ \\
\hline
\end{tabular}

Clark Micrometer II was used at the first three oppositions of Mars. The Repsold micrometer was used at the later oppositions except for an occasional observation. 
Deimos (at 7 Oppositions)

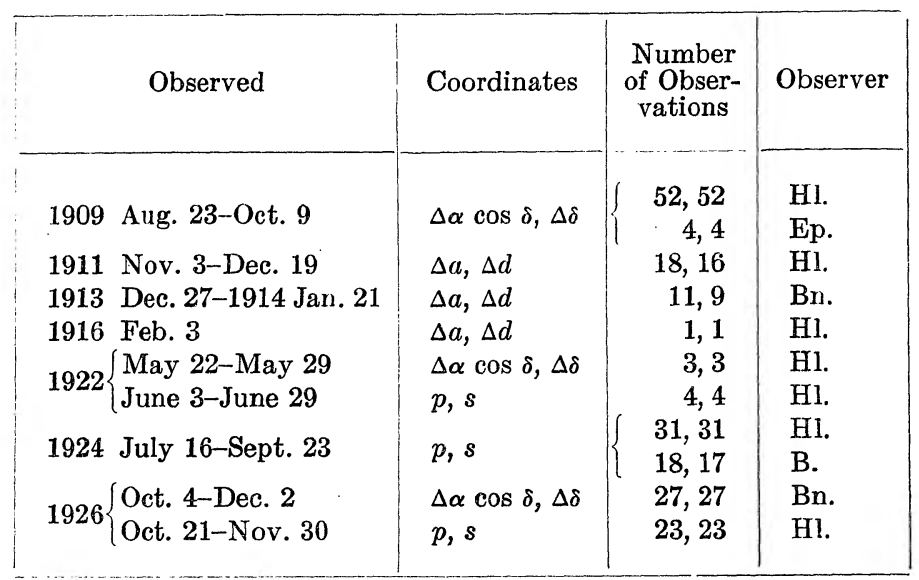

Clark Micrometer II was used at the first three oppositions of Mars. The Repsold micrometer was used at the later oppositions except for an occasional observation.

An observation of a satellite of Mars consisted usually of four measures in each of two coordinates, taking Mars as the origin, and was made with the driving clock running.

Three systems of coordinates were used:

(1) Parallel and perpendicular to the celestial equator, that is, $\Delta \alpha^{\circ} \cos \delta$ and $\Delta \delta$; $\Delta d$;

(2) Parallel and perpendicular to the equator of Mårs, indicated by $\Delta a$ and

(3) Position angle and distance, or $p$ and $s$.

In 1909 the measures were taken in the rectangular coordinates $\Delta \alpha \cos \delta$ and $\Delta \delta$. They were made with respect to the limbs of Mars, and were symmetrically arranged so that the means of the times of the measures with respect to two opposite limbs were nearly equal.

In addition to corrections for differential refraction and instrumental constants the following corrections were applied to the measures:

(1) For the phase of the planet, or defective illumination, to obtain coordinates referred to the planet's center;

(2) For the motion of the satellite, to reduce the mean of four measures to the mean of the corresponding times.

The data for phase corrections were taken from the British Nautical Almanac. The phase corrections $p_{\alpha}, p_{\delta}$ in $\Delta \alpha \cos \delta$ and $\Delta \delta$ are given by the formulæ

where

$$
\begin{aligned}
& p_{\alpha}=\frac{1}{4}\left(1-\sqrt{1-\sin ^{2} d \sin ^{2} Q}\right) \Delta=p_{1} \cdot \Delta \\
& p_{\delta}=\frac{1}{4}\left(1-\sqrt{1-\sin ^{2} d \cos ^{2} Q}\right) \Delta=p_{2} \cdot \Delta
\end{aligned}
$$

$$
\begin{aligned}
& \Delta=\text { the planet's apparent diameter (Mars considered spherical); } \\
& d=\text { the angle between the Earth and Sun as seen from the planet; } \\
& Q=\text { the position angle of the point of greatest defect. }
\end{aligned}
$$

A table was computed for the coefficient $1 / 4\left(1-\sqrt{1-\sin ^{2} d \sin ^{2} Q}\right)$ in which the arguments were $d$ and $Q$ for $p_{1}, d$ and $Q \pm 90^{\circ}$ for $p_{2}$. 
The sign of the correction in right ascension was taken positive when the planet transited after apparent midnight and negative if it transited before apparent midnight; the sign of the correction in declination was taken positive for values of $Q$ between $90^{\circ}$ and $270^{\circ}$, and negative for values greater than $270^{\circ}$ and less than $90^{\circ}$.

The corrections for motion $m_{a}, m_{\delta}$ were obtained from the formulæ

$$
\begin{aligned}
& m_{\alpha}=\left(\sec \frac{\theta}{2}-1\right) \Delta \alpha \cos \delta=F_{\alpha} \cdot \Delta \alpha \cos \delta \\
& m_{\delta}=\left(\sec \frac{\theta}{2}-1\right) \Delta \delta \quad=F_{\delta} \cdot \Delta \delta
\end{aligned}
$$

where, neglecting the eccentricity of the satellite's orbit, $\theta^{\circ}=$ the true angular distance described by the satellite in its orbit in the interval of time, $t$ minutes, between the first and fourth measures, or between the second and third measures.

For Phobos, $\theta=0^{\circ} .784 t$; for Deimos, $\theta=0^{\circ} .198 t$. Tables were constructed for the factor $\left(\sec \frac{\theta}{2}-1\right)$, the argument being $t$ in minutes and tenth minutes.

$M, m, W, w$ being differential-refraction coefficients from Appendix III, Volume IV, and $\lambda_{a}^{\circ}, \lambda_{\delta}^{\circ}$ small deviations from the correct orientation of the micrometer due to instrumental constants, the final values of the coordinates were

$$
\begin{aligned}
(\Delta \alpha \cos \delta)_{0} & =\Delta \alpha \cos \delta+M \cdot \Delta \alpha \cos \delta+F_{\alpha} \cdot \Delta \alpha \cos \delta+m \cdot \Delta \delta+\sin \lambda_{\alpha} \cdot \Delta \delta+p_{\alpha} \\
\Delta \delta_{0} & =\Delta \delta+W \cdot \Delta \delta+F_{\delta} \cdot \Delta \delta+w \cdot \Delta \alpha \cos \delta-\sin \lambda_{\delta} \cdot \Delta \alpha \cos \delta+p_{\delta}
\end{aligned}
$$

Eyepiece 3C (360 diameters) was used throughout for the observations of 1909 . One-half the eyepiece lens nearest the focal plane was covered with a semicircular piece of red glass behind which Mars was placed while the measures were being made. This arrangement had the effect of throwing Mars and the wire seen through the red glass slightly out of focus, but the focus was kept on the satellite. It would have been necessary to pull the eyepiece out a little to bring the planet into focus.

Red light was used for wire illumination. It was generally unnecessary to illuminate the wires, as they could be seen without illumination in the vicinity of Mars.

Periodic errors of the driving clock were troublesome and made the measures in $\Delta \alpha \cos \delta$ somewhat difficult; therefore these should be given, perhaps, less weight as compared with the measures of $\Delta \delta$.

The measures in 1911 were made in the coordinates $\Delta a$ and $\Delta d$, the position circle being set $0^{\circ}$ and $90^{\circ}$ from the position angle given by the British Nautical Almanac for the north end of the axis of rotation of Mars. A pair of fixed wires about $14^{\prime \prime}$ apart was used on Mars and a single movable wire on the satellite. The fixed wires were placed so as to make equal distances, not equal areas of light, between the fixed wires and the limbs. Four measures in a coordinate were usually made before turning the position circle for the other coordinate. The coincidence of the movable wire with the mean of the two fixed wires was obtained, and the difference between coincidence and the mean of four measures was regarded as a complete observation in one coordinate.

In 1911 two eyepieces were used - 3C with red glass and 3B (388 diameters). In front of the field lens of $3 \mathrm{~B}$ was mounted a circular piece of microscope cover glass, the surface of which was smoked and then cleaned, so as to leave a smoked 
semicircular portion behind which Mars was placed during the measures. The smoked glass was suggested by Assistant E. D. Tillyer.

The final values of the coordinates were

where

$$
\begin{gathered}
\Delta a_{\mathrm{o}}=\Delta a+\left(A+F_{\mathrm{a}}\right) \Delta a+\left(a+\sin \epsilon_{\mathrm{a}}\right) \Delta d+p_{\mathrm{a}} \\
\Delta d_{\mathrm{o}}=\Delta d+\left(d-\sin \epsilon_{\mathrm{d}}\right) \Delta a+\left(D+F_{\mathrm{d}}\right) \Delta d+p_{\mathrm{d}}
\end{gathered}
$$

$$
\begin{aligned}
& A=\frac{M+W}{2}+\frac{M-W}{2} \cos 2 P-\frac{m+w}{2} \sin 2 P \\
& a=\frac{M-W}{2} \sin 2 P+\frac{m+w}{2} \cos 2 P+\frac{m-w}{2} \\
& D=\frac{M+W}{2}-\frac{M-W}{2} \cos 2 P+\frac{m+w}{2} \sin 2 P \\
& d=\frac{M-W}{2} \sin 2 P+\frac{m+w}{2} \cos 2 P-\frac{m-w}{2} .
\end{aligned}
$$

$M, m, W, w$ were taken from the tables of differential refraction; $P$, the position angle of the north end of the rotation axis of Mars, was taken from the British Nautical Almanac.

$\mathrm{F}_{a}, \mathrm{~F}_{d}=$ factors depending upon the motion of the satellite, $=\sec \frac{\theta}{2}-1$, taking $\theta$ as defined for the reductions of 1909 .

$\epsilon_{a}, \epsilon_{d}=$ crrors in setting the position circle for the measures in $\Delta a$ and $\Delta d$, respectively $=S+\lambda_{\tau}-p^{\mathrm{e}} \mathrm{n}-P \pm 90^{\circ}$ and $S+\lambda_{\tau}-p_{\mathrm{m}}^{\mathrm{e}}-P$ in which

$\mathrm{S}=$ the reading of the position circle when the measures were made;

$\lambda_{\tau}=$ the instrumental correction depending upon the hour angle $\tau$ and the declination of Mars;

$\mathrm{P}=$ the position angle of the planet's rotation axis, as previously defined.

$p^{\circ}{ }_{m}=$ the standard parallel = the setting of the position circle determined by the trail of an equatorial star along the micrometer wire when the telescope was east of the pier and near the meridian.

When rectangular coordinates are measured the value of $p_{\mathrm{m}}^{\mathrm{e}}$ should be the mean of determinations made on both the fixed and movable short wires used in measuring. It has been found preferable to determine the parallel for the movable wire and derive the inclination of a fixed wire to the movable by taking coincidences; whence $p_{\text {m }}^{\mathrm{e}}$ for the mean is easily determined.

With Clark Micrometer II it was difficult to make a good determination of the parallel on the short wires, not only on account of the shortness of the wires but also on account of the lack of a transverse slide for the eyepiece. The parallel was usually taken on the central long wire and assumed to be practically equal to $90^{\circ}$ from the required parallel.

$p_{\mathrm{a}}, p_{\mathrm{d}}$ are corrections for the phase of Mars

$$
\begin{aligned}
& p_{\mathrm{a}}=1 / 4\left[1-\sqrt{1-\sin ^{2} d \sin ^{2}(Q-P)}\right] \Delta=p_{1} \cdot \Delta \\
& p_{\mathrm{d}}=1 / 4\left[1-\sqrt{1-\sin ^{2} d \cos ^{2}(Q-P)}\right] \Delta=p_{2} \cdot \Delta
\end{aligned}
$$

where $d, Q, P, \Delta$ are as previously defined for phase corrections.

$p_{1}$, tabulated for arguments $d$ and $Q-P$, was taken positive for values of $Q-P$ between $180^{\circ}$ and $360^{\circ} ; p_{2}$, taken from the same table with arguments $d$ and $Q-P$ $\pm 90^{\circ}$, was taken positive for values of $Q-P \pm 90^{\circ}$ between $90^{\circ}$ and $270^{\circ}$.

At the opposition of 1914 the satellites were again measured in $\Delta a$ and $\Delta d$. Single wires were used and the four measures in each coordinate were, with one exception (Dec. 20, 1st observation), arranged symmetrically, as in 1909. Eyepiece $3 \mathrm{C}$ with red glass was used throughout and focused on the wire which was used on the satellite. Black wires were used for Phobos, red or black for Deimos. 
In 1922 a few observations were obtained in $\Delta \alpha \cos \delta$ and $\Delta \delta$, the measures being made with respect to the limbs and arranged symmetrically, as to the times, that is, in the order $a, b, b, a$, where $a$ and $b$ were opposite limbs. Also a few observations were made in position angle and distance, $p$ and $s$.

When the measures were in $p$ and $s$ the illuminated portion of the disk was bisected, for both coordinates, by division into equal areas of light, practically the same as measuring from the estimated center of gravity of the illuminated disk. The measures were also symmetrically arranged so that the mean of the times of measures in position angle was equal approximately to the mean of the times of the distance measures.

Position angles were measured with one of the short fixed wires in order to use the box screw instead of the slow-motion handle which moves the telescope in declination. The micrometer was turned $90^{\circ}$ for the distance measures.

Eyepiece 3C with red glass attached was used throughout in 1922. Black wires were used for Phobos, red for Deimos.

The corrected values of $\Delta \alpha \cos \delta$ and $\Delta \delta$ were

$$
\begin{aligned}
(\Delta \alpha \cos \delta)_{0} & =\Delta \alpha \cos \delta+\left(M+F_{\alpha}\right) \Delta \alpha \cos \delta+\left(m+\sin \epsilon_{\alpha}\right) \Delta \delta+p_{\alpha} \\
\Delta \delta_{0} & =\Delta \delta+\left(w-\sin \epsilon_{\delta}\right) \Delta \alpha \cos \delta+\left(W+F_{\delta}\right) \Delta \delta+p_{\delta}
\end{aligned}
$$

in which $M ; m, w, W, F_{\alpha}, F_{\delta}, p_{\alpha}, p_{\delta}$ have the same meaning as in the reductions of $1909 ; \epsilon_{\alpha}, \epsilon_{\delta}=$ errors in setting the position circle for the measures in $\Delta \alpha \cos \delta$ and $\Delta \delta$, respectively, $=S+\lambda_{\tau}-p^{\mathrm{e}}{ }_{\mathrm{m}} \pm 90^{\circ}$ and $S+\lambda_{\tau}-p_{\mathrm{m}}^{\mathrm{e}}$, where $S, \lambda_{\tau}, p^{\mathrm{e}}{ }_{\mathrm{m}}$ are as defined for the reductions of 1911 .

The corrected values of $p$ and $s$ were

$$
\begin{aligned}
& p_{0}=p+\Delta p+\lambda+\left(90^{\circ}-p_{\mathrm{m}}^{\mathrm{e}}\right)+F_{\mathrm{p}}+\varphi_{\mathrm{p}} \\
& s_{\mathrm{o}}=s+\left[h+(\sec \epsilon-1)+F_{\mathrm{s}}\right] s+\varphi_{\mathrm{s}}
\end{aligned}
$$

$\Delta p, h$ are corrections for refraction from Volume IV, Appendix III; $\lambda=$ the correction for instrumental constants; $p_{\mathrm{m}}^{\mathrm{e}}=$ the standard parallel; $F_{\mathrm{p}}, F_{\mathrm{s}}=$ corrections for motion to reduce the mean of the measures to the mean of the corresponding times; $\epsilon=$ error in setting the position circle for measures in $s ; \varphi_{\mathrm{p}}, \varphi_{\mathrm{s}}=$ phase corrections. $F_{\mathrm{p}}$ was considered to be negligible.

$F_{\mathrm{s}}=\sec \frac{\theta}{2}-1$, taking $\theta$ as defined for the reductions of 1909 .

The phase corrections $\varphi_{\mathrm{p}}, \varphi_{\mathrm{s}}$ were given by the formulæ

$$
\begin{aligned}
s \sin \varphi_{\mathrm{p}} & =+\frac{4 q}{3 \pi} \sin (p-Q) \\
\varphi_{\mathrm{B}} & =-\frac{4 q}{3 \pi} \cos (p-Q)
\end{aligned}
$$

$p$ and $s$ are the observed position angle and distance, respectively; $Q$ is the position angle and $q$ the amount of the greatest defect of illumination (from the American Ephemeris or the British Nautical Almanac); and $\pi$ is the constant 3.1416.

The opposition of 1924 was favorable for observing the satellites, but owing to the southern declination of Mars there was considerable poor seeing.

The observations were all made in $p$ and $s$ and reduced mostly by the methods used for the opposition of 1922 . The position angles, including the correction for 
motion $F_{p}$, were reduced to the mean of the times of the distance measures. The method of the latter reduction, suggested by Mr. WiLlis, was as follows:

Let $F_{\mathrm{p}}^{\mathrm{p}}=$ the required reduction,

$a=$ the apparent semimajor axis of the satellite's orbit,

$b=$ the apparent semiminor axis,

$M=$ angle in real orbit between elongation and satellite, assuming $e=0$ ( $e=$ eccentricity);

$p^{\mathrm{c}}=$ corresponding angle in the apparent orbit, computed from $\tan p^{\mathrm{c}}=\frac{b}{a} \tan M$.

Let $p^{\mathrm{o}_{1}}, p^{\mathrm{o}}{ }_{2}, \cdots-p_{\mathrm{m}}^{\mathrm{o}}=$ observed angles and their mean;

$p^{c_{1}}, p^{c_{2}}, \cdots-p^{\mathrm{c}} \mathrm{m}=$ corresponding computed angles and their mean;

$p^{\mathrm{s}_{1}}, p^{\mathrm{s}_{2}}, \ldots-\cdots p_{\mathrm{m}}^{\mathrm{s}}=$ the observed angles and their mean transferred to a given epoch; $p_{s}^{\mathrm{c}}=$ corresponding computed angle at that epoch.

Then

Whence

$$
\begin{aligned}
& p^{o_{1}}+\left(p_{{ }_{\mathrm{B}}}^{\mathrm{c}}-p^{\mathrm{c}_{1}}\right)=p^{\mathrm{y}_{1}} \\
& p^{\mathrm{o}_{2}}+\left(p_{\mathrm{s}}^{\mathrm{c}}-p_{2} \mathrm{c}_{2}\right)=p_{\mathrm{s}}^{\mathrm{s}_{2}} \\
& \text { - - - - } \\
& p^{\mathrm{o}}+\left(p_{\mathrm{s}}^{\mathrm{c}}-p^{\mathrm{c}}{ }_{\mathrm{m}}\right)=p_{\mathrm{m}}^{\mathrm{s}}
\end{aligned}
$$

$$
F^{\mathrm{s}}{ }_{\mathrm{p}}=p_{\mathrm{s}}^{\mathrm{c}}-p^{\mathrm{c}}{ }_{\mathrm{m}} \text {. }
$$

The phase corrections $\varphi_{p}, \varphi_{s}$ were computed from the formulæ

and

$$
\sin \varphi_{\mathrm{p}}=\frac{+4 q}{3 \pi s_{\mathrm{p}}} \sin (p-Q), \text { or } \varphi_{\mathrm{p}}=+24.32 q \sin (p-Q)
$$

where

and

$$
\varphi_{\mathrm{s}}=\frac{-4 q}{3 \pi} \cos (p-Q)=-0.4244 q \cos (p-Q)
$$

$$
p=\text { the observed position angle }
$$

$$
s_{\mathrm{p}}=\text { the observed distance transferred to the time of } p \text {. }
$$

$Q, q$, and $\pi$ are as previously defined.

$s_{\mathrm{p}}$ is given by the formula

where

$$
s_{\mathrm{p}}=s_{\mathrm{s}} \frac{\cos M_{\mathrm{p}}}{\cos p_{\mathrm{p}}} \frac{\cos p_{\mathrm{s}}}{\cos M_{\mathrm{s}}}=a \frac{\cos M_{\mathrm{p}}}{\cos p_{\mathrm{p}}}
$$

and

$$
M_{\mathrm{p}}, M_{\mathrm{s}}=\text { angles in real orbit }
$$

$p_{\mathbf{p}}, p_{\mathbf{s}}=$ angles in apparent orbit, between elongation and satellite at the times of $p$ and $s$, respectively.

$$
s_{s}=\text { the observed distance. }
$$

Eyepiece 3C with red glass attached was used throughout the opposition of 1924. Black wires were generally used on Phobos, black or red on Deimos.

The position angles were measured with the middle short movable wire $\mathbf{M}_{6}$, the settings being made with the micrometer screw together with the slow-motion tangent screw which rotates the micrometer. This method is convenient and the parallel may be well determined on $\mathrm{M}_{6}$.

The correction to be applied to measures in rectangular coordinates, or distance measures, for the motion of a satellite, neglecting eccentricity, has usually been obtained by means of tables intended to be used when the measures were made in pairs, as in 1909. Following is the development of a process of approximately correcting for motion when the measures were not made in pairs.

In the apparent elliptical orbit of a satellite:

Let $X_{0}, Y_{0}=$ the satellite's rectangular coordinates taken parallel and perpendicular, respectively, to the major axis of the apparent ellipse with the center of the planet as origin.

$a, b=$ the semimajor and semiminor axes of the apparent ellipse. 
$\theta=$ the uniformly varying angle in the plane of the true circular orbit at the center of the planet between the satellite and elongation.

Then $X_{0}=a \cos \theta$ and $Y_{0}=b \sin \theta$.

Let $x_{1}, x_{2},---x_{\mathrm{n}}=\mathrm{a}$ set of measures of any linear coordinate, and $t_{1}, t_{2},---t_{\mathrm{n}}=$ the corresponding times.

Let $x=\frac{1}{n}\left(x_{1}+x_{2}+--+x_{n}\right)$

$t_{\mathrm{o}}=\frac{1}{n}\left(t_{1}+t_{2}+--+t_{\mathrm{n}}\right)$

$x_{\mathrm{o}}=$ the corrected coordinate which corresponds to $t_{0}$.

$\gamma=$ the angle between the major axis of the apparent ellipse and the direction in which the measures were made; this angle is assumed to be constant during the observation.

Let $\theta$ (previously defined) correspond to $t_{\mathrm{o}}$.

$\theta^{\prime}=$ rate of change of $\theta$.

$\beta_{1}=\left(t_{1}-t_{\mathrm{o}}\right) \theta^{\prime}, \beta_{2}=\left(t_{2}-t_{\mathrm{o}}\right) \theta^{\prime}, \cdots-\beta_{\mathrm{n}}=\left(t_{\mathrm{n}}-t_{\mathrm{o}}\right) \theta^{\prime}$.

$X_{1}=a \cos \left(\theta+\beta_{1}\right) \quad Y_{1}=b \sin \left(\theta+\beta_{1}\right)$

$X_{2}=a \cos \left(\theta+\beta_{2}\right) \quad Y_{2}=b \sin \left(\theta+\beta_{2}\right)$

$\bar{X}=a \cos (\theta+\beta) \quad \bar{Y}=b \sin \left(\theta+\beta_{B}\right)$

Then $x_{\mathrm{o}}=X_{\mathrm{o}} \cos \gamma-Y_{\mathrm{o}} \sin \gamma$

and $x_{1}=X_{1} \cos \gamma-Y_{1} \sin \gamma$

$=a \cos \left(\theta+\beta_{1}\right) \cos \gamma-b \sin \left(\theta+\beta_{1}\right) \sin \gamma$

$=a \cos \theta \cos \beta_{1} \cos \gamma-a \sin \theta \sin \beta_{1} \cos \gamma-b \sin \theta \cos \beta_{1} \sin \gamma-b \cos \theta \sin \beta_{1} \sin \gamma$

$=x_{\mathrm{o}} \cos \beta_{1}-c \sin \beta_{1}$

where $\quad c=a \sin \theta \cos \gamma+b \cos \theta \sin \gamma$.

Therefore $x_{0}=x_{1}$ sec $\beta_{1}+c \tan \beta_{1}$.

Similarly $x_{0}=x_{2} \sec \beta_{2}+c \tan \beta_{2}$.

$$
-\cdots----\cdots-
$$

$x_{\mathrm{o}}=x_{\mathrm{n}} \sec \beta_{\mathrm{n}}+c \tan \beta_{\mathrm{n}}$

Whence $n x_{0}=x_{1} \sec \beta_{1}+x_{2} \sec \beta_{2}+--+x_{n} \sec \beta_{n}+c\left(\tan \beta_{1}+\tan \beta_{2}+\cdots-+\tan \beta_{n}\right)$.

If third order terms in the expansions of $\tan \beta_{1}, \tan \beta_{2},----\tan \beta_{\mathrm{n}}$ be neglected, the term containing $c$ may be omitted, since $\beta_{1}+\beta_{2}+--+\beta_{\mathrm{n}}=0$.

Neglecting also the small differences between $x_{1}, x_{2},---x_{\mathrm{n}}$ and $x$

$$
\begin{aligned}
n x_{\mathrm{o}} & =x\left(\sec \beta_{1}+\sec \beta_{2}+--+\sec \beta_{\mathrm{n}}\right) \\
& =n x+\left[\left(\sec \beta_{1}-1\right)+\left(\sec \beta_{2}-1\right)+--+\left(\sec \beta_{\mathrm{n}}-1\right) \mid x .\right.
\end{aligned}
$$

Let $\sec \beta_{1}-\stackrel{\circ}{1}=F_{1}$, sec $\beta_{2}-1=F_{2},---\sec \beta_{\mathrm{n}}-1=F_{\mathrm{n}}$ and $\frac{1}{n}\left(F_{1}+F_{2}+---+F_{\mathrm{n}}^{\prime}\right)=F_{\mathrm{x}}^{\prime}$.

Then $x_{0}=x+F_{\mathrm{x}} x$.

This process becomes rigorous when applied to a pair of measures and is practically the same as heretofore employed when the measures were made in pairs.

Satellite VI of Jupiter has been observed as follows:

\begin{tabular}{|l|c|c|}
\hline \multicolumn{1}{|c|}{ Observed } & $\begin{array}{c}\text { Number } \\
\text { of Obser- } \\
\text { vations }\end{array}$ & Observer \\
\hline 1909 Apr. 9-Apr. 23 & 6 & Fn. \\
1910 Apr. 8-Apr. 13 & 3 & Ep. \\
1911 Mar. 24-June 1 & 5 & Ep. \\
1912 Apr. 23-June 8 & 5 & Bn. \\
1913 June 5-July 7 & 5 & Bn. \\
1914 Sept. 14-Sept. 22 & 3 & Bn. \\
1915 Oct. 27-Oct. 29 & 4 & Bn. \\
1918 Dec. 2-1919, Jan. 31 & 4 & Bn. \\
1922 May 29 & 1 & B. \\
1923 Apr. 18 & 1 & B. \\
1926 Aug. 30-Sept. 11 & 3 & Bn. \\
& & \\
\hline
\end{tabular}

Satellite VI is usually difficult, especially for southern declinations of Jupiter, but attempts are made to secure at least three observations at an opposition. The position of the satellite was determined with reference to a star by measuring $\Delta \alpha$ 
and $\Delta \delta$ by transits, or $\Delta \alpha \cos \delta$ and $\Delta \delta$ with the driving clock running. Red light (ruby or darker) was used for wire illumination. Eyepieces AF 54 (183 diameters), 3 B (388 diameters), and AF 27 (367 diameters), were used. The lowest power permits the use of five transit threads without sliding the eyepiece; the other two powers will give three transit wires. No attempt was made to slide the eyepiece during transits on account of the difficulty of keeping the satellite in sight.

For comparisons by transits the comparison star was usually chosen as near in declination as possible to make the corrections for differential refraction and instrumental constants small, and to eliminate practically any error due to the transit wires not being parallel. The micrometer was set $90^{\circ}$ from the parallel taken on the middle long wire $T_{3}$. The time of transit of the satellite over $T_{3}$ was taken as the time of the observation.

The Satellites of Saturn.--Eight satellites were observed in pairs, the coordinates usually being $p$ and $s$ (sometimes $\Delta \alpha$ and $\Delta \delta$ in the case of Titan-Hyperion and Titan-Japetus). When $\Delta \alpha$ and $\Delta \delta$ were measured the time of the transit of Titan was taken as the time of observation and the measures were then corrected for the motions of Saturn and the outer satellite during the interval $\Delta \alpha$.

The satellites, except Hyperion, were generally observed with bright field illumination, and a prism eyepiece was often used, as shown in the list of observations. When an eyepiece with prism was used the short wires were placed apparently vertical for distance measures, and the wire, either long or short, used for angle measures was generally placed apparently vertical. An eyepiece with occulting strip attached was sometimes employed to screen Saturn when the fainter satellites were being observed.

Satellites were observed in pairs as follows:

\begin{tabular}{|c|c|c|c|}
\hline Pair & Observed & $\begin{array}{l}\text { Number of } \\
\text { Observations }\end{array}$ & Observer \\
\hline \multirow{6}{*}{ Tethys-Mimas_- } & 1908 Aug. 29-Sept. 30 & 6,6 & Hd. \\
\hline & 1910 Sept. $12-$ Oct. 18 & 4,4 & $\mathrm{Hl}$. \\
\hline & 1911 Sept. 6-Dec. 19 & 11,10 & Bn. \\
\hline & 1912 Sept. 20-1913 Jan. 14 & 19,19 & Bn. \\
\hline & 1914 Oct. $2-1915$ Mar. 13 & 19,19 & $\mathrm{Hl}$. \\
\hline & 1915 Nov. 9-1916 Feb. $3 \ldots$ & 5,5 & $\mathrm{Hl}$. \\
\hline \multirow[t]{6}{*}{ Rhea-Mimas......... } & 1908 Aug. 29-Sept. 30 & 6,6 & Hd. \\
\hline & 1910 Oct. 17 & 1,1 & Hl. \\
\hline & 1911 Sept. 6-Nov. 16 & 9,9 & Bn. \\
\hline & 1912 Sept. 20-1913 Jan. 14 & 18,18 & Bn. \\
\hline & 1914 Nov. 23-1915 Mar. 13 & 20,20 & $\mathrm{Hl}$. \\
\hline & 1915 Nov. 3-Dec. 6 & 4,4 & Hl. \\
\hline \multirow[t]{6}{*}{ Tethys-Enceladus..... } & 1908 Aug. 29-Oct. 14 & 13,13 & Hd. \\
\hline & 1909 Oct. 20-Dec. 6 & 6,6 & $\mathrm{Hl}$. \\
\hline & 1910 Sept. 12-1911 Jan. 6 $\ldots \ldots$ & 13,13 & Hl. \\
\hline & 1911 Sept. 6-Dec. 5 & 16,16 & $\mathrm{Hl}$. \\
\hline & 1912 Oct. 1-1913 Jan. 4 & 20,20 & Bn. \\
\hline & 1914 Sept. 26-1915 Mar. 31 & 61,61 & HI. \\
\hline \multirow[t]{6}{*}{ Dione-Tethys... } & 1908 Aug. $29 \div$ Oct. 14 & 16,16 & Hd. \\
\hline & 1909 Sept. 2-Dec. 20 & 16,17 & $\mathrm{Hl}$. \\
\hline & 1910 Sept. 7-1911 Jan. 6 $\ldots \ldots$ & 13,13 & $\mathrm{Hl}$. \\
\hline & 1911 Sept. 12-Nov. $30 \ldots \ldots$ & 20,20 & Bn. \\
\hline & 1912 Oct. 1-1913 Feb. $1 \ldots$ & 23,23 & Bn. \\
\hline & 1914 Sept. 26-1915 Apr. 7 & 67,67 & $\mathrm{Hl}$. \\
\hline
\end{tabular}




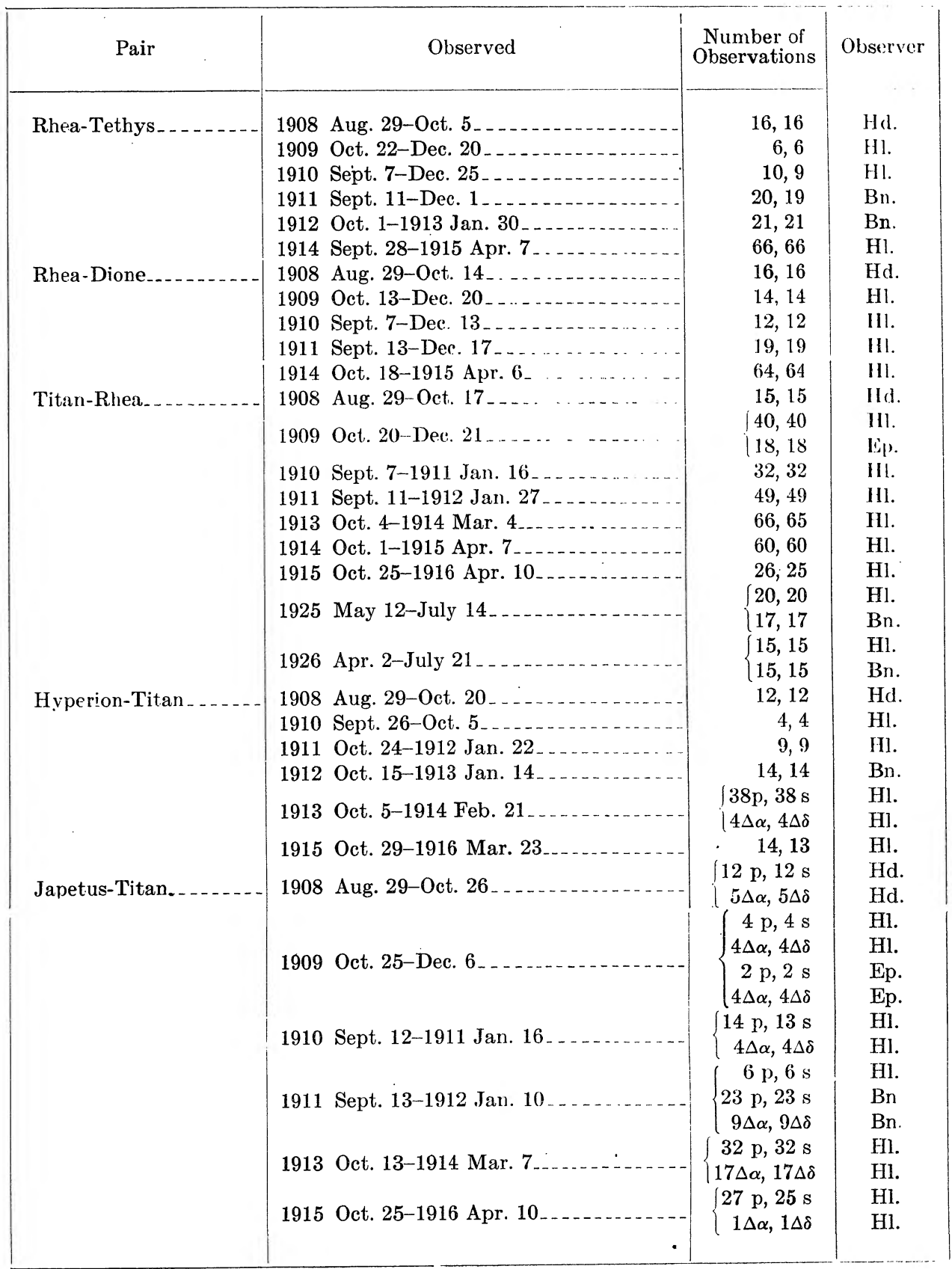


The Satellites of Uranus.-These satellites were observed in position angle and distance as follows:

\begin{tabular}{|c|c|c|c|}
\hline Combination & Observed & $\begin{array}{l}\text { Number of } \\
\text { Observations }\end{array}$ & Observer \\
\hline \multirow{7}{*}{ Titania-Uranus_- } & 1908 June 4-Aug. 1... & 11,10 & Hl. \\
\hline & 1909 Apr. 23-July 19_. & 15,15 & Hl. \\
\hline & 1910 July 5-Aug. 9 _.. & 7,7 & Hl. \\
\hline & 1911 June 1-Sept. 13... & 16,16 & Ep. \\
\hline & 1920 Aug. 8-Nov. 13 & 13,13 & Hl. \\
\hline & 1921 Aug. 25-Nov. 25 & $\begin{aligned} 11,11 \\
2\end{aligned}$ & HI. \\
\hline & 1922 Aug. 21-Sept. 26... & $\left\{\begin{array}{l}2,2 \\
3,3\end{array}\right.$ & B. \\
\hline \multirow[t]{6}{*}{ Oberon-Uranus... } & 1909 Apr. 26-July $20 \ldots$ & 19,15 & $\mathrm{Hl}$. \\
\hline & 1910 July 9-Aug. $9 \ldots$ & $\begin{array}{r}6,6 \\
8\end{array}$ & H1. \\
\hline & 1911 June 9-Sept. 12 & $\left\{\begin{array}{l}8,8 \\
9,9\end{array}\right.$ & $\begin{array}{l}\text { Bn. } \\
\text { Ep. }\end{array}$ \\
\hline & 1920 Aug. 26-Nov. 13 & 12,12 & Hl. \\
\hline & 1921 Aug. 24-Nov. 25 & 10,10 & Hl. \\
\hline & 1922 Aug. 15-Sept. 26 & $\left\{\begin{array}{l}3,3 \\
3,3\end{array}\right.$ & $\begin{array}{l}\text { Hi. } \\
\text { B. }\end{array}$ \\
\hline \multirow[t]{2}{*}{ Oberon-Titania.. } & 1908 June 7 -Aug. $2 \ldots$ & 11,11 & Hl. \\
\hline & 1910 July 5-Aug. 5 & 4,4 & Hl. \\
\hline Ariel-Uranus.... & 1921 Aug. 29 & 1,1 & Hl. \\
\hline Titania-Umbriel. & 1911 July 19-July $27 \ldots \ldots$ & 3,3 & Ep. \\
\hline Oberon-Umbriel_ & 1911 July 27-Sept. 13 $\ldots \ldots \ldots$ & 4,4 & Ep. \\
\hline Oberon-Ariel_.... & 1911 July $31 \ldots$ & $1, \cdot 1$ & Ep. \\
\hline Titania-Ariel.... & 1911 Sept. 13 & 1,1 & Ep. \\
\hline
\end{tabular}

The planet being far south, the satellites of Uranus were usually observed within about $1 \frac{1}{4}$ hours from the meridian. The seeing was somewhat improved when the planet was near the meridian. The satellites were faint and could be observed only on very clear nights. Single red wires were used at all oppositions except 1911.

In 1911 double movable red wires about $6^{\prime \prime}$ apart were employed in the distance measures with respect to the planet, and a single wire in the measures of position angle. In the distance measures with respect to the planet bisections were made on the satellite with the double wires, the planet being bisected with a single wire. When the satellites were measured in pairs double wires were generally used on the fainter. Single wires were employed for Umbriel-Titania on July 19.

The micrometer was turned $180^{\circ}$ for half the measures in a set in order to eliminate the necessity of taking readings for coincidence of the movable and fixed threads, although a small error was likely on account of the coincidence varying with the tension on the micrometer-screw spring when the micrometer was reversed. It was the intention to try a reversing prism in connection with the double threads, but on account of the faintness of the satellites and loss of light the prism was found to be undesirable and was used only twice.

When the satellites of Uranus were measured in pairs the planet was usually placed behind a narrow strip of black paper pasted on the field lens of the eyepiece. 
The Satellite of Neptune.-Observations were obtained in position angle and distance with respect to the center of Neptune as follows:

\begin{tabular}{|c|c|c|}
\hline Observed & $\begin{array}{l}\text { Number of } \\
\text { Observations }\end{array}$ & Observer \\
\hline 1908 Dec. 2-1909 Mar. $26 \ldots$ & 27,25 & HI. \\
\hline 1909 Dec. 9-1910 Apr. $14 \ldots \ldots$ & 32,29 & HI. \\
\hline 1911 Jan. 28-Mar. $31 \ldots$ & 19,16 & Hl. \\
\hline 1911 Jan. 28-1nar. $01 \ldots . . . .$. & 20,19 & Bn. \\
\hline 1911 Dec. 18-1912 Apr. 11 & 85,85 & Bn. \\
\hline 1912 Dec. 9-1913 May $8 \ldots$ & $\left\{\begin{array}{l}37,37 \\
59,59\end{array}\right.$ & $\mathrm{Hl}$. \\
\hline 1918 Dec. $17-1919$ Apr. $2 \ldots$ & $\begin{array}{r}59,59 \\
47,47\end{array}$ & $\begin{array}{l}\text { Bn. } \\
\text { Hl. }\end{array}$ \\
\hline 1919 Nov. 5-1920 May 4 & 26,26 & H.l. \\
\hline 1920 Dec. 14-1921 Apr. 11 & 23,23 & Hl. \\
\hline 1921 Dec. 19-1922 Apr. $22 \ldots$ & $\left\{\begin{array}{l}3,3 \\
3,3\end{array}\right.$ & $\begin{array}{l}\text { Hl. } \\
\text { B. }\end{array}$ \\
\hline 1923 Feb. 21-May 19 & 12,12 & Hl. \\
\hline 1925 Feb. 18-Apr. 13 & 11,11 & Hl. \\
\hline 1926 Jan. 20-May 5 & 5,5 & Hl. \\
\hline
\end{tabular}

Comparison of the elements of the satellite of Neptune derived from the observations at the oppositions of 1908-09 and 1909-10 with the elements in the Connaissance des Temps seemed to show a large personal equation in distance measures which were made with single red wires. In the measures of position angle a single red wire was passed through the center of the disk and the satellite. It was suspected that there might be a systematic error, due to unsymmetrical illumination of the short wires, in the case of Clark Micrometer II. In the Repsold micrometer the illumination is supposed to be symmetrical.

At the oppositions of $1910-11$ and 1912-13 double movable wires about $6^{\prime \prime}$ apart were used as described under the satellites of Uranus. It was the intention to use a reversing prism, but this was found to be possible only when the seeing was fine. At the other oppositions single wires were used, as in 1908-09. Single wires seem to be preferable to double for measuring very faint objects.

In general, a dark shade of red was preferred for bright wire illumination. Various colors were tried, but the red seemed to interfere less with the visibility of faint objects.

The eyepieces employed in observing faint objects were low or medium powers.

There were few nights when the seeing was good enough to permit the use of an eyepiece such as $8 \mathrm{C}$ (power 771). Eyepieces with friction fit were preferred to those with the screw-thread arrangement for focusing. 


\section{B. OBSERVATIONS OF DIAMETERS OF PLANETS AND WIDTHS OF SATURN'S RINGS}

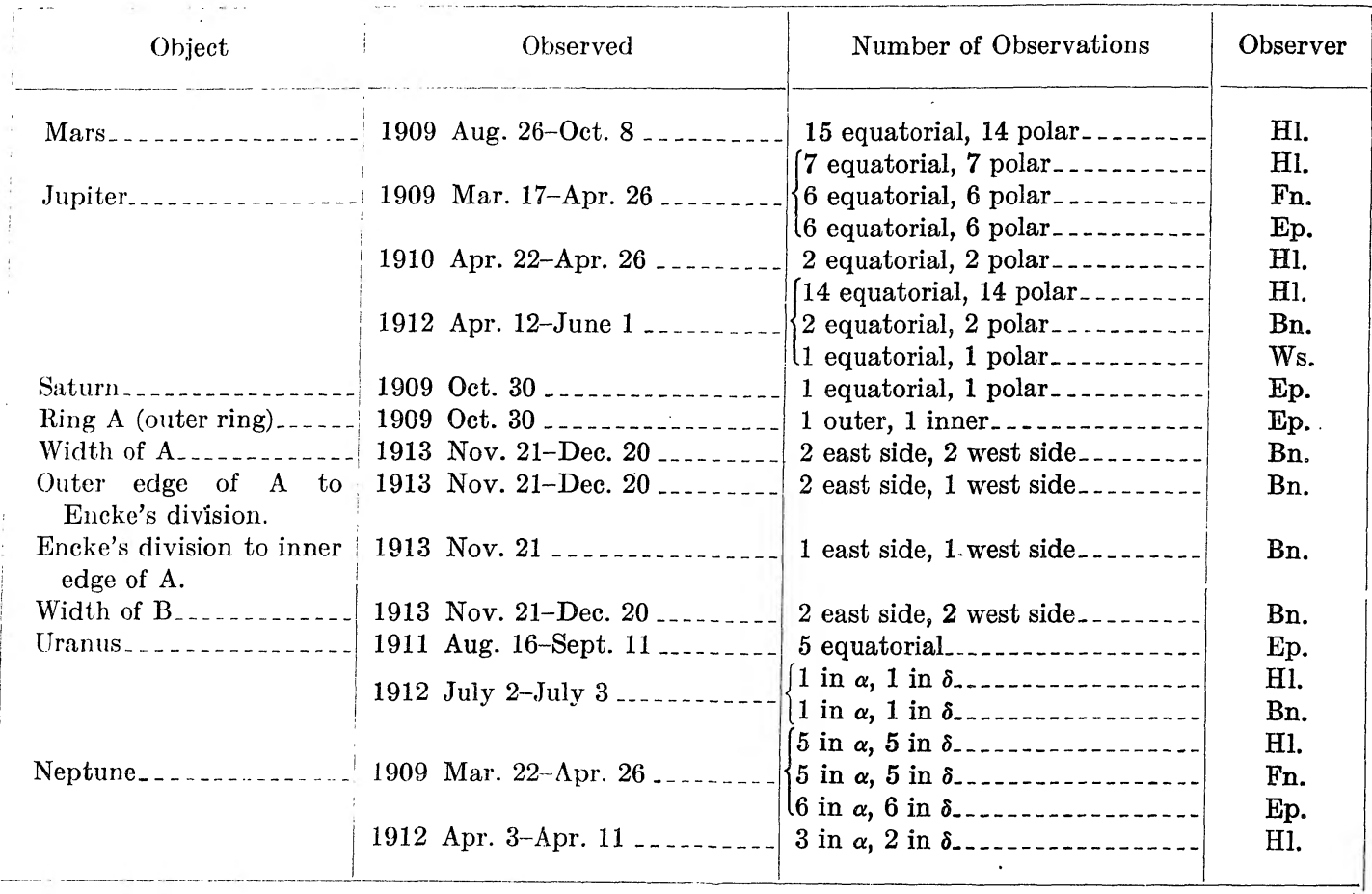

The observed values of all diameters were decreased by $0^{\prime \prime} .131$, the average thickness of a spider wire, and reduced to unit distance.

Mars and Jupiter.-In addition to corrections for differential refraction, the observations were corrected for phase. Observations of the polar diameter were corrected also for inclination of the planet's equator to the line of sight. The equatorial diameter, $2 a$, as corrected for phase is

$$
2 a=\frac{2 m}{1+\sqrt{1-\sin ^{2} d \sin ^{2}(Q-P)}}=p_{\mathrm{D}} \cdot m
$$

(planet considered spherical), where $m=$ measured diameter.

$d, Q, P$ are as previously defined in connection with the satellites of Mars.

A table with arguments $d$ and $Q-P$ was formed giving $\log p_{\mathrm{D}}$ in units of the fifth decimal place.

For the polar diameter the same table was used with the arguments $d$ and $Q-P \pm 90^{\circ}$.

The correction to the measured polar diameter for inclination was $-(2 a-2 \rho) \tan ^{2} B$, where

$$
\begin{aligned}
2 a & =\text { observed equatorial diameter. } \\
2 \rho & =\text { measured polar diameter. } \\
B & =\text { planetocentric declination of Earth. }
\end{aligned}
$$

The polar diameter, $2 b$, was then $2 b=p_{\mathrm{D}} \cdot 2 \rho-(2 a-2 p) \tan ^{2} B$.

The quantities $d, Q, P$, and $B$ were taken from the British Nautical Almanac. 
Saturn and Rings.-The correction for differential refraction was applied, but the phase correction and correction for inclination were omitted.

In the observations by BuRTon the attempt was made to set the wires on the limbs instead of tangent to them, thereby eliminating the correction for thickness of threads. This correction was therefore not applied.

The rings were measured along the major axis, the setting being taken from the American Ephemeris. The outer ring is designated by $A$ and the middle ring by $B$.

Uranus.-In 1911 the equatorial diameter of Uranus was measured, assuming the plane of the equator to be very nearly at right angles to the mean of the position angles given in the Connaissance des Temps for the poles of the satellites' orbits. The planet was not in a good position for measures of the polar diameter. In 1912 diameters were measured in the direction of both right ascension and declination. The phase correction was negligible, and the corrections for differential refraction were only about $0^{\prime \prime} .001$ to $0^{\prime \prime} .005$.

Neptune.-All measures of diameters of Neptune were in the direction of both right ascension and declination. Corrections for phase and differential refraction were of about the same order as for Uranus.

\section{OBSERVATIONS OF ASTEROIDS}

The observations of each object are printed in chronological order. The observations were made either by transits or with the driving clock running, as described under Satellite VI of Jupiter.

The asteroids are arranged in order of the numbers assigned by the Astronomischen Rechen-Institut, which is in general the order of discovery. In a few instances the numbers to be assigned are not at hand.

A number of asteroids were observed at the request of Rev. J. H. Metcalf of Winchester, Mass. Nos. (55) and (127) were observed for Prof. D. T. Wilson of the Case School of Applied Science, Cleveland, Ohio. Observations of (288) Glauke were obtained for the Bilk Observatory, Dusseldorf, Germany. A request for observations of asteroids belonging to the Jupiter group was received from Prof. Eurs Stromgren of the University of Copenhagen, and some of these were observed. An ephemeris furnished by Miss Julie M. Vinter Hansen of the Copenhagen University Observatory was used in finding (588) Achilles. 
One hundred and nineteen asteroids were observed, as follows:

\begin{tabular}{|c|c|c|c|c|}
\hline & Asteroid & Observed & $\begin{array}{c}\text { Number of } \\
\text { Observations }\end{array}$ & Observer \\
\hline \multirow[t]{3}{*}{ (1) } & Ceres.... . & 1915 Oct. $28 \ldots$ & 1. & B. \\
\hline & & 1917 Mar. 19-25 _.... & 3 & C. \\
\hline & & 1923 June 9-Sept. 17.. & 9 & B. \\
\hline \multirow[t]{2}{*}{$(2)$} & Pallas.. & 1914 June 30 & 1 & B. \\
\hline & & 1923 Apr. 9-16 & 3 & B. \\
\hline \multirow[t]{3}{*}{ (3) } & Juno $\ldots$ & 1915 Mar. $10-17 \ldots$ & 2 & Wr. \\
\hline & & 1917 July 23-Aug. 13 & 3 & C. \\
\hline & & 1923 Apr. 26 & 1 & B. \\
\hline \multirow[t]{4}{*}{ (4) } & Vesta & 1912 Mar. 10-Apr. 6.- & 3 & Ws. \\
\hline & & 1915 Feb. 8-27 & 3 & Wr. \\
\hline & & 1916 Apr. 15-May 31 & 3 & B. \\
\hline & & 1917 Aug. 25-Oct. 15 & 4 & C. \\
\hline (5) & Astraea & 1917 Mar. 24-25 & 2 & C. \\
\hline (7) & Iris _..... & 1917 July 23-Aug. 13 & 3 & C. \\
\hline$(8)$ & Flora $\ldots \ldots$ & 1917 Mar. 9 & 1 & C. \\
\hline (11) & Parthenope & 1916 Sept. $17-20 \ldots$ & 4 & C. \\
\hline \multirow[t]{2}{*}{ (13) } & Egeria $\ldots . .$. & 1910 Apr. 2-14 & 3 & $\mathrm{Bn}$. \\
\hline & & 1916 Oct. $6-10$ & 2 & C. \\
\hline \multirow[t]{2}{*}{$(15)$} & Eunomia.. & 1916 Sept. 9-Oct. 6 & 6 & C. \\
\hline & & 1918 Feb. 28 & 1 & C. \\
\hline (16) & Psyche & 1909 July 28 & 1 & Fn. \\
\hline \multirow[t]{3}{*}{ (19) } & Fortuna & 1908 Apr. 6-20 & 5 & Fn. \\
\hline & & 1909 July 24-Aug. 7_- & 2 & Ep. \\
\hline & & 1917 Sept. 19-Oct. 15_ & 3 & C. \\
\hline \multirow[t]{2}{*}{$(22)$} & Kalliope & 1909 Apr. 16-26 & 3 & Ep. \\
\hline & & 1916 Oct. $10-27$ & 2 & C. \\
\hline \multirow[t]{2}{*}{$(28)$} & Bellona_. & 1908 Dec. $18-20$ & 3 & Ep. \\
\hline & & 1910 Apr. 30-May $4 \ldots$ & 2 & $\mathrm{Bn}$. \\
\hline$(29)$ & Amphitrite. & 1917 Oct. 6 -Nov. 17 & 2 & C. \\
\hline (33) & Polyhymnia. & 1917 Sept. 17-Oct. 15 & 4 & C. \\
\hline \multirow[t]{2}{*}{ (39) } & Laetitia $\ldots . . . .$. & 1908 July $1-8$ & 2 & Fn. \\
\hline & & 1918 Oct. $3-22 \ldots$ & 11 & C. \\
\hline (40) & Harmonia_. & 1908 July 29-Aug. 3_- & 3 & Fn. \\
\hline (42) & Isis _... . . & 1909 Apr. $10-17$ & 3 & Ep. \\
\hline (43) & Ariadne.... & 1909 Feb. 20 & 1 & Ep. \\
\hline \multirow[t]{2}{*}{ (49) } & Pales...... & 1908 Jan. 29 & 2 & Fn. \\
\hline & & 1917 Oct. $6-17$ & 3 & C. \\
\hline (55) & Pandora $\ldots . .$. & 1913 Sept. 11-Oct. 26 & 5 & Ws. \\
\hline (57) & Mnemosyne. & 1909 Aug. 10-21 & 3 & Fn. \\
\hline (64) & Angelina ...... & 1918 Mar. $17-19$ & 2 & C. \\
\hline (68) & Leto & 1918 Nov. 6 & 3 & C. \\
\hline (78) & Diana $\ldots$ & 1918 Mar. 2 & 1 & C. \\
\hline (79) & Eurynome & 1908 June $23-26$ & 2 & Fn. \\
\hline (88) & Thisbe $\ldots . . .$. & 1917 Sept. 18-19 & 2 & C. \\
\hline (90) & Antiope & 1908 Feb. 6 & 1 & Fn. \\
\hline (93) & Minerva_... & 1908 Sept. $1-6$ & 5 & Fn. \\
\hline \multirow[t]{2}{*}{ (95) } & Arethusa..... & 1909 Aug. 7 & 1 & Ep. \\
\hline & & 1910 Nov. $22-30$ & 3 & Ep. \\
\hline \multirow[t]{2}{*}{ (101) } & Helena... & 1908 Mar. $7-10$ & $\left\{\begin{array}{l}4 \\
1\end{array}\right.$ & Fn. \\
\hline & & 1918 Nov. 3-14 & $\begin{array}{l}1 \\
13\end{array}$ & $\begin{array}{l}\text { Hd. } \\
\text { C. }\end{array}$ \\
\hline (104) & Klymene... & 1913 Oct. 22 & 1 & Ws. \\
\hline (105) & Artemis.... & 1908 Aug. 30-Sept. 18 & 5 & Fn. \\
\hline (111) & Ate $\ldots$ & 1908 Aug. 31-Oct. 6 & 7 & Fn. \\
\hline \multirow[t]{2}{*}{ (115) } & Thyra....... & 1908 Sept. 30-Oct. 14 & 2 & Fn. \\
\hline & & 1912 Dec. 21-1913 Jan & 5 & Ws. \\
\hline (121) & Hermione & 1908 Jan. $27-30$ & 5 & Fn. \\
\hline (127) & Johanna..... & 1913 Oct. $31-$ Nov. 21 & 6 & Ws. \\
\hline
\end{tabular}




\begin{tabular}{|c|c|c|c|c|}
\hline & Asteroid & Observed & $\begin{array}{l}\text { Number of } \\
\text { Observations }\end{array}$ & Observer \\
\hline (129) & Antigone $\ldots . . . .$. & 1908 July $20 \ldots$ & 2 & Fn. \\
\hline (133) & Cyrene. ........ & 1908 Jan. 3-10 & 5 & $\mathrm{Hd}$. \\
\hline (135) & Hertha . . . . . . . & 1917 Oct. 17 & 1 & C. \\
\hline$(150)$ & Nuwa . . . . . . . . & 1908 Feb. 1 & 1 & Fn. \\
\hline (161) & Athor $\ldots \ldots$ & 1908 Jan. 3-10 & 5 & Hd. \\
\hline$(182)$ & Elsa $\ldots \ldots \ldots . . . . .$. & 1908 Mar. 4-9 & 2 & Fn. \\
\hline (190) & Ismene $\ldots \ldots \ldots$ & 1910 Nov. 26 & 1 & Ep. \\
\hline (192) & Nausikaa_..... & 1918 Sept. 9-Oct. $22 \ldots$ & 12 & C. \\
\hline (198) & Ampella . . . . . . & 1908 Feb. 1-3 & 2 & Fn. \\
\hline & & 1918 Sept. $13-$ Oct. $3 \ldots$ & 7 & C. \\
\hline$(202)$ & Chryseis ... & 1909 Mar. 23-28 $\ldots$ & 3 & Ep. \\
\hline$(203)$ & Pompeja & 1908 Jan. 27 & 2 & Fn. \\
\hline$(221)$ & Eos......... & 1909 Apr. 15-22 & 3 & Fn. \\
\hline$(229)$ & Adelinda $a_{-. . .}$ & 1908 Oct. $26-$ Nov. $27 \ldots$ & $\left\{\begin{array}{l}6 \\
2 \\
2\end{array}\right.$ & Hd. \\
\hline$(241)$ & Germania...... & 1909 Apr. 10-26 & 5 & Fn. \\
\hline & & 1910 July $24-25 \ldots$ & 2 & Bn. \\
\hline$(246)$ & Asporina ............ & 1912 May 24-June 3........ & 2 & Ws. \\
\hline$(288)$ & 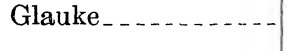 & 1909 June 15-July 6_......... & 5 & Fin. \\
\hline & & 1916 Nov. $27-$ Dec. 28 & $\left\{\begin{array}{l}2 \\
2\end{array}\right.$ & $\begin{array}{l}\text { H1. } \\
\text { Bn. }\end{array}$ \\
\hline & & 1918 May 1-June 5 & $\left\{\begin{array}{l}2 \\
3\end{array}\right.$ & $\begin{array}{l}\mathrm{Hl} \text {. } \\
\text { B. }\end{array}$ \\
\hline$(323)$ & Brucia_... . . . . . . & 1924 Aug. 14-Dec. 10_. & 7 & B. \\
\hline$(329)$ & Svea . . . . . . & 1908 May $26-28 \ldots$ & 2 & Fn. \\
\hline$(349)$ & Dembowska...... & 1914 Mar. 18-23 . . . . . . & 2 & Ws. \\
\hline$(354)$ & Eleonora & 1908 June $2-6 \ldots$ & 2 & Fn. \\
\hline$(387)$ & Aquitania ......... & 1908 Apr. 19-20 & 4 & Fn. \\
\hline$(402)$ & Chloë_......... & 1908 June 8-28_... & $\left\{\begin{array}{l}1 \\
6\end{array}\right.$ & $\mathrm{Hd}$. \\
\hline (415) & Palatia...... & 1913 Oct. 4-Nov. $7 \ldots$ & $\begin{array}{r}10 \\
2\end{array}$ & $\begin{array}{l}\text { Fn. } \\
\text { Ws. }\end{array}$ \\
\hline$(433)$ & Eros & 1912 July 8-Aug. $6 \ldots$ & $\left\{\begin{array}{l}3 \\
4\end{array}\right.$ & Bn. \\
\hline & & 1914 Aug. 9-1915 Apr. 17. & 23 & Bn. \\
\hline & & 1919 July 25-Aug. 2 & 3 & Bn. \\
\hline & & 1923 Oct. $13-1924$ Feb. $8 \ldots$ & $\left\{\begin{array}{l}2 \\
9\end{array}\right.$ & $\begin{array}{l}\text { Hl. } \\
\text { B }\end{array}$ \\
\hline$(447)$ & Valentine $\ldots \ldots . . .$. & 1918 May 8-June 12 & 7 & $\mathrm{Bn}$. \\
\hline$(451)$ & Patientia $\ldots \ldots \ldots$ & 1912 Apr. 10-11 & 2 & Ws. \\
\hline$(454)$ & Mathesis & 1908 Feb. 2 & 1 & Fn. \\
\hline$(465)$ & Alekto ............ & 1908 June 27-Aug. 3 & 7 & Fn. \\
\hline$(480)$ & Hansa $\ldots \ldots \ldots$ & 1911 Nov. 21-22 & 2 & Ep. \\
\hline (491) & Carina & 1912 June $12-20 \ldots$ & 3 & Bn. \\
\hline$(492)$ & Gismonda. . . . . . . & 1913 Oct. 5 & 1 & Ws. \\
\hline$(495)$ & Eulalia_........ & 1908 Mar. 25-Apr. 4... & $\left\{\begin{array}{l}2 \\
2\end{array}\right.$ & $\mathrm{Hd}$ \\
\hline$(506)$ & 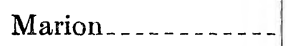 & 1908 Feb. 8-20 & 3 & Fn. \\
\hline$(507)$ & Laodica & 1908 Jan. 9 & 1 & Fn. \\
\hline$(532)$ & Herculina . . . . . . . & 1908 Jan. 5-15 . . . . . & 6 & Fn. \\
\hline$(534)$ & Nassovia ....... & 1908 Feb. 24-Mar. 4 & $\left\{\begin{array}{l}1 \\
2\end{array}\right.$ & Fn. \\
\hline$(536)$ & Merapi ........... & 1909 Mar. 22-26 . . . & 3 & Fn. \\
\hline (537) & Pauly & 1914 Apr. 2-21 $\ldots$ & 6 & $\mathrm{Bn}$. \\
\hline$(547)$ & Praxedis & 1908 July $17 \ldots \ldots$ & 2 & Fn. \\
\hline$(554)$ & 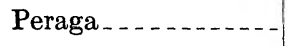 & 1909 Mar. 17-22 $\ldots . .$. & 3 & Fn. \\
\hline & & 1918 Sept. 14 -Oct. 7 & 7 & C. \\
\hline$(569)$ & Misa $\ldots \ldots \ldots \ldots$ & 1910 Dec. 8-21 & 3 & Ep. \\
\hline (588) & Achilles.......... & 1919 Apr. 26-May 3. & 4 & Bn. \\
\hline (600) & Musa .............. & 1909 Jan. $26-28 \ldots$ & 3 & Fn. \\
\hline
\end{tabular}


EQUATORIAL OBSERVATIONS, 1908-1926

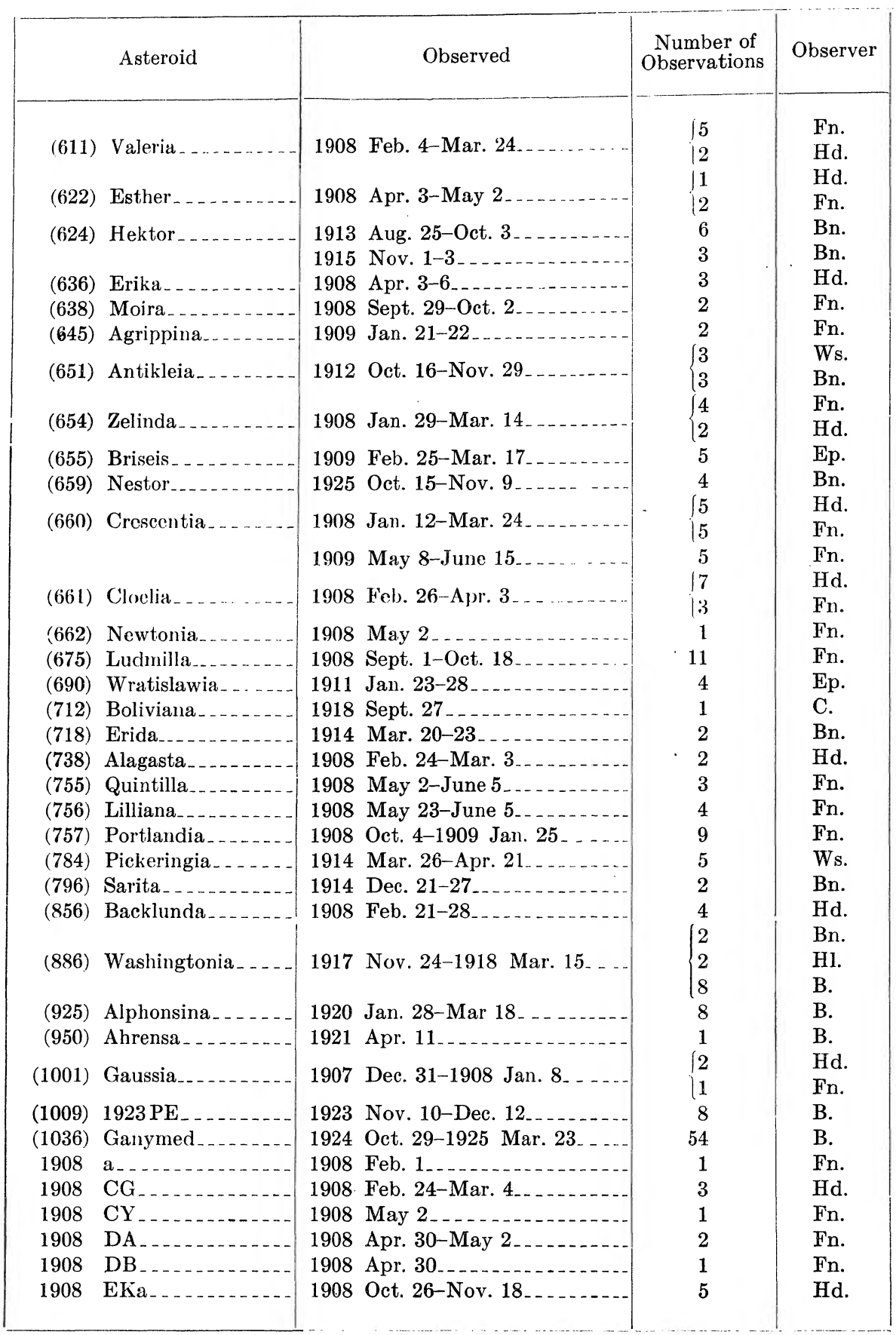




\section{OBSERVATIONS OF COMETS}

The comets are arranged in general in the order of announcement of discovery or rediscovery. In some cases the names of more than one discoverer are given, separated by a hyphen. In this connection the Comet Catalogue prepared by A. C. D. Crommelin was consulted. (Memoirs of the British Astronomical Association, Volume XXVI, Part 2.)

A number of comet observations were made with the 12-inch equatorial; some of which were taken with that instrument on account of being able to observe nearer the horizon than with the 26 -inch.

Fifty-five comets were observed as follows:

\begin{tabular}{|c|c|c|c|c|}
\hline Comet & $\begin{array}{l}\text { Approxi- } \\
\text { mate } \\
\text { Period } \\
\text { (sidereal } \\
\text { years) }\end{array}$ & Observed & $\begin{array}{l}\text { Number of } \\
\text { Observations }\end{array}$ & Observer \\
\hline Daniel $(1907 d)$ & & 1908 Feb. $3 \ldots \ldots$ & $\begin{array}{r}1 \\
19\end{array}$ & $\begin{array}{l}\text { Fn. } \\
\text { Fn. }\end{array}$ \\
\hline Morehouse (1908c) .. & & 1908 Sept. 6-Dec. $3 \ldots$ & $\left\{\begin{array}{l}2 \\
7\end{array}\right.$ & $\begin{array}{l}\mathrm{Hd} . \\
\mathrm{Hl} .\end{array}$ \\
\hline Borrelly (1909a) _. & & 1909 June $18-$ July $19 \ldots$ & 6 & Fn. \\
\hline Perrine $(1909 b)$ & 6.5 & 1909 Oct. 7-Oct. 8 & $\begin{array}{l}2 \\
1\end{array}$ & $\begin{array}{l}\text { Fn. } \\
\text { Fn. }\end{array}$ \\
\hline Halley $(1909 c)$ & 76. 0 & 1909 Oct. $9-1910$ June $7 \ldots$ & $\left\{\begin{array}{r}21 \\
7\end{array}\right.$ & $\begin{array}{l}\text { Ep. } \\
\text { Hl. }\end{array}$ \\
\hline Daniel $(1909 \mathrm{e})$ & 6. 5 & $\begin{array}{l}1909 \text { Dec. } 10-1910 \text { Jan. } 15 \\
1910 \text { Jan. } 25 \text {-Apr. } 9\end{array}$ & $\begin{array}{l}4 \\
5\end{array}$ & $\begin{array}{l}\text { Ep. } \\
\text { Ep. }\end{array}$ \\
\hline Metcalf $(1910 b) \ldots$ & & 1910 Aug. 10-Sept. $28 \ldots$ & $\left\{\begin{array}{l}2 \\
14\end{array}\right.$ & $\begin{array}{l}\text { Bn. } \\
\text { Ep. }\end{array}$ \\
\hline D'Arrest $(1910 \mathrm{c}) \ldots$ & 6.5 & 1910 Aug. $30 \ldots \ldots$ & 1 & Ep. \\
\hline Faye $(1910 \mathrm{e}) \ldots \ldots$ & ?. 4 & 1910 Nov. 11-1911 Feb. $4 \ldots$ & 7 & Ep. \\
\hline Kiess $(1911 b) \ldots \ldots$ & & 1911 July 9-Aug. $9 \ldots$ & 4 & Ep. \\
\hline Brooks $(1911 c) \ldots$ & & 1911 July 24-Oct. 23 _ & $\left\{\begin{array}{l}2 \\
6\end{array}\right.$ & $\begin{array}{l}\text { Bn. } \\
\text { Ep. }\end{array}$ \\
\hline Quénisset (1911f) ... & & 1911 Sept. 25-Oct. 16 & $\left\{\begin{array}{l}3 \\
1\end{array}\right.$ & $\begin{array}{l}\text { Ep. } \\
\text { Bn. }\end{array}$ \\
\hline Beljawsky (1911g) ..... & & 1911 Sept. 30-Oct. $4 \ldots$ & 2 & Ep. \\
\hline Gale (1912a) ..... & & 1912 Sept. 28-1913 Apr. 5 & $\left\{\begin{array}{l}6 \\
5\end{array}\right.$ & $\begin{array}{l}\text { Ws. } \\
\text { Bn. }\end{array}$ \\
\hline Tuttle $(1912 b) \ldots$ & 13.5 & 1912 Nov. 9 & 1 & $\mathrm{Bn}$. \\
\hline Borrelly $(1912 \mathrm{c}) \ldots \ldots$ & & 1912 Nov. 5-Nov. $16 \ldots$ & 3 & Ws. \\
\hline Schaumasse (1913a) ......... & & 1913 May 8-June 29... & 6 & Ws. \\
\hline Metcalf $(1913 b)$ & & 1913 Sept. 4-Nov. $2 \ldots$ & 5 & Ws. \\
\hline Neujmin $(1913 c) \ldots$ & 18 & 1913 Sept. 9-Oct. 22 & $\left\{\begin{array}{l}4 \\
1\end{array}\right.$ & $\begin{array}{l}\text { Bn. } \\
\text { Ws. }\end{array}$ \\
\hline Westphal (1913d) $\ldots \ldots$ & 61.7 & 1913 Sept. 27-Oct. $4 \ldots$ & $\left\{\begin{array}{l}1 \\
1\end{array}\right.$ & $\begin{array}{l}\text { Bn. } \\
\text { Ws. }\end{array}$ \\
\hline Giacobini (1913e) $\ldots$ & 6.5 & 1913 Oct. $26-$ Nov. $6 \ldots$ & 4 & Ws. \\
\hline Delavan (1913f) ... & & 1913 Dec. 18-1915 Jan. 20 _ & $\left\{\begin{array}{r}20 \\
4\end{array}\right.$ & $\begin{array}{l}\text { Bn. } \\
\text { Ws. }\end{array}$ \\
\hline Kritzinger (1914a) . . & & 1914 Mar. 30-June 29.. & 6 & Ws. \\
\hline Zlatinsky (1914b) & & 1914 May 21-June 2... & 5 & Bn. \\
\hline Neujmin $(1914 c)$ & & 1914 July 28 & 1 & Ws. \\
\hline $\begin{array}{l}\text { Campbell-Westland-Lunt } \\
\text { (1914e). }\end{array}$ & & 1914 Oct. 1-Nov. $19 \ldots$ & 7 & Bn. \\
\hline Mellish (1915a) . . . . . . . & & 1915 Feb. 17-1916 Jan. $8 \ldots$ & 18 & $\mathrm{Bn}$. \\
\hline Taylor (1915e) . . . . . & 6.4 & 1915 Dec. 6-1916 Mar. $31 \ldots$ & 10 & $\mathrm{Bn}$. \\
\hline Neujmin $(1916 a) \ldots \ldots \ldots$ & 5. 4 & 1916 Mar. 4-May 5......... & 4 & Bin. \\
\hline Wolf $(1916 b) \ldots$ & & 1916 May 6-1917 Dec. $10 \ldots$ & $\begin{array}{r}131 \\
19\end{array}$ & $\begin{array}{l}\text { Bn. } \\
\text { B. }\end{array}$ \\
\hline
\end{tabular}




\begin{tabular}{|c|c|c|c|c|}
\hline Comet & $\begin{array}{l}\text { Approxi- } \\
\text { mate } \\
\text { Period } \\
\text { (sidereal } \\
\text { years) }\end{array}$ & Observed & $\begin{array}{l}\text { Number of } \\
\text { Observations }\end{array}$ & Observer \\
\hline Mellish (1917a) $\ldots \ldots$ & & 1917 Mar. 22-Mar. $30 \ldots$ & 3 & $\mathrm{Bn}$. \\
\hline Schaumasse $(1917 \mathrm{~b}) \ldots \ldots$ & & 1917 May 1-June $16 \ldots$ & 6 & $\mathrm{Bn}$. \\
\hline Wolf $(1918 \mathrm{~h}) \ldots \ldots$ & 6.8 & 1918 July 15-1919 Mar. 3.. & 25 & Bn. \\
\hline Borrelly $(1918 \mathrm{c})=(1925 f) \ldots$ & 6.9 & 1918 Oct. 23-1919 Apr. 21 . & $\left\{\begin{aligned} 3 \\
15\end{aligned}\right.$ & $\begin{array}{l}\text { Bn. } \\
\text { B. }\end{array}$ \\
\hline Schorr $(1918 d) \ldots$ & 6.7 & $\begin{array}{l}1925 \text { Nov. 18-1926 Feb. 6 } \\
1918 \text { Nov. 29-Dec. } 2\end{array}$ & $\begin{array}{l}5 \\
3\end{array}$ & $\begin{array}{l}\text { Bn. } \\
\text { Bn. }\end{array}$ \\
\hline Brorsen $(1919 b) \ldots$ & $69-72$ & 1919 Aug. 22-Sept. 13 & $\left\{\begin{array}{l}3 \\
0\end{array}\right.$ & B. \\
\hline Metcalf-Borrelly (1919c) $\ldots$ & & 1919 Aug. 25-Oct. 3.. & $\{5$ & B. \\
\hline Finlay $(1919 \mathrm{~d})$ & 6.7 & 1919 Nov. $13-$ Dec. 22 & $\begin{array}{l}2 \\
7\end{array}$ & $\begin{array}{l}\text { Bn. } \\
\text { B. }\end{array}$ \\
\hline Tempel II $(1920 \mathrm{~b})=(1925 \mathrm{~d}) \ldots$ & 5. 2 & $\{1920$ July $26-$ Nov. $4 \ldots$ & 6 & B. \\
\hline Taylor-Skjellerup (1920c) _.... & & 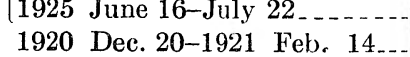 & $\begin{array}{l}4 \\
3\end{array}$ & $\begin{array}{l}\mathrm{Bn} . \\
\mathrm{Bn} .\end{array}$ \\
\hline Reid (1921a) & & 1921 Mar. 22-May 31...... & 8 & B. \\
\hline Pons-Winnecke (1921b) $\ldots \ldots . .$. & 6. 0 & 1921 May 9-June 14 & 4 & B. \\
\hline Dubiago (1921c) & 79.5 & 1921 May 25-May 31... & 2 & B. \\
\hline $\begin{array}{l}\text { Grigg-Skjellerup } \quad(1922 b)= \\
\text { Grigg }(1902 c) .\end{array}$ & 5.0 & 1922 May 23-June 21... & 5 & B. \\
\hline Baade (1922c) ... & \multirow{11}{*}{3.3} & 1922 Oct. $24-1923$ Dec. 1. & $\left\{\begin{array}{l}10 \\
10\end{array}\right.$ & Hl. \\
\hline Skjellerup (1922d) & & 1922 Dec. 5 & 1 & B. \\
\hline Encke $(1924 b)$ & & 1924 Sept. 3-Oct. 22 & 19 & B. \\
\hline Finsler (1924c) & & 1924 Sept. 23-Oct. 13_.... & $\begin{array}{l}10 \\
1\end{array}$ & B. \\
\hline Schain-Comas Solà (1925a) & & 1925 Mar. 25-June 16.... & $\left\{\begin{array}{l}1 \\
6\end{array}\right.$ & Bn. \\
\hline Reid $(1925 b) \ldots$ & & 1925 Mar. 28-May 19_... & $\left\{\begin{array}{l}1 \\
4\end{array}\right.$ & $\begin{array}{l}\mathrm{B} . \\
\mathrm{Bn}\end{array}$ \\
\hline Orkisz $(1925 \mathrm{c})$ & & 1925 Apr. 7-July 18_... & $\begin{array}{r}4 \\
7\end{array}$ & $\begin{array}{l}\text { Dn. } \\
\text { Bn. }\end{array}$ \\
\hline $\begin{array}{l}\text { Tempel II }(1925 d)=(1920 b) \\
\text { Borrelly }(1925 f)=(1918 c)\end{array}$ & & $\begin{array}{l}{ }^{\prime} \\
n^{\prime}\end{array}$ & & \\
\hline Van Biesbroeck (1925j) & & 1925 Nov. $18-1926$ Feb. 15 & 9 & Bn. \\
\hline $\begin{array}{l}\text { Peltier-Wilk }(1925 \mathrm{k}) \\
\text { Blathwayt }(1926 \mathrm{~b})\end{array}$ & & 1925 Nov. 21-Dec. 10 & 4 & Bn. \\
\hline & & 1926 Feb. 16 & 1 & Bn. \\
\hline
\end{tabular}

\section{E. OBSERVATIONS OF OCCULTATIONS}

Occultations published in the American Ephemeris for observation at Washington have been observed with both instruments as part of the regular program.

Occulting bars of black paper have sometimes been used on two of the eyepieces for observations at the bright limb, or dark limb if near full Moon. The bar obscures all of the Moon except a small area where the star is to disappear or reappear. This arrangement is helpful in cutting off the glare of the Moon, especially when a low-power eyepiece is used; but sometimes an observer may find the glare sufficiently reduced by using an eyepiece of higher power without the bar. The occulting bar is pasted to the field lens of the eyepiece so as not to interfere with the micrometer wires, but it would be more efficient if it could be in the focal plane.

Unless otherwise noted it will be understood that the observations were recorded on a chronograph in sidereal time. A number of observations were recorded by eye and ear, indicated by the letter $i$.

An observation of an occultation of a star by Venus (disappearance at the bright limb only) follows the occultations by the Moon. 


\section{F. OBSERVATIONS OF SOLAR ECLIPSES AND TRANSIT OF MERCURY}

Solar eclipses were observed for times of contact on the following dates: 1908 , June 27; 1914, August 20; 1916, February 3; 1918, June 8; 1920, November 10; 1923, September 10; and 1925, January 24. A transit of Mercury (egress) was observed on November 6, 1914.

The instruments used were: The 26-inch equatorial (reduced to 12-inch aperture) with a Herschel solar eyepiece; the 5 -inch finder (reduced to 1 -inch aperture) of the 26-inch; the 12-inch equatorial (reduced to 4-inch aperture or used with full aperture) with a solar eyepiece or helioscope, usually the polarizing eyepiece John A. Brashear, No. 16; and a number of Clark 5-inch Transit-of-Venus equatorials (used with full aperture) with diagonal eyepieces and dark glass. Most of the 5 -inch equatorials were mounted on the roof of the main building; one was mounted on the porch of the superintendent's residence.

The observers were J. A. HoogewerfF (Superintendent), H. E. Smiri, F. B. Littelel, A. Hall, J. C. Hammond, G. A. Hill, C. W. Frederick, M. Frederickson, H. E. Burton, E. C. Bower, C. B. Watts, Paul Sollenberger, and G. C. WHITTAKER.

The observations with the 26-inch and 12-inch equatorials were recorded on the chronograph except on January 24, 1925, when the eye-and-ear method of recording was used. With the other instruments the eye-and-ear method was usually employed, the seconds beat of a meantime chronometer being counted aloud by an assistant. Mr. HiLl used a stop watch for the time of the last contact on January $24,1925$.

\section{G. OBSERVATIONS UF ECLIPSES OF SATELLITES}

Disappearances and reappearances (D. and R.) of Satellites eclipsed by the primaries were as follows:

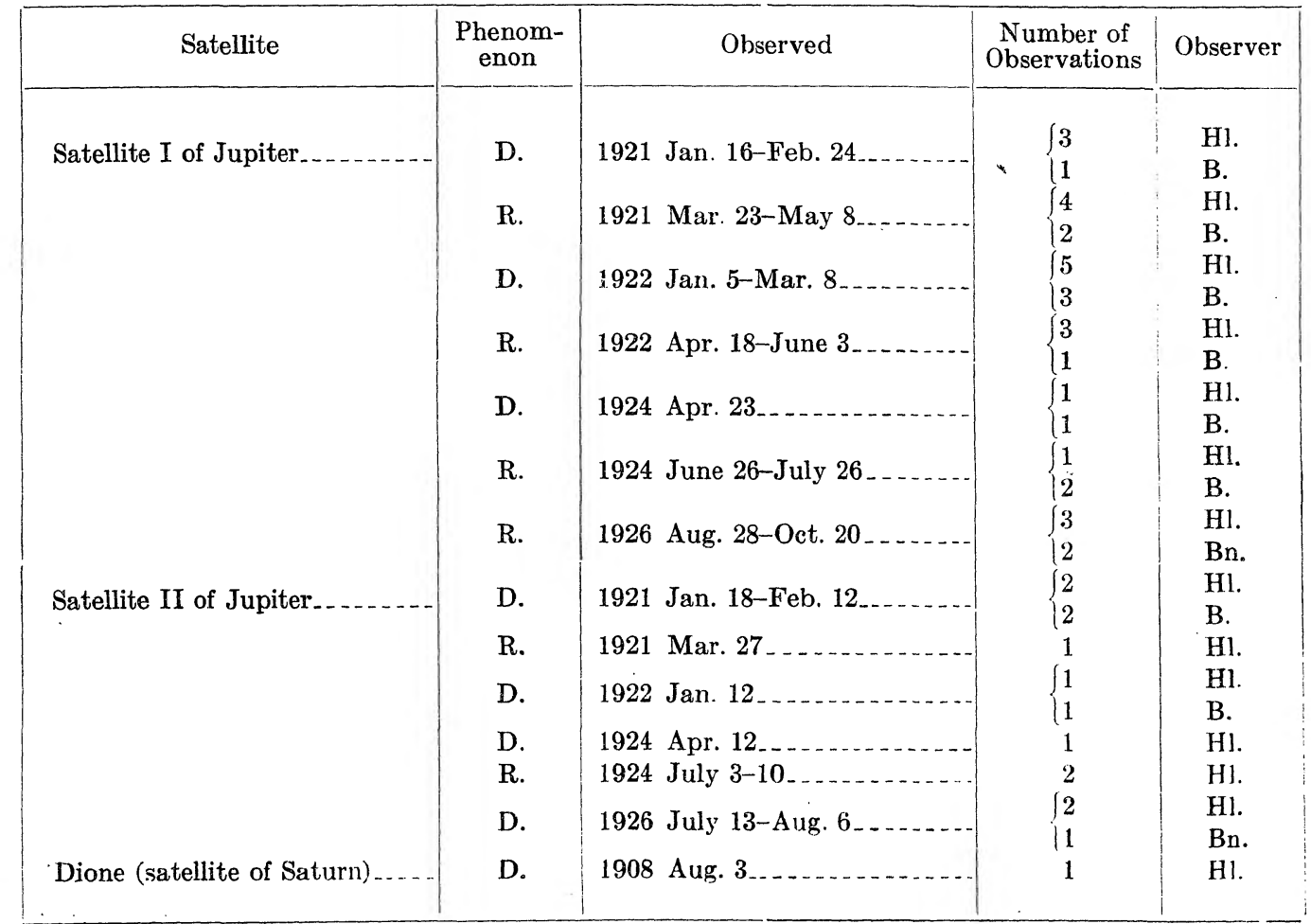




\section{H. OBSERVATIONS OF DOUBLE STARS}

Double stars were measured in position angle and distance with reference to the brighter component as follows:

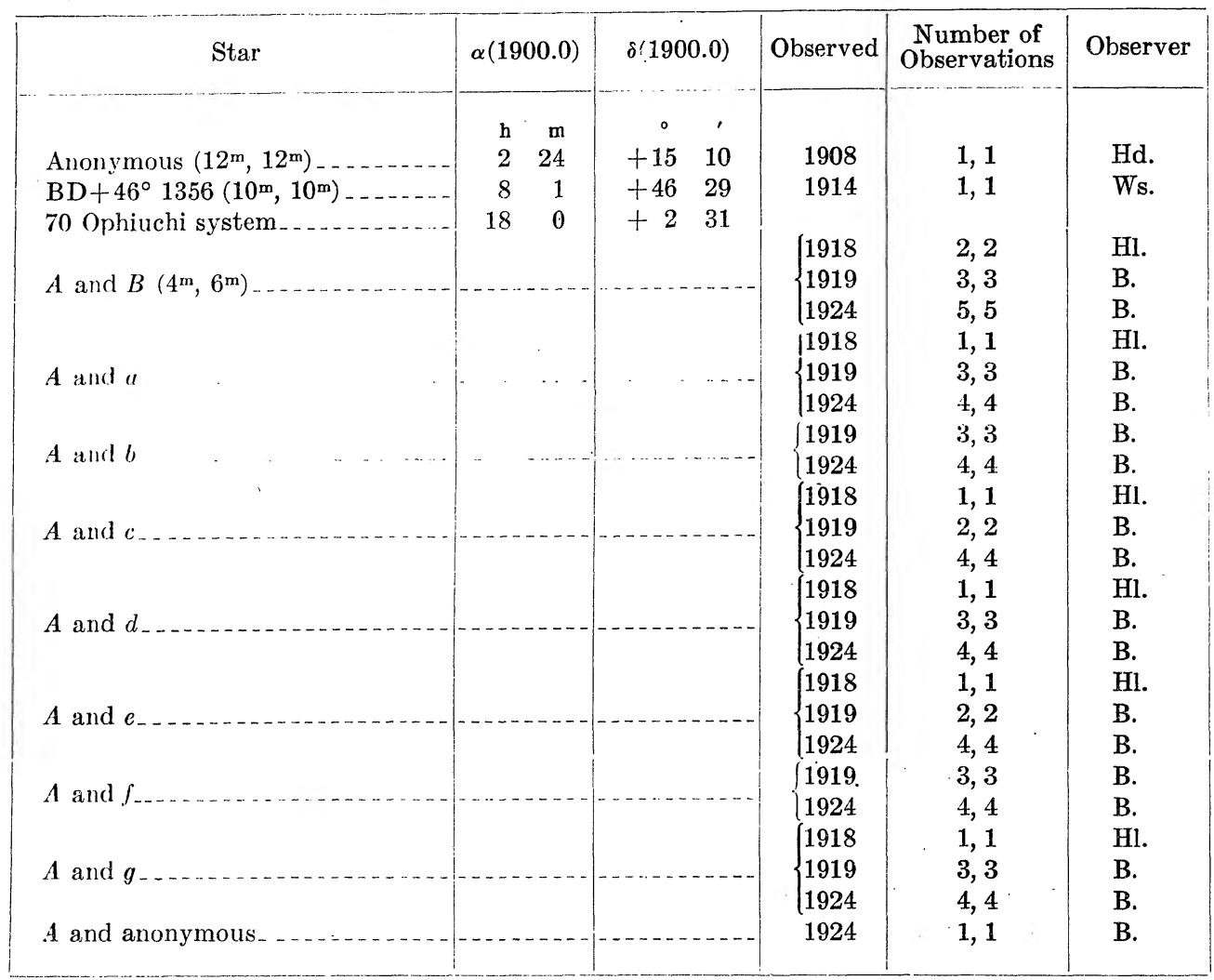

The observations of the system of 70 Ophiuchi were made at the request of Dr. A. D. Risteen, of Hartford, Conn. The star designations for this system are those found in Burnham's General Catalogue, page 775. An additional star, anonymous, is included.

\section{OBSERVATIONS OF MISCELLANEOUS STARS, NOVÆ, AND NEBULA}

The miscellaneous stars include step stars, or stars which were selected as comparison stars, and at the time were not found in a catalogue. By means of a step star an observation of an object was reduced with reference to a catalogue star.

Following the miscellaneous stars are Novæ with notes as to their appearance, and Nebulæ.

\section{J. MISCELLANEOUS OBSERVATIONS}

Under this heading are included observations and notes pertaining to the following subjects: Polar Cap of Mars, Jupiter's Cloud Forms, Saturn and Rings, Meteors, an Aurora, and examination of faint objects in the field around Uranus.

\section{GENERAL REMARKS}

The seeing was indicated in two ways, as follows: $1=\mathrm{e}=$ excellent, $2=\mathrm{g}=\mathrm{good}$, 3. f fair, $4=\mathrm{p}-$ poor, $5=\mathrm{b}=$ bad; $\mathrm{v} \cdots$ very (used with $\mathrm{g}$, $\mathrm{p}$, or b).

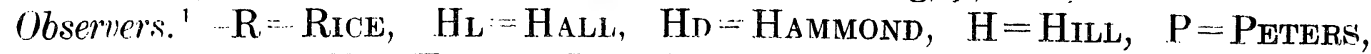

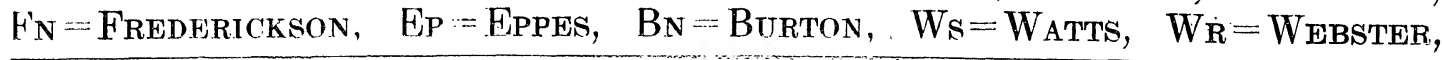

\footnotetext{
1 See page 3 et seq.
} 
$\mathrm{B}=$ Bower, $\mathrm{C}=$ Conrad, $\mathrm{Wl}=$ Willis. Messrs. Gustave Harrison, J. E. Willis, U. S. Lyons, and W. C. Myers occasionally recorded for the observers on the 26-inch equatorial.

A correction of +0.10 inch has been applied to the aneroid barometer readings. The index correction to the thermometer was negligible.

Except for occasional observations the Repsold micrometer was used after June 30, 1914.

When a prism eyepiece was employed for satellite measures the wire used in measuring position angles was generally placed apparently vertical; in measuring distances the short wires were placed apparently vertical. In measuring $\Delta \delta$ by transits for screw value the short wires were placed apparently vertical.

Catalogue proper motions have in general been applied to the positions of comparison stars.

When more than one authority is mentioned for the position of a star equal weight is assigned in taking the mean unless otherwise stated.

A star taken from an astrographic catalogue in which the coordinates are not already expressed in right ascension and declination is designated by the name of the catalogue followed by the coordinates of the plate center (in degrees of declination and hours and minutes of right ascension), and the number assigned to the star in the catalogue.

In computing precessions Newcomb's precession constants were used throughout, except for the observations by CONRAD who used the catalogue precessions. The apparent place reductions of the comparison stars were obtained by use of the formulæ and constants given in the American Ephemeris, except for the years 1909, 1910, and 1911 when the formulæ and constants given in the Star List of the American Ephemeris were used.

The clock corrections were based on Newcomb to October 27, 1914; Boss, October 27, 1914, to January 1, 1923; and the American Ephemeris, as corrected by Table XIII of 1925, from January 1, 1923.

Throughout Part I of this volume the astronomical dates are used as employed before 1925. The change to civil time was NOT made for the observations of 1925 , 1926.

\section{ABBREVIATIONS}

In addition to the designations previously given for seeing and observers, a number of the following abbreviations have been used:

\section{(a) Star Catalogues in $\alpha$ and $\delta$}

(1) ASTRONOMische GESELLSCHAFT ZONES

Alb. $=$ Albany

Alg. $=$ Algiers.

Ber. $\mathrm{A}=$ Berlin $\mathrm{A}$.

[When A G precedes abbreviation]

Ber. $\mathrm{B}=$ Berlin $\mathrm{B}$.

Ber. $\mathrm{C}=$ Berlin $\mathrm{C}$.

Bo. $=$ Bonn.

Cam. $=$ Cambridge, Eng.

Chr.:- Christiania.

Har. = Harvard.

Hels $:=$ Helsingfors-Crotha.

Kas. $=$ Kasan

Lei. $=$ Leiden.

Lpz. I= Leipzig I.

Lpz. II = Leipzig II.

$\mathrm{Lu} .=$ Lund.

Nic. $=$ Nicolajew.

Ott. = Wien-Ottakring $=$ Wien-Ott.

Str. = : Straszburg.

Wa.--.- Washington. 
(2) MisceillaNEOUS

Abb. $\mathrm{A}=$ Abbadia $\mathrm{A}, \mathrm{Zone}+16^{\circ} \mathrm{a}+24^{\circ}$.

Abb. $\mathrm{B}=$ Abbadia $\mathrm{B}$, Zone $+4^{\circ} \mathrm{a}-2^{\circ}$.

Boss $=$ Preliminary General Catalogue $=$ P. G. C. Ci. $18=$ Cincinnati Publications No. 18.

Cor. $\mathrm{A}=$ Cordoba $\mathrm{A}$.

Cor. $\mathrm{B}=$ Cordoba $\mathrm{B}$.
Cor. $\mathrm{C}=$ Cordoba $\mathrm{C}$.

Gr. Ast. = Greenwich Astrographic Cat. Vol. III.

Gr. 1910= Greenwich Catalogue for 1910 .

Newcomb $=$ Catalogue of Fundamental Stars.

P. G. C. $=$ Preliminary General Catalogue by Boss.

\section{(b) Astrographic Catalogues}

[When Ast precedes abbreviation]

Grn. $=$ Greenwich

Rom. = Rome (Vatican).

Cat. = Catania.

Hel. $=$ Helsingfors.

Pot. $=$ Potsdam .

Oxf. = Oxford (University).

Par. $=$ Paris.

Bor. $=$ Bordeaux.
Tou. $=$ Toulouse

Alg. = Algiers.

Fer. $=$ San Fernando.

Tac. $=$ Tacubaya.

Hyd. $=$ Hyderabad.

Cor. $=$ Cordoba.

Per. $=$ Perth.

\section{(c) Observations of Occultations}

$\mathrm{c}=$ cloudy; thin clouds.

d = daylight.

$\mathrm{e}=$ early.

$f=$ star faint.

$\mathrm{g}=$ gradual.

$\mathrm{h}=$ haze.

$\mathrm{i}=$ eye and ear.

$\mathrm{k}=$ dark limb visible.

l=late.

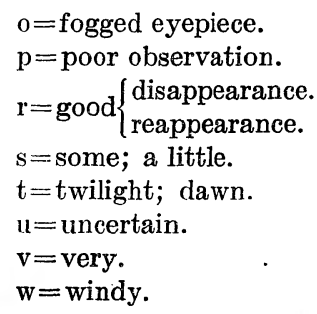

Numbers following $e, l$, or $u$ are estimates in tenths of seconds of time.

$\mathrm{A}, \mathrm{B}, \mathrm{C}$, etc., refer to footnotes.

\section{ALSO: UNDER PH (PHENOMENON)}

D. B. = disappearance at bright limb.

D. D. = disappearance at dark limb.

D. E. = disappearance at eclipsed limb.
R. B.=reappearance at bright limb.

R. D. = reappearance at dark limb.

R. E.=reappearance at eclipsed limb.

\section{(d) Mlumination of Field of View}

Blk.=Black wires in field illuminated otherwise than by artificial light; e. g., by Moon, planet, or daylight. Brt. $=$ Bright field of suitable intensity, artificially illuminated, showing black wires. Red $=$ Dark red wires. red $=$ Light red wires.

\section{(e) Accessories to Eyepieces}

After number indicating magnifying power of eyepiece;

b. =occulting bar pasted to field lens of eyepiece.

$\mathrm{p} .=$ with totally reversing prism in front of eye lens.

$r .=$ red glass outside of field lens.

s. $=$ smoked glass outside of field lens. 
(f) Position of Micrometer Head

$$
\mathrm{u} .=\text { down } \quad \mathrm{lt} .=\text { left } \quad \mathrm{rt} .=\text { right } \quad \mathrm{u} .=\mathrm{up}
$$

(g) Miscellaneous

A. J.=Astronomical Journal. A. N.=Astronomische Nachrichten. App. pl.=Apparent place.

Ast. = Astrographic.

B. D. $=$ Bonn Durchmusterung.

Beg. $=$ Beginning.

C. $=$ Computed

C. D. = Cordoba Durchmusterung.

Clds. $=$ Clouds.

c. $\mathrm{w} .=$ Compared with.

d. = Diameters; driving clock running (measures made with).

Ft. = Faint; feet.

Gr. M. T. $=$ G. M. T. $=$ Greenwich Mean Time.

$\mathrm{L} .=$ Lower culmination.

N. G. C. = Dreyer's New General Catalogue (of Nebulæ and Clusters of Stars).

O., Obs. $=$ Observed.
ค. $=$ Position angle.

p. e. = Probable error.

Ph., Phen.= Phenomenon; Phenomena.

Pr. = Power (magnifying).

R., r., Rev. = Revolutions (of the micrometer screw) r. $=$ Probable error; radians.

Red. $=$ Reduction .

Rem. $=$ Remarks.

$\mathrm{T} .=$ Temperature (Fahrenheit); telescope.

t. = Transits (measures made by).

$\mathrm{Tr}$. = Transit (wires).

$\mathrm{I}^{\mathrm{r}}$ = = Upper culmination.

$\mathrm{V} .=$ Very.

Var. $=$ Variable

Wash. $=$ Washington.

W. M. T. $=$ Washington Mean Time (counted from noon).

W. Sid. T. $=$ Washington Sidereal Time. 